MQXFS1 Design Report

Editors:

Giorgio Ambrosio (FNAL)

Paolo Ferracin (CERN)
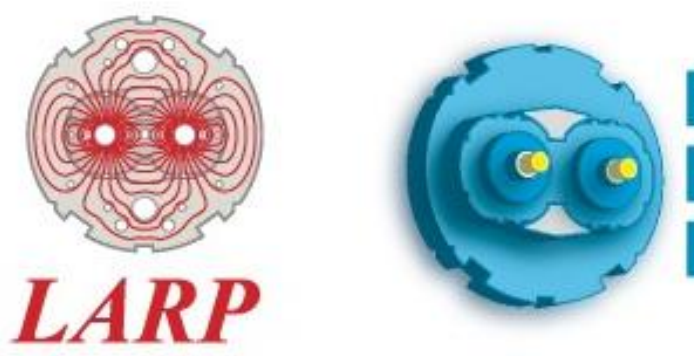

High

Luminosity

FERMILAB-TM-2613-TD

LARP DocDB 1074-v5

April 14, 2016

\title{
MQXFS1 QUADRUPOLE DESIGN REPORT
}

G. Ambrosio ${ }^{1}$, M. Anerella ${ }^{2}$, F. Borgnolutti ${ }^{3}$, R. Bossert ${ }^{1}$, E. Cavanna ${ }^{4}$, D. Cheng ${ }^{3}$, G. Chlachidize ${ }^{1}$, L.D. Cooley ${ }^{1}$, D. Dietderich ${ }^{3}$, H. Felice ${ }^{3}$, P. Ferracin ${ }^{4}$, A. Ghosh ${ }^{2}$, A. Godeke ${ }^{3}$, R. Hafalia ${ }^{3}$, E.F. Holik ${ }^{1}$, S. Izquierdo Bermudez ${ }^{4}$, M. Juchno ${ }^{4}$, V.V. Kashikhin ${ }^{1}$, S. Krave ${ }^{1}$, M. Marchevsky ${ }^{3}$, V. Marinozzi ${ }^{5}$, J. Muratore ${ }^{2}$, F. Nobrega ${ }^{1}$, I. Novitski ${ }^{1}$, H. Pan $^{3}$, J.C. Perez ${ }^{4}$, I. Pong ${ }^{3}$, S. Prestemon ${ }^{3}$, G.L. Sabbi ${ }^{3}$, T. Salmi ${ }^{6}$, C. Santini ${ }^{1}$, J. Schmalzle ${ }^{2}$, M. Sorbi ${ }^{5}$, P. Wanderer ${ }^{2}$, X. Wang ${ }^{3}$, M. Yu ${ }^{1}$, A.V. Zlobin ${ }^{1}$

\footnotetext{
${ }^{1}$ Fermi National Accelerator Laboratory, Batavia IL 60510, USA

${ }^{2}$ Brookhaven National Laboratory, Upton NY 11973, USA

${ }^{3}$ Lawrence Berkeley National Laboratory, Berkeley CA 94720, USA

${ }^{4} \mathrm{CERN}, \mathrm{CH}-1211$ Geneva 23, $\mathrm{CH}$

5INFN-LASA and University of Milan, 20090 Segrate (Milano), Italy

${ }^{6}$ Tampere University of Technology, 33720 Tampere, Finland
}

Abstract:

This report presents the reference design of MQXFS1, the first $1.5 \mathrm{~m}$ prototype of the low-beta quadrupoles (MQXF) for the LHC High Luminosity Upgrade. The MQXF quadrupoles have $150 \mathrm{~mm}$ aperture, coil peak field of about $12 \mathrm{~T}$, and use Nb3Sn conductor. The design is based on the LARP HQ quadrupoles, which had $120 \mathrm{~mm}$ aperture.

MQXFS1 has $1^{\text {st }}$ generation cable cross-section and magnetic design. 


\section{TABLE OF CONTENTS}

1. INTRODUCTION

2. CONDUCTOR CHARACTERISTICS

Edited by:

Strand A. Ghosh

Cable D. Dietderich and I. Pong

Cable insulation I. Pong

3. MAGNETIC DESIGN

Edited by:

2D F. Borgnolutti

3D S. Izquierdo Bermudez

4. COIL DESIGN, WINDING and CURING

Edited by:

Coil design $\mathrm{M}$. Yu

Winding \& curing by LARP M. Yu

Winding \& curing by CERN E. Cavanna and P. Ferracin

5. COIL REACTION, IMPREGNATION and INSTRUMENTATION

Edited by:

Reaction \& potting J. Schmalzle

Coil instrumentation M. Marchevsky

Shipment J. Schmalzle

6. STRUCTURE DESIGN and INSTRUMENTATION

Edited by H. Felice and H. Pan

7. MAGNET ASSEMBLY, HANDLING \& SHIPMENT

Edited by $\mathrm{H}$. Felice

8. QUENCH PROTECTION

60

Edited by G. Ambrosio 


\section{INTRODUCTION}

MQXFS1 is the first short prototype of the MQXF (the $150 \mathrm{~mm}$ aperture quads for the high luminosity upgrade of the LHC [1]). The cable selected for this model was the result of a compromise between few sheared subelements and cable mechanical stability. Experience during fabrication of these coils and magnet tests results are going to provide useful feedback for possible small optimization of the cable design. Coil fabrication tooling and magnet structure are not expected to change as result of this further optimization.

The coil fabrication technology is based on past LARP experience (TQ, LQ, HQ, LHQ coils) in order to reduce risks aiming at high coil yield. The flexibility of the end parts was increased by adding more slits (accordion style) that in past LARP coil designs. These features have been optimized during MQXFS practice coil fabrication.

The support structure is made of two shell segments allowing for: (i) minimizing shell axial strain during cooldown and therefore the risk of stick-slip behavior; (ii) reducing significantly shell fabrication cost; (iii) practicing with structure segment assembly in preparation for long prototypes and production magnets.

The development of the quench protection system for the MQXF magnets is in progress and we plan using MQXFS1 as test bed for protection heaters developments and for the possible use of the CLIQ (Coupling-Loss Induced Quench) system.

\section{References}

[1] “THE HIGH LUMINOSITY LARGE HADRON COLLIDER”, edited by O. Bruning and L. Rossi, Advanced Series on Directions in High Energy Physics: Volume 24, World Scientific, 2015. 


\section{CONDUCTOR CHARACTERISTICS}

The Rutherford cable for the MQXFS magnets is fabricated using $40 \mathrm{Nb}_{3} \mathrm{Sn}$ strands of diameter 0.85 $\mathrm{mm}$. The strand is either a Rod-Restack-Process RRP ${ }^{\circledR}$ strand manufactured by Oxford-Instrument Superconducting Technology or a Powder-In-Tube PIT strand produced by Bruker Energy \& Supercon Technologies (BEST). The coils fabricated by LARP will use RRP conductor, whereas those made by CERN will use both RRP and PIT conductors. MQXFS1 is going to use RRP coils from LARP and CERN.

\section{LARP Conductor}

\section{a. Strand Characteristics}

The cable for the MQXFS1 magnet will be fabricated using the Rod-Restack Process $\left(\mathrm{RRP}^{\circledR}\right) \mathrm{Nb}_{3} \mathrm{Sn}$ wire from Oxford-Instruments Superconducting Technology (OST). Strand diameter is nominally 0.85 $\mathrm{mm}$ and the first generation coils will use strands of the 108/127 design with Ti-doping. Ti-doping is introduced by replacing a few $\mathrm{Nb}$ rods in the sub-element with rods of $\mathrm{Nb}$ - $\mathrm{Ti}$. The minimum strand requirements are specified in the LARP conductor specification LARP-MAG-M-8002 Rev-G. The main characteristics of the strand are summarized in Table 2.1.

Table 2.1: Main parameters of the 108/127 strand.

\begin{tabular}{|l|l|}
\hline Process & Ti-Ternary RRP $\mathrm{Nb}_{3} \mathrm{Sn}$ \\
Strand Diameter, $\mathrm{mm}$ & $0.85 \pm .003$ \\
$\mathrm{~J}_{\mathrm{c}}(12 \mathrm{~T})$ at $4.2 \mathrm{~K}, \mathrm{~A} / \mathrm{mm}^{2}$ & $\geq 2650$ \\
$\mathrm{~J}_{\mathrm{c}}(15 \mathrm{~T})$ at $4.2 \mathrm{~K}, \mathrm{~A} / \mathrm{mm}^{2}$ & $>1400$ \\
$\mathrm{D}_{\mathrm{s}}, \mu \mathrm{m}$ (sub-element diameter) & $<60$ \\
Cu-fraction, $\%$ & $53 \pm 3$ \\
RRR (after full reaction) & $\geq 60$ \\
Twist Pitch, mm & $19 \pm 2$ \\
Twist Direction & right-hand screw \\
Minimum Piece length, $\mathrm{m}$ & 550 \\
High temperature HT duration, $\mathrm{h}$ & $\geq 48$ \\
\hline
\end{tabular}

Initial acceptance tests of several billets at OST and within LARP for a wire diameter of $0.778 \mathrm{~mm}$ (this diameter wire used for the $120 \mathrm{~mm}$ aperture HQ magnets) showed that, although the wires meet 
the critical current requirement, the residual resistance ratio (RRR) was in many cases barely above the minimum requirements when reacted using the standard reaction schedule of $210^{\circ} \mathrm{C} / 72 \mathrm{hr}+400^{\circ} \mathrm{C} / 48$ $\mathrm{hr}+650^{\circ} \mathrm{C} / 48 \mathrm{hr}$. The reaction used by OST to qualify the strand before delivery of strand to LARP is $210^{\circ} \mathrm{C} / 48 \mathrm{hr}+400^{\circ} \mathrm{C} / 48 \mathrm{hr}+650^{\circ} \mathrm{C} / 50 \mathrm{hr}$.

To increase the manufacturing margin and increase the likelihood of RRR exceeding 150 in the round wire, the tin content in the sub-element core was reduced by $5 \%$ from the standard amount. The wires from these "Reduced-Sn" billets showed a marked increase in RRR to values over 300. Since coils for MQXFS will use wires from both standard and reduced tin, the reaction at the high temperature will be restricted to $640^{\circ} \mathrm{C} / 48 \mathrm{hr}$.

The second generation conductor for the MQXFS2 and the MQXFA coils may use RRP wire with a 132/169 design and with a Sn content that is reduced by $5 \%$ from the standard amount. The increase in the number of filaments effectively reduces the sub-element diameter to $\sim 50 \mu \mathrm{m}$. The latest strand specification and requirements are in the new specification LARP-MAG-M-8004 Rev. B. The main characteristics of the strand are summarized in Table 2.2.

Table 2.2: Main parameters of the 132/169 strand.

\begin{tabular}{|l|l|}
\hline Process & Ti-Ternary RRP® $\mathrm{Nb}_{3} \mathrm{Sn}$ \\
Strand Diameter, mm & $0.85 \pm .003$ \\
$\mathrm{I}_{\mathrm{c}}(12 \mathrm{~T})$ at $4.2 \mathrm{~K}, \mathrm{~A}$ & $\geq 684$ \\
$\mathrm{I}_{\mathrm{c}}(15 \mathrm{~T})$ at $4.2 \mathrm{~K}, \mathrm{~A}$ & $>361$ \\
$\mathrm{n}$-value & $>30$ \\
$\mathrm{D}_{\mathrm{s}}, \mu \mathrm{m}$ (sub-element diameter) & $<50$ \\
Cu-fraction, \% & $>53$ \\
RRR (after full reaction) & $\geq 150$ \\
Twist Pitch, mm & $14 \pm 2$ \\
Twist Direction & Right-hand screw \\
Minimum Piece length, $\mathrm{m}$ & 750 \\
High temperature HT duration, $\mathrm{h}$ & $\geq 48$ \\
\hline
\end{tabular}

\section{b. Cable Characteristics}

The MQXFS keystone cable will use 40 strands and have a minimum length of $170 \mathrm{~m}$. For this program the plan is to initially manufacture 6 unit lengths (UL) of cable. Each cable run will require 40 $\mathrm{kg}$ of wire with UL's of $\sim 170 \mathrm{~m}$. The detailed cabling map will be drawn-up by LBNL before cable manufacture. Prior to cabling, the strand will be annealed at $170^{\circ} \mathrm{C}$ for $16-24$ hours. The cable will be manufactured in accordance with specification LARP-MAG-M-8005 Rev A, titled " $\mathrm{Nb}_{3} \mathrm{Sn}$ 
Superconductor Cable for LARP $150 \mathrm{~mm}$ Aperture Quadrupole Magnets”. The cable dimensions are the following: width: $18.15 \pm 0.05 \mathrm{~mm}$, mid-thickness: $1.825 \pm 0.010 \mathrm{~mm}$ and keystone angle: $0.55 \pm 0.10$ degrees (see Table 2.3).

Each cable UL is accepted for coil winding after examining the minor edge compaction by light microscopy for strand damage, and evaluating $\mathrm{I}_{\mathrm{c}}$, and RRR values of extracted strands that are reacted using the MQXFS-heat-treatment schedule. This schedule is the following: $210{ }^{\circ} \mathrm{C} / 72 \mathrm{hr}+400{ }^{\circ} \mathrm{C} / 48$ $\mathrm{hr}+640{ }^{\circ} \mathrm{C} / 48 \mathrm{hr}$.

At present LARP has $350 \mathrm{~kg}$ of the RRP-108/127 Ti-Ternary strand in inventory which is more than adequate for all the coils that will be fabricated for the first MQXFS1.

Table 2.3: MQXFS cable parameters.

\begin{tabular}{|c|c|}
\hline Requirement & Value \\
\hline Number of Wires in Cable & 40 \\
\hline Cable Mid-Thickness & $1.525 \pm 0.010 \mathrm{~mm}$ \\
\hline Cable Width & $18.15 \pm .05 \mathrm{~mm}$ \\
\hline Cable Keystone Angle & $0.55 \pm 0.1$ degrees \\
\hline Cable Lay Direction & Left \\
\hline Cable Lay Pitch & $109 \pm 3 \mathrm{~mm}$ \\
\hline Stainless Steel Core Width & $10.1-14.0 \mathrm{~mm}$ \\
\hline Core Thickness & $0.025 \mathrm{~mm}$ \\
\hline Maximum Cable Residual Twist & +150 degrees \\
\hline Cable Surface Condition & $\begin{array}{l}\text { Clean and free from chips, roughness, } \\
\text { sharp edges or burrs; surface uniform to } \\
\quad<25 \% \text { of a single wire diameter; no } \\
\text { broken wires or crossovers. No oil residue. }\end{array}$ \\
\hline MQXFS Cable Unit Lengths & $170 \mathrm{~m}$ \\
\hline
\end{tabular}




\section{c. Cable Insulation}

The $18 \mathrm{~mm}$ wide keystone cable will be insulated by braiding S-2 glass fiber directly on the cable using an appropriate braiding machine. This will be done at New England Wire Technologies ${ }^{1}$. The cable is insulated by braiding the glass yarn using a 48 carrier braiding machine. The insulation material will be S-2 Glass fiber which is SCG 75 1/0 $0.7 Z$ fiber with 933 sizing. The source of the glass fiber is $\mathrm{AGY}^{2}$. Two-ply yarn of this fiber is used for braiding. The two-ply yarn has a twist pitch of 3 inch. The nomenclature for the glass being applied to the cable is SCG 75 2/0 0.3S with 933 sizing. The insulation thickness is specified to be $0.145 \mathrm{~mm} \pm 0.005 \mathrm{~mm}$ as determined by a 10 -stack measurement at $5 \mathrm{MPa}$, following a standard procedure outlined in the LARP-MAG-R-8006 titled "QXF Magnet Cable Insulation".

\section{CERN Conductor}

The cable for the MQXFS1 coils will be fabricated using the Rod-Restack Process $\left(\mathrm{RRP}^{\circledR}\right) \mathrm{Nb}_{3} \mathrm{Sn}$ wire from Oxford-Instruments Superconducting Technology (OST) of the 132/169 design with Tidoping. Strand diameter is nominally $0.85 \mathrm{~mm}$. All main parameters are presented in Table 2.2.

The cable parameters, equal to the parameters of LARP coils, are presented in Table 2.3. The only difference between CERN cables and LARP cables is that CERN strands are not annealed before cabling.

${ }^{1} 130$ North Main Street, Lisbon, NH 03585

22558 Wegener Road, Aiken, SC, 29801 


\section{MAGNETIC DESIGN}

\section{a. 2D Magnetic Design}

\section{- Coil main parameters}

The cross-section of the QXF coil is shown in Fig. 3.1. It is based on the $\cos 2 \theta$-type design. With four blocks of conductor (two blocks per layer) the coil has enough free parameters to fine tune the multipoles (angular position) while keeping the complexity of the winding low. Besides providing a large gradient and a field quality within specifications, the selected coil also features:

- a total number of turns (50) close to the maximum one can get for this coil layout (a large number of turns is needed to reduce the current).

- a peak stress due to azimuthal magnetic force about the same in both layers.

- a coil layout that is very similar to the $120 \mathrm{~mm}$ aperture HQ quadrupole (see Fig. 3.3 where HQ and QXF coil cross-sections are superimposed). This is a valuable feature as the experience in $\mathrm{Nb}_{3} \mathrm{Sn}$ coil fabrication gained with $\mathrm{HQ}$ will be directly transferred to QXF.

More information about the selection of the coil cross-section can be found in [1]. The QXF coil main parameters are summarized in Table 3.1. Dimensions of the cable before and after reaction are both given but only the dimension of the reacted cable is used for the calculations. After reaction the cable is assumed to have its thickness and width increased by $4.5 \%$ and $2 \%$, respectively.
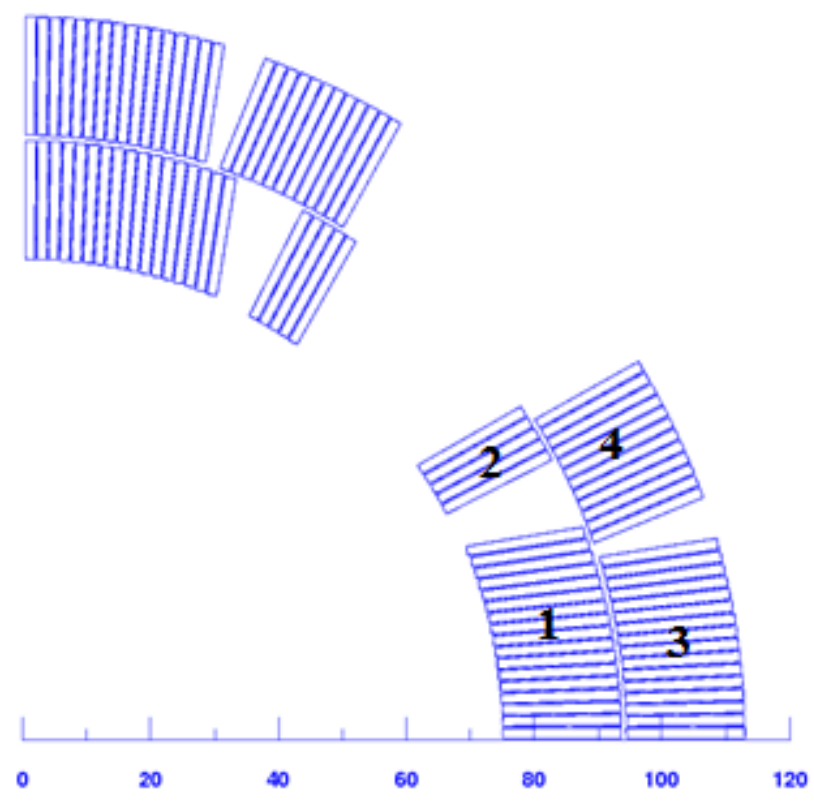

Fig. 3.1: Cross-section of the QXF_v1 coil (units are mm). 
Table 3.1: Main parameters of the QXF coil.

\begin{tabular}{lcc}
\hline \hline & unit & \\
\hline Coil aperture radius & $\mathrm{mm}$ & 75.000 \\
Layer 1 outer radius & $\mathrm{mm}$ & 93.813 \\
\hline Inter-layer insulation thickness & $\mathrm{mm}$ & 0.500 \\
\hline Outer layer inner radius & $\mathrm{mm}$ & 94.313 \\
Outer layer outer radius & $\mathrm{mm}$ & 113.126 \\
\hline Mid-plane shim thickness (per coil) & $\mathrm{mm}$ & 0.250 \\
\hline Number of turns in block 1 & & 17 \\
Number of turns in block 2 & & 5 \\
Number of turns in block 3 & & 12 \\
Number of turns in block 4 & 6 \\
\hline Bare unreacted/reacted conductor width & $\mathrm{mm}$ & $18.150 / \mathbf{1 8 . 5 1 3}$ \\
Bare unreacted/reacted conductor thickness & $\mathrm{mm}$ & $1.525 / \mathbf{1 . 5 9 4}$ \\
Keystone angle & $\mathrm{deg}$ & 0.55 \\
Insulation thickness & $\mathrm{mm}$ & 0.150 \\
\hline \hline
\end{tabular}

The relative position of the block number 2 and 4 (top block of layer 1 and top block of layer 2) is such that the broad face of the layer jump turn (green conductor) is parallel to the broad face of the top conductor of the upper block outer layer (see Fig. 3.2). This way a shim with a uniform thickness $(\sim 0.86 \mathrm{~mm})$ can be used.

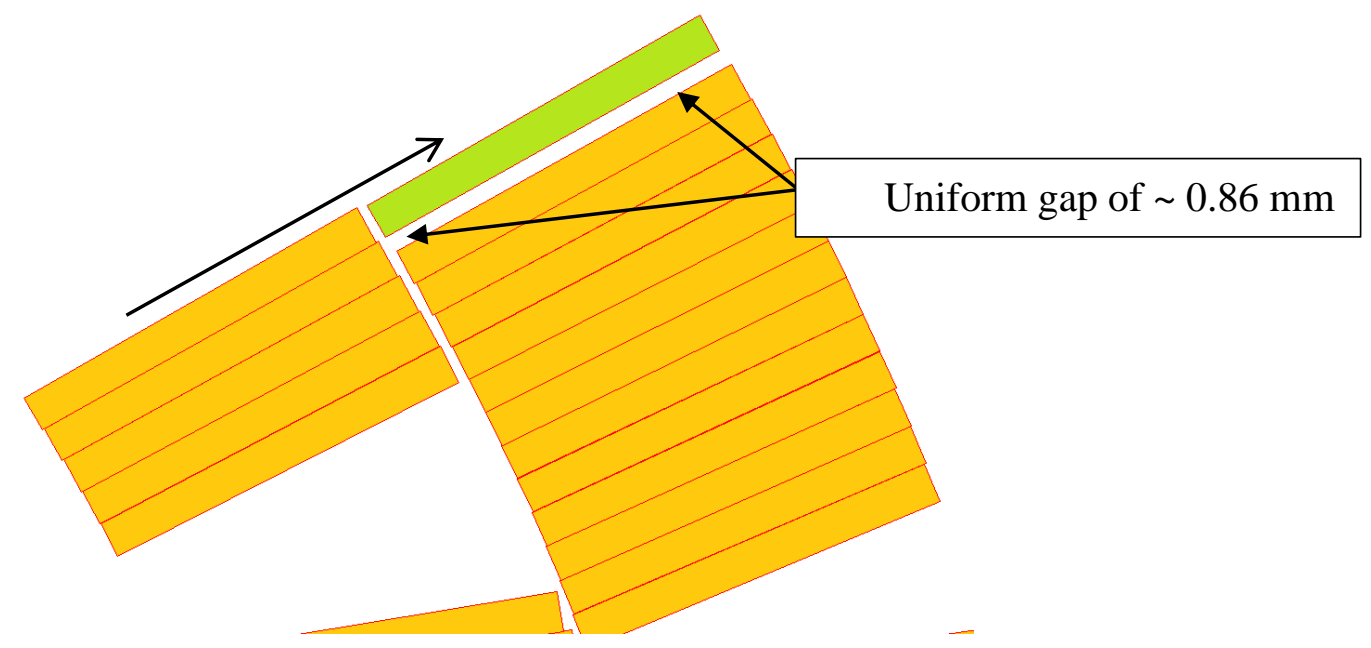

Fig. 3.2: Coil layer jump. 


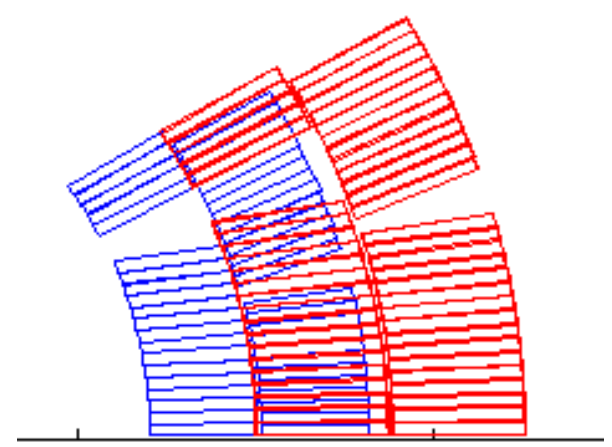

Fig. 3.3: Cross-section of the QXF coil (red) superimposed on the cross-section of the HQ coil. Both QXF and HQ feature a similar coil layout.

\section{- ROXIE model}

The computation of the magnetic field was performed with the ROXIE software [2]. In Fig. 3.4 is given the 2D data table as implemented in ROXIE. As for HQ design, the option "alignment of the conductor on the coil OD" was selected $($ ODFAC $=1)$. Practically, this reflects the fact that the coil has the tendency to move away from the winding mandrel after winding (spring back) as seen from practice coil cross section.

In the QXF assembly the superconducting coil is surrounded by iron pads and yokes which reinforce the field in the aperture and reduce the stray field outside the magnet. These elements are also integral components of the shell-based support structure. As a consequence the yoke and the pad implement slots for the insertion of the bladders and grooves for the keys. The 2D FEM model used for the computation of the magnetic field is shown in Fig. 3.5. The $B H$ characteristic used for the iron components is defined as "BHiron1" in the roxie.bhdata file. This $B H$ curve assumes a filling factor of 1 (full body).

Note that no thermal contraction factor was used for the computation of the harmonics, i.e., the coil is assumed to be at room temperature (cooldown effects are discussed in the following pages).

\begin{tabular}{|c|c|c|c|c|c|c|c|c|c|c|c|c|c|c|}
\hline \multicolumn{15}{|c|}{ [T] Block Data 2D } \\
\hline No & Type & & NCab & $\mathbf{R}$ & 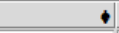 & $\alpha$ & Current & Cable name & & N1 & N2 & Imag & Tum & 田 \\
\hline 1 & Cos & $\nabla$ & 17 & 75 & 0.19099 & 0 & 17460 & XF150HT & $\nabla$ & 2 & 20 & 0 & 0 & $\Delta$ \\
\hline 2 & $\operatorname{Cos}$ & $\nabla$ & 5 & 75 & 28 & 27 & 17460 & XF150HT & $\nabla$ & 2 & 20 & 0 & 0 & \\
\hline 3 & Cos & $\nabla$ & 16 & 94.313 & 0.15188 & 0 & 17460 & XF150HT & $\nabla$ & 2 & 20 & 0 & 0 & \\
\hline 4 & Cos & $\nabla$ & 12 & 94.313 & 18.95 & 22.6 & 17460 & XF150HT & $\nabla$ & 2 & 20 & 0 & 0 & 1 \\
\hline
\end{tabular}

Fig. 3.4: Input-file of the QXF coil used in ROXIE. 


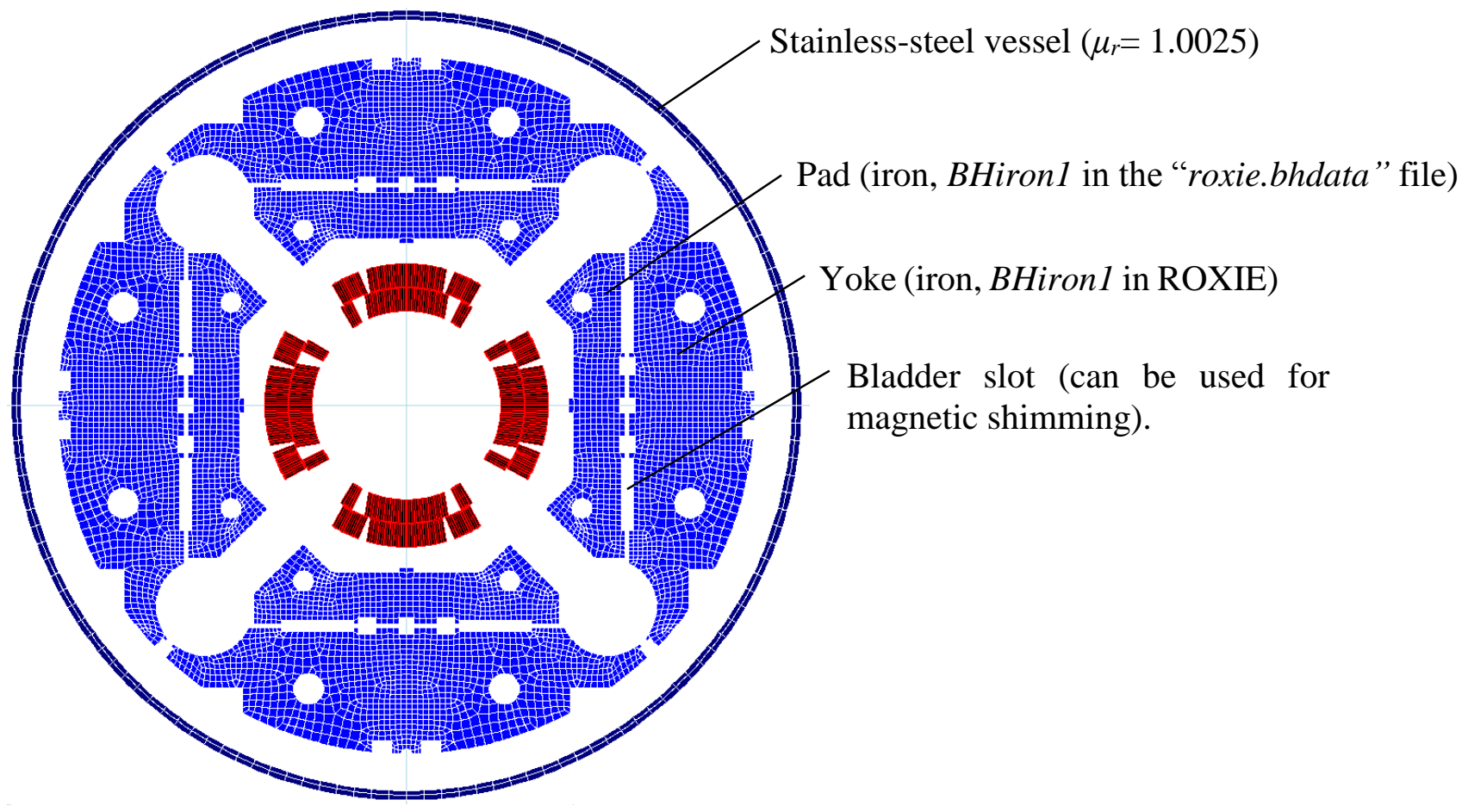

Fig. 3.5: QXF magnet modeled used in ROXIE.

\section{- Magnet performance}

Minimal requirements for wire manufacturing set by CERN and LARP require a critical current larger than $632 \mathrm{~A}$ and $361 \mathrm{~A}$ in $12 \mathrm{~T}$ and $15 \mathrm{~T}$ applied field respectively and at a temperature of $4.2 \mathrm{~K}$. For the computation of the magnet short sample current $5 \%$ degradation on the current due to cabling is assumed and a correction factor of $0.429 \mathrm{~T} / \mathrm{kA}$ is used to take into account the strand self-field. It corresponds to the magnetic field produced at $89 \%$ of the radius of a straight wire. For the characterization of the critical surface the scaling law developed in [3] is used.

In Table 3.2 are given the magnetic parameters of the QXF magnet when powered at short sample $\left(I_{s s}\right)$ and nominal $\left(I_{n o m}\right)$ currents. The operational temperature of the QXF magnet is $1.9 \mathrm{~K}$. Because magnetic forces generated at $I_{s s}$ translate to a mechanical stress that exceed intrinsic safe limit of $\mathrm{Nb}_{3} \mathrm{Sn}$ the maximum current $\left(I_{\max }\right)$ is set to $90 \%$ of $I_{s s}$.

In Fig. 3.7 is plotted the magnetic field in the coil (left) and in the yoke (right) at nominal current. At $I=I_{\text {nom }}$ the peak field in the coil reaches $12.07 \mathrm{~T}$. The peak field is located in the upper block of the inner layer (block 2). The proximity of the yoke to the coil results in a highly saturated iron yoke that translate to a $\sim 9 \%$ reduction in the transfer function at nominal current (see Fig. 3.8-left). For the same reason the differential inductance $L_{d}$ is strongly non-linear (see Fig. 3.8-right). In spite of being highly saturated the iron yoke still contributes to enhancing the magnet gradient by $\sim 8 \%$ at $I_{\text {nom }}$ (from $129 \mathrm{~T} / \mathrm{m}$ to $140 \mathrm{~T} / \mathrm{m}$ ). 
Table 3.2: Main magnetic parameters of the QXF cross-section considering an operational temperature of $1.9 \mathrm{~K}$.

\begin{tabular}{|c|c|c|c|c|}
\hline & unit & $I_{s s}$ & $I_{\max }$ & $I_{\text {nom }}$ \\
\hline \% of Iss & $\%$ & 100 & 90 & 82 \\
\hline Current & $\mathrm{kA}$ & 21.25 & 19.12 & 17.46 \\
\hline Gradient & $\mathrm{T} / \mathrm{m}$ & 168 & 152 & 140 \\
\hline Peak field & $\mathrm{T}$ & 14.51 & 13.14 & 12.06 \\
\hline Temperature margin & $\mathrm{K}$ & 0 & 2.69 & 4.16 \\
\hline Fx per octant & $\mathrm{MN} / \mathrm{m}$ & 3.85 & 3.20 & 2.75 \\
\hline Fy per octant & $\mathrm{MN} / \mathrm{m}$ & -5.69 & -4.63 & -3.89 \\
\hline Energy & $\mathrm{MJ} / \mathrm{m}$ & 1.92 & 1.56 & 1.32 \\
\hline$L_{d}$ & $\mathrm{mH} / \mathrm{m}$ & 8.15 & - & 8.22 \\
\hline
\end{tabular}

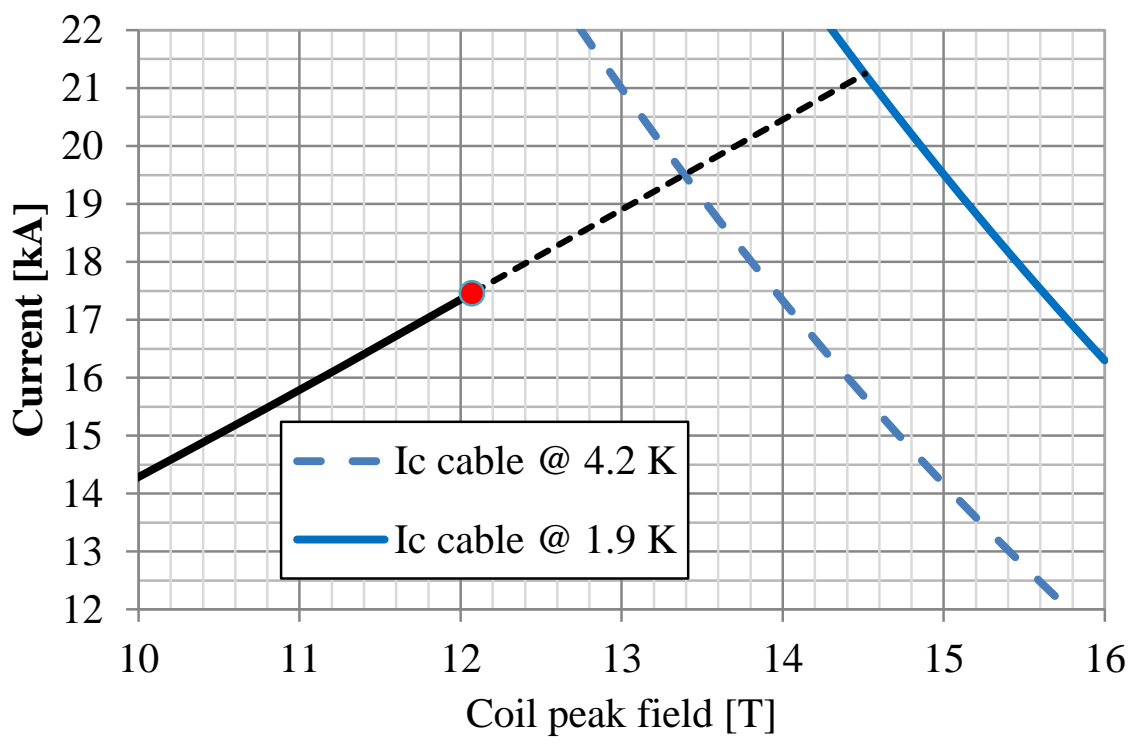

Fig. 3.6: QXF quadrupole load line (current in the cable versus peak field in the coil). The peak field is always located in block 2 . The load line has been obtained by gradually increasing the current in the coil. This way the non-linearity of the load line is taken into account. The red dot shows the operating point. The critical surface accounts for $5 \%$ current degradation and for selffield correction. 

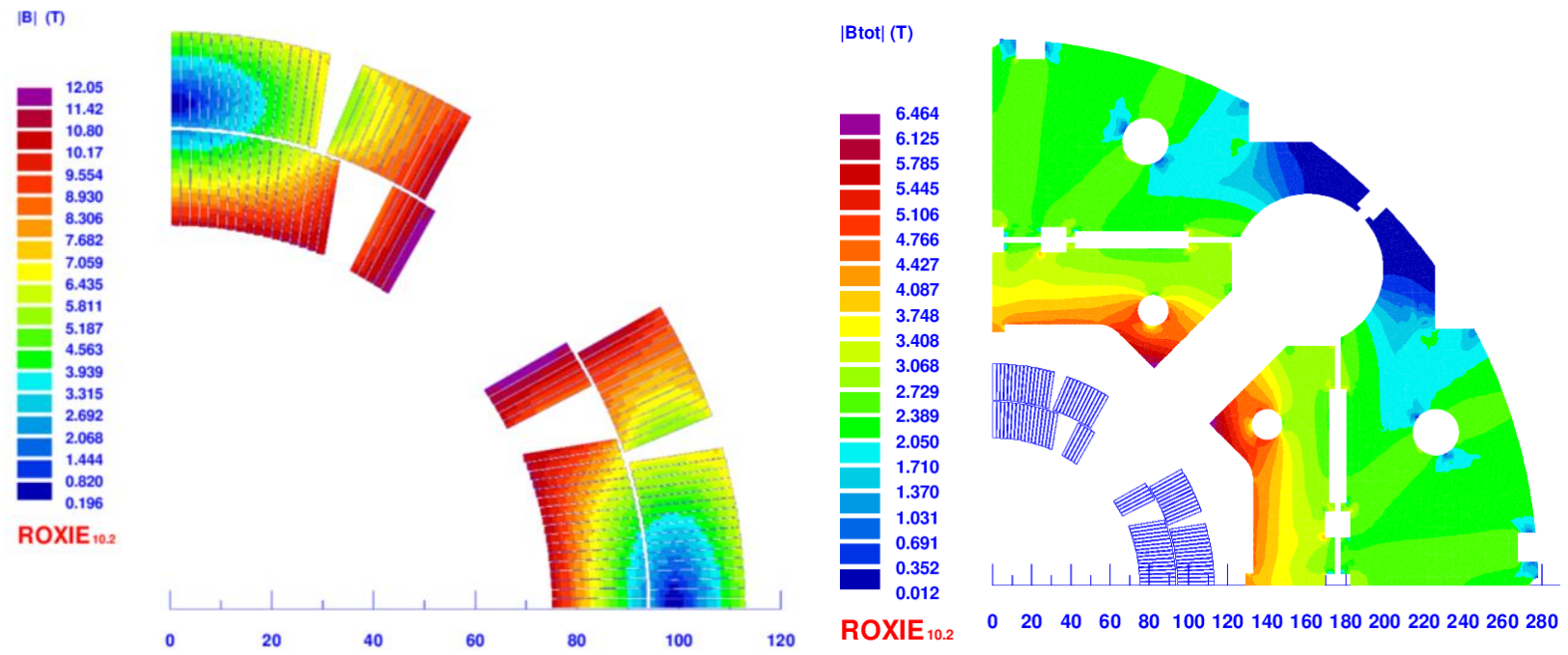

Fig. 3.7: Magnetic flux density in the coil (left) and in the yoke (right) at nominal current $\left(I_{\text {nom }}\right)$.
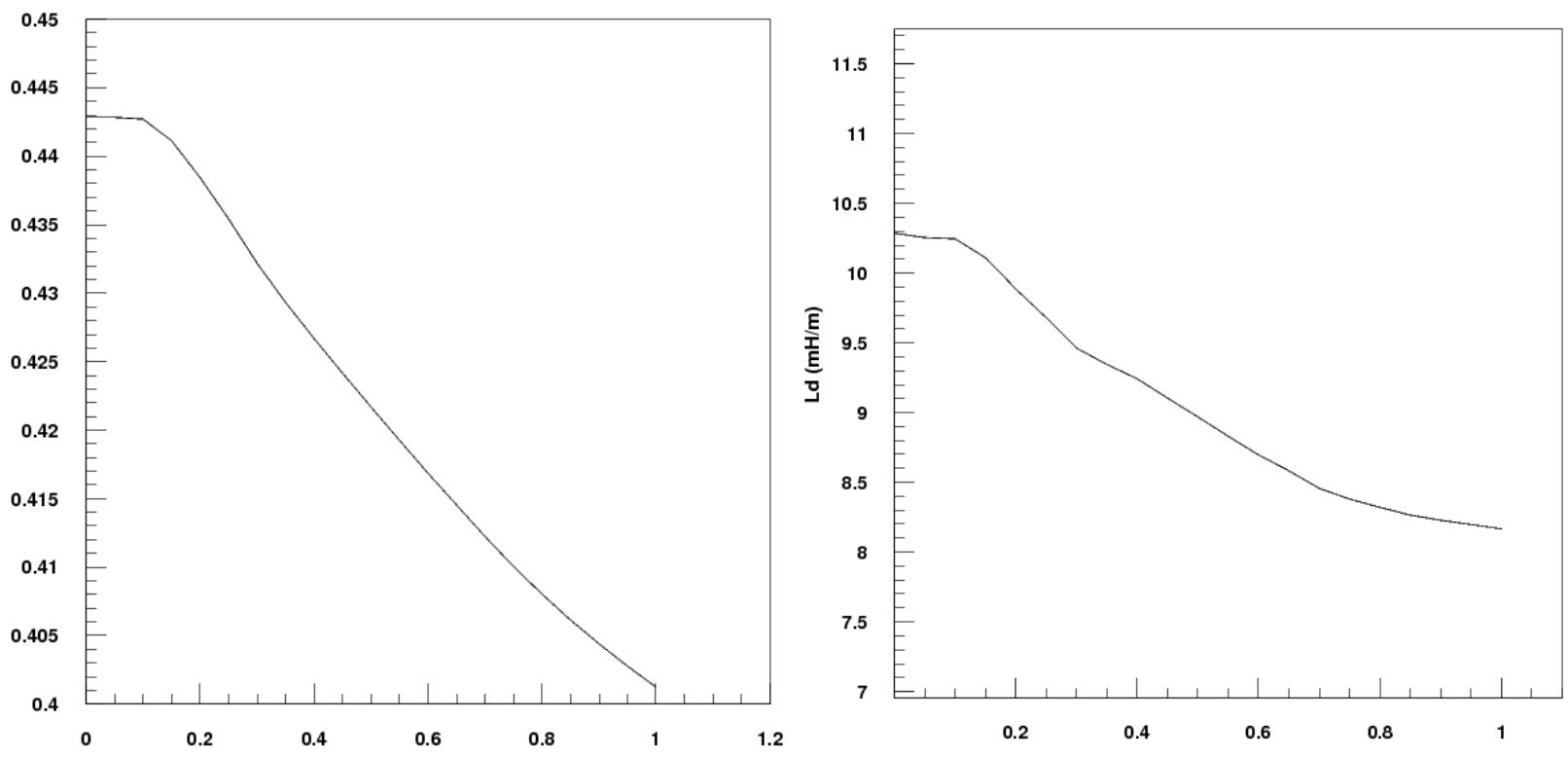

Fig. 3.8: Left: Transfer function defined as $B_{2}\left(R_{r e f}, I\right) / I$ and expressed in $[\mathrm{T} / \mathrm{kA}]$ plotted versus $I / I_{\text {nom }}$. Right: differential inductance $L_{d}$ in $\mathrm{mH} / \mathrm{m}$ plotted versus $I / I_{\text {nom }}$. Roxie was used for the computations. 


\section{- Field quality}

Regarding the magnetic field in the magnet aperture, it was required that all allowed harmonics are below one unit at nominal current and at a reference radius taken as $2 / 3$ of the coil aperture radius $\left(R_{\text {ref }}\right.$ $=50 \mathrm{~mm}$ ). The following convention for the definition of the multipoles is used:

$$
B_{y}+i B_{x}=10^{-4} B_{2} \sum_{n=1}^{\infty}\left(b_{n}+i a_{n}\right) \frac{(x+i y)^{n-1}}{R_{r e f}^{n-1}}
$$

The evolution of the first four allowed harmonics $\left(b_{6}, b_{10}, b_{14}\right.$ and $\left.b_{18}\right)$ with the current is plotted in Fig. 3.9. Numerical values of the field components calculated for $I_{s s}, I_{\max }$ and $I_{\text {nom }}$ are given in Table 3.3.
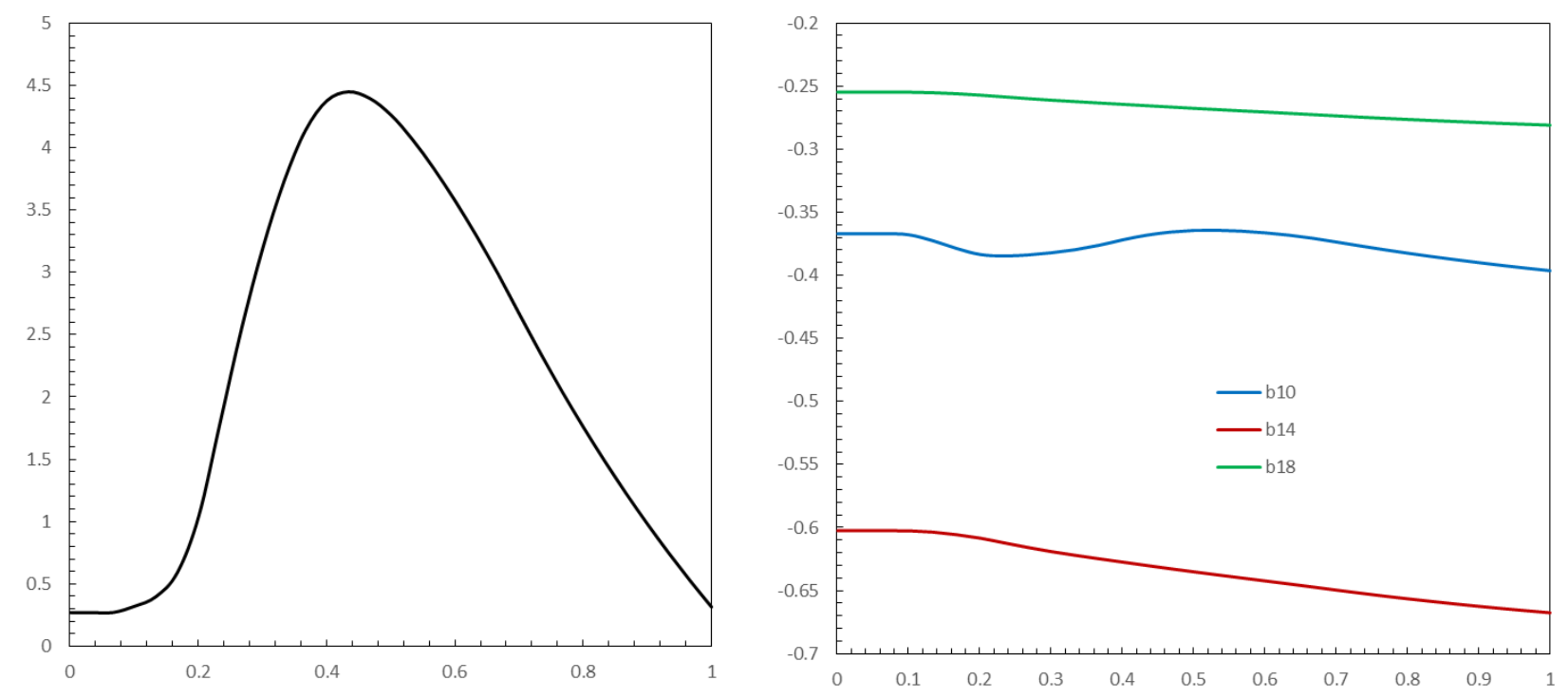

Fig. 3.9: First four allowed harmonics (left: $b_{6}$; right: $b_{10}, b_{14}$ and $b_{18}$ ) plotted versus the $I / I_{\text {nom }}$ ratio. Harmonics are expressed in units.

Table 3.3: Field harmonic components calculated for $I_{s s}, I_{\max }$ and $I_{n o m}$.

\begin{tabular}{|c|c|c|c|c|}
\hline & & $I_{s s}$ & $I_{\max }$ & $I_{\text {nom }}$ \\
\hline \% of Iss & $\%$ & 100 & 90 & 82 \\
\hline Current & $\mathrm{kA}$ & 21.25 & 19.12 & 17.46 \\
\hline Gradient & T/m & 168 & 152 & 140 \\
\hline$b_{6}$ & unit & -0.82 & -0.25 & 0.32 \\
\hline$b_{10}$ & unit & -0.41 & -0.40 & -0.40 \\
\hline$b_{14}$ & unit & -0.68 & -0.67 & -0.67 \\
\hline$b_{18}$ & unit & -0.28 & -0.28 & -0.28 \\
\hline
\end{tabular}




\section{- Systematic field error}

Field calculations are performed assuming that conductors are aligned on the layer OD, which seems to be the natural position of the turns due to spring back. However, it is clear that one does not totally control the position of the cable in the impregnation cavity. Therefore, for completeness, in Table 3.4 multipoles are presented for the case where conductors are aligned on the layer ID. The current is set to Inom.

Table 3.4: Allowed harmonics at nominal current and with turns either aligned on the coil OD (baseline) or ID.

\begin{tabular}{ccc}
\hline Multipoles & $\begin{array}{c}\text { Turns aligned on } \\
\text { the coil OD } \\
\text { (baseline) }\end{array}$ & $\begin{array}{c}\text { Turns aligned on } \\
\text { the coil ID }\end{array}$ \\
\hline$b_{6}$ & $\mathbf{0 . 3 2}$ & -1.08 \\
$b_{10}$ & $\mathbf{- 0 . 4 0}$ & -0.98 \\
$b_{14}$ & $\mathbf{- 0 . 6 7}$ & -0.65 \\
$b_{18}$ & $\mathbf{- 0 . 2 8}$ & -0.26 \\
\hline
\end{tabular}

Another source of systematic error is the deformation of the coil after cool-down due to thermal contraction and pre-load of the coil (see Fig. 3.10) taking into account that these factors were not included in the field analysis presented above.

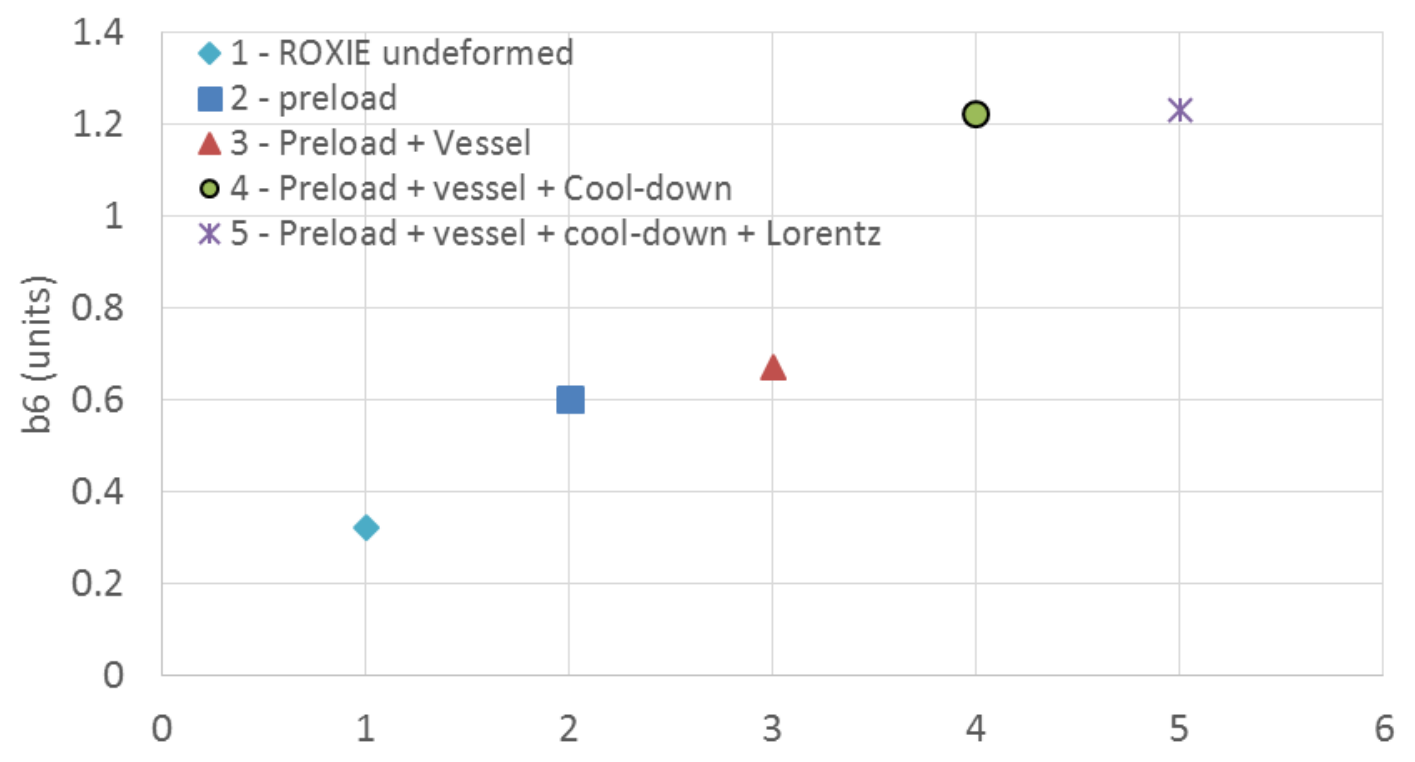

Fig. 3.10: Impact on $b_{6}$ of coil deformations due to cool-down, pre-loading, and energizing. 


\section{- Sensitivity of the field harmonics to geometric random error}

The impact of some pre-defined geometric errors randomly distributed among the eight octants of the QXF quadrupole coil has been estimated using a Monte-Carlo method. For the coil a model built with Matlab was used. The iron yoke is not taken into account in the model because of the small impact on relative differences. Obtained results are shown in Figs. 3.11 and 3.12 where the standard deviations of the normal and skew harmonics are given for the harmonics 3 to 10 .

Several types of defect have been studied:

- Random defect in the layer 1 pole piece.

- $\quad$ Random defect in the thickness of the wedge of layer 1.

- $\quad$ Random defect in the radial position of the wedge of layer 1.

- Random defect in the radial position of the inner layer of each octant (inner radius of the inner layer). The defect is randomly distributed among the eight octant (outer layer is left unchanged).

- Random defect on the position of each turn of the inner layer.

- All the above mentioned defects were also applied to the outer layer (Layer 2).

- Random defect on the mid-plane thickness (L1\&L2).

In all the cases a normal distribution with a mean of zero and a sigma of $25 \mu \mathrm{m}$ was used for the Monte-Carlo simulation. Moreover, in order to be closer to reality defects larger than $25 \mu \mathrm{m}$ were discarded from the study.

Results show that multipoles are mostly sensitive to the inner layer radial position, the thickness of the mid-plane, and the outer layer radial position. Impact of the wedges dimensions and radial position is marginal. 


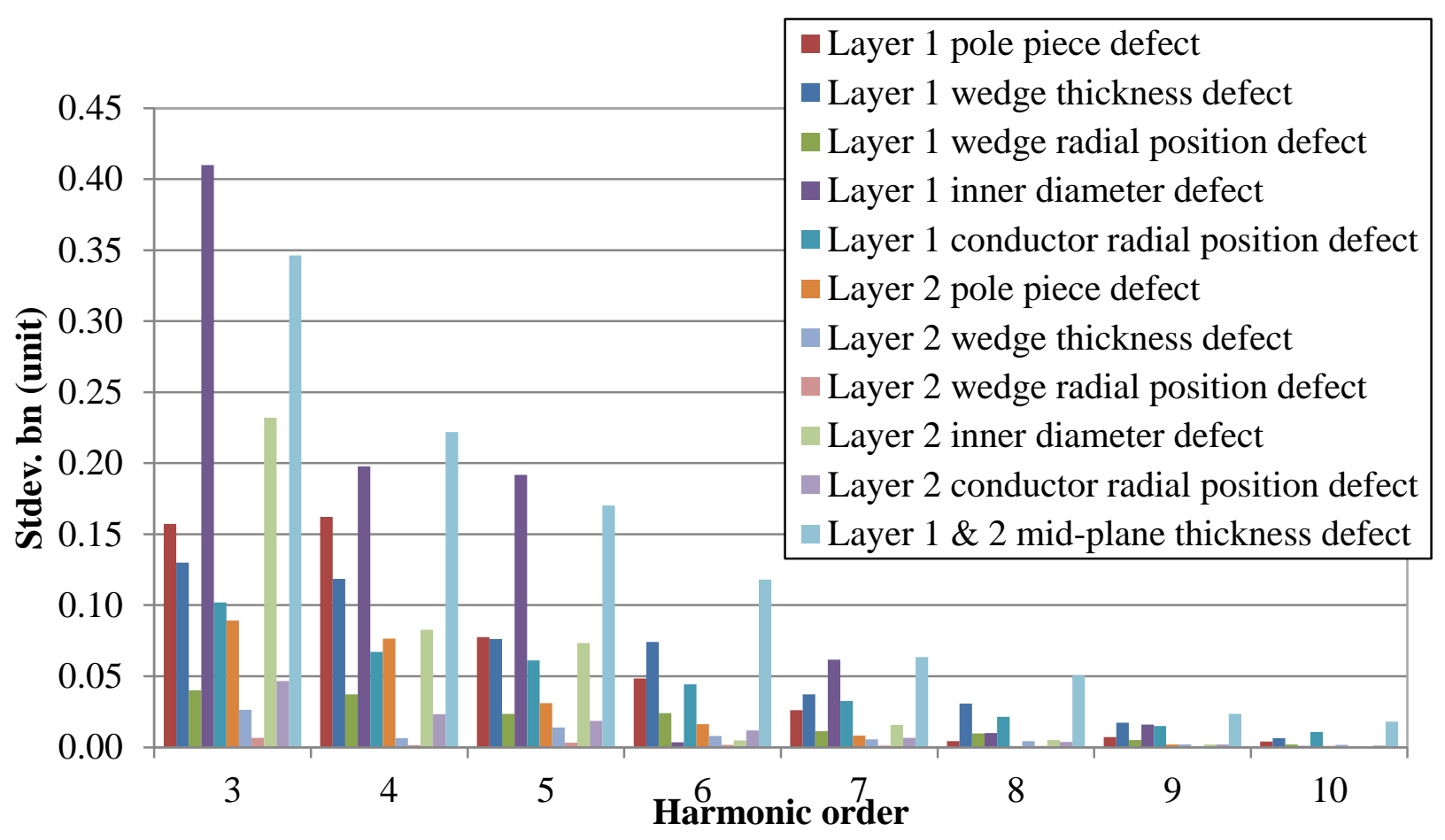

Fig. 3.11: Effect of random defects on the Normal multipoles.

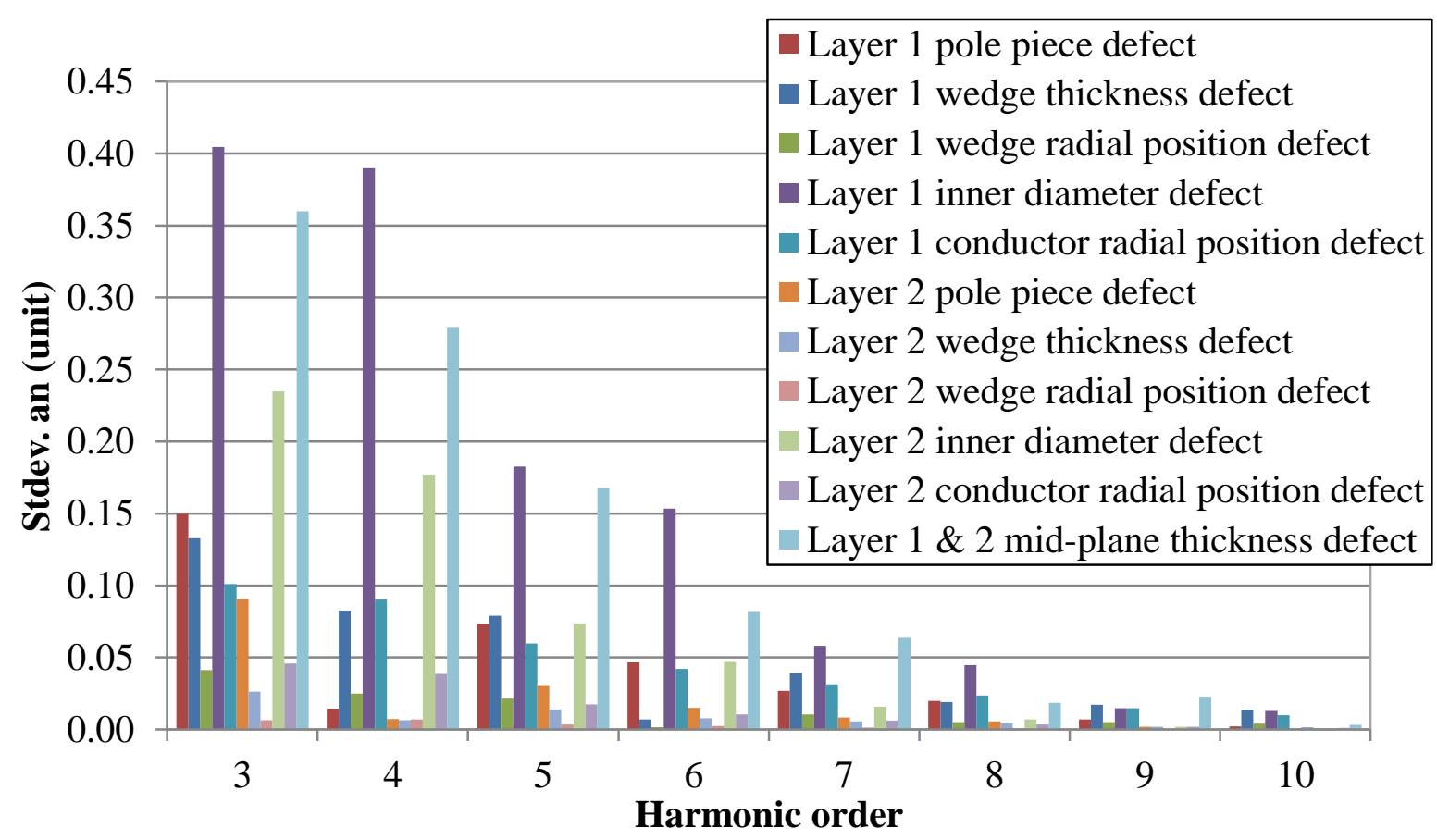

Fig. 3.12: Effect of random defects on the Skew multipoles. 


\section{b. 3D Magnetic Design}

\section{- Introduction}

The design of coil ends is carried out in three stages:

1. The design of mechanically favorable shapes for the end parts minimizing the strain energy on the cable.

2. The determination of the longitudinal spacing between coil blocks and the number of blocks in the ends to reduce the maximum field and integrated field harmonics. The optimization process was carried out in ROXIE.

3. Fine tuning of the shapes to assure the optimal solution in terms of cable mechanical stability.

Additional design goals were considered:

1. To avoid corners of coil blocks in one layer coinciding with sharp edges of spacers in the other layer. Experience from the LARP program shows that this overlapping may increase the risk of insulation damage [8].

2. To keep the coil end compact in order to increase the magnetic length.

Two different strategies have been studied. The first approach aims at reducing the number of blocks in the ends by keeping the same coil blocks in the straight section and in the ends. The second approach minimizes the strain energy, peak field and integrated field harmonics by dividing coil blocks in the ends.

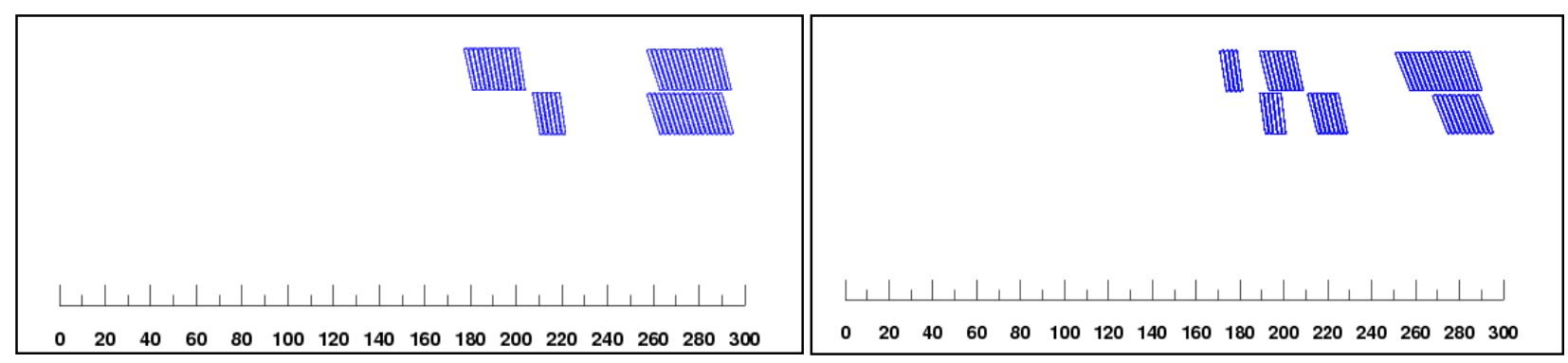

Fig. 3.13: yz-plane sections of the coil end variants: 4 blocks (left) and 6 blocks (right; selected for MQXFS1). Dimensions are in mm.

\section{- Study of Peak Field Enhancement}

The aim of the optimization process is to guarantee that the maximum field in the coil ends ( $\mathrm{B}_{\text {Pends) }}$ is lower than the peak field in the straight section ( $\left.\mathrm{B}_{\text {Pss }}\right)$.

One of the options to reduce the field enhancement is to remove the magnetic iron in the end region. A study was carried out to determine the optimal cut-back length of the magnetic iron, which is a compromise between the reduction of the magnetic length and the decrease of the peak field in the ends. In order to evaluate the impact of the magnetic iron reduction the two following parameters are defined:

- $\Delta B_{P}$ : ratio between the increase or decrease of field in the ends and the field in the straight section 


$$
\Delta B_{P}=\frac{B_{\text {Pends }(I L \text { or } O L)}-B_{P s s(I L)}}{B_{P S S(I L)}} \cdot 100
$$

- $\Delta \mathrm{l}_{\mathrm{m}}$ : fractional decrease of magnetic length due to the reduction of the magnetic iron in the end region

$$
\Delta \mathrm{l}_{\mathrm{m}}=\frac{\mathrm{l}_{\mathrm{m}}-\mathrm{l}_{\mathrm{m}(\text { full yoke and pad extension })}}{\mathrm{l}_{\mathrm{m}(\text { full yoke and pad extension })}}
$$

Fig. 3.14 shows the evolution of these ratios as a function of the yoke cut back. A yoke cut-back equal to 0 represents the location of the last conductor in the $\mathrm{z}$ axis and a yoke cut-back of $-152 \mathrm{~mm}$ corresponds to the location where the cable starts bending. A yoke cut-back of 160-170 mm taking as reference the longitudinal position of the last conductor assures that the peak field in the coil is located in the straight section. As a drawback, the magnetic length is reduced by about $2 \%$.

As described in [7] the mechanical structure presently considered for MQXF is a shell-based structure. Iron yoke and pad are independent so a possible solution is to shorten only the pad. Fig. .15 shows the peak field in the ends along the conductor in three cases: (i) if the pad and yoke are full length; (ii) if the yoke is full length and the pads are short; (iii) and if both yoke and pads are short. Table presents the relative change in peak field in the ends with respect to the straight section for the three cases outlined before.
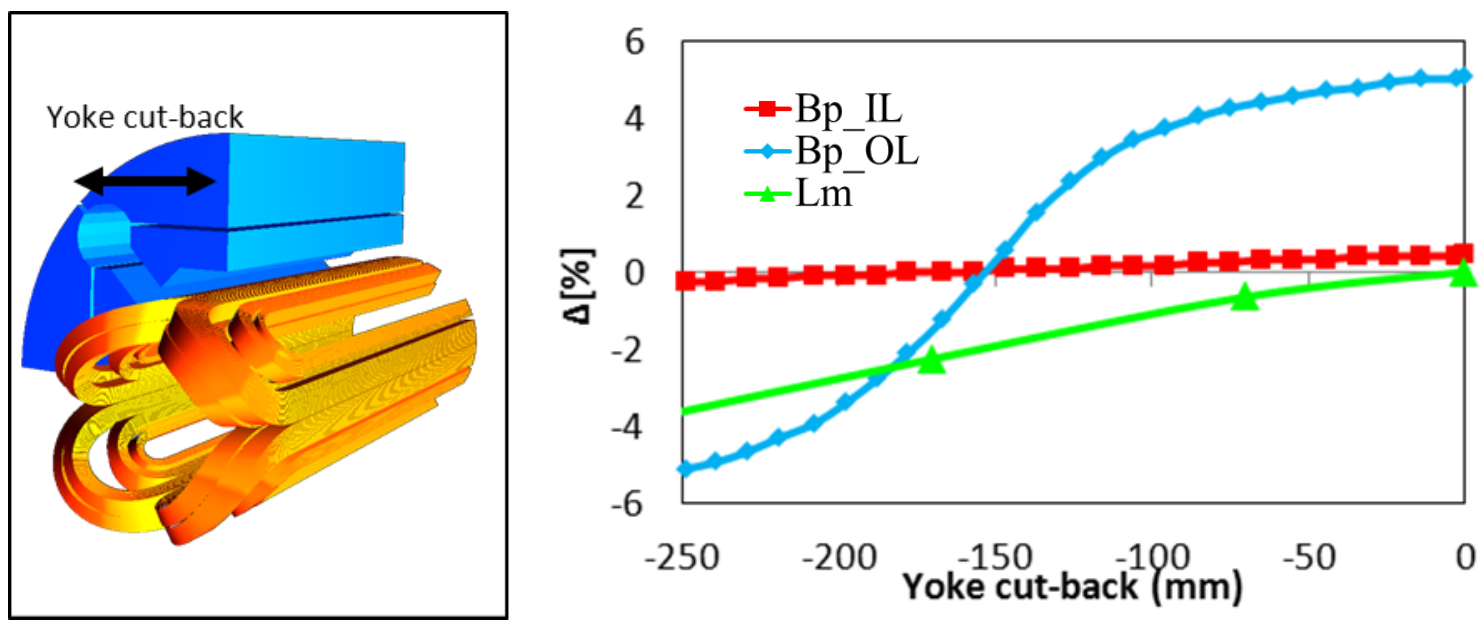

Fig. 3.14: Impact of the yoke extension in the peak field and the magnetic length. $(\mathrm{IL}=$ Inner layer, $\mathrm{OL}=$ Outer layer) 


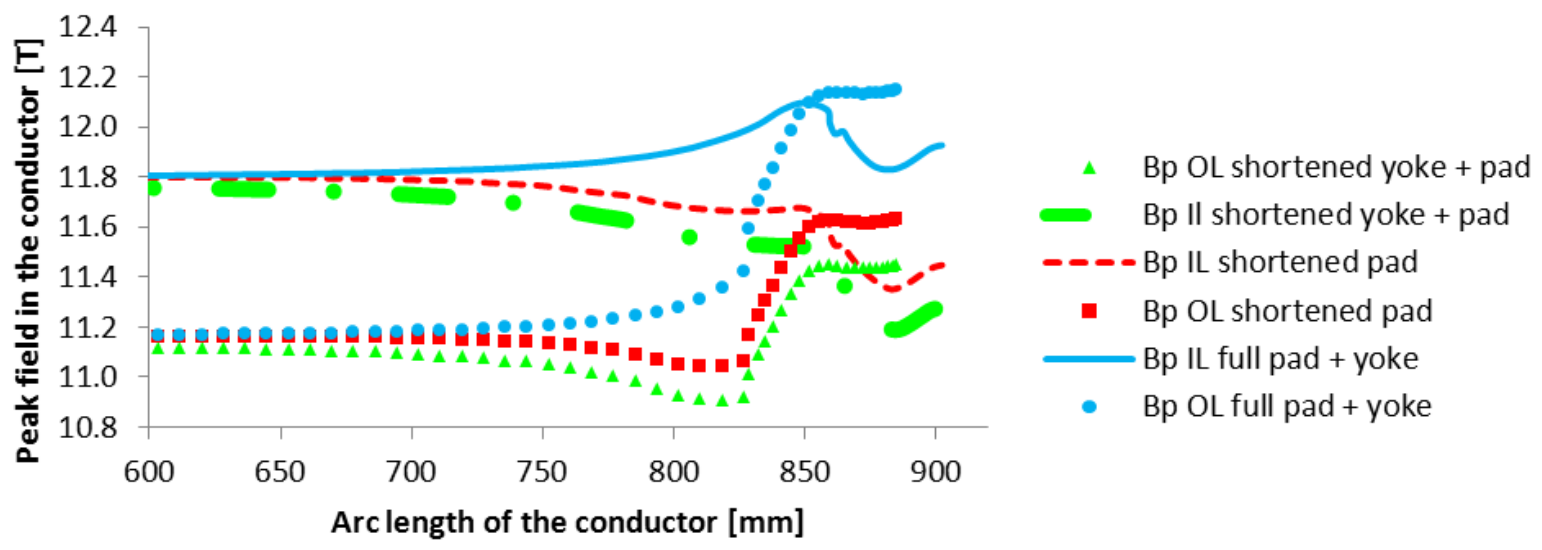

Fig. 3.15: Peak field enhancement in the return end.

Table 3.5: Change in the 3D peak field and magnetic length for different magnetic pad and yoke.

\begin{tabular}{|c|c|c|c|}
\hline & \multicolumn{2}{|c|}{$\Delta B_{p}$} & $\Delta l_{m}$ \\
\hline & {$[\mathrm{T}]$} & [\%] & {$[\mathrm{mm}]$} \\
\hline Full iron pad and yoke & 0.31 & 3 & 0 \\
\hline $\begin{array}{c}\text { Pad shortened by } 170 \mathrm{~mm} \\
\underline{\text { (Selected design) }}\end{array}$ & -0.15 & -1.3 & -17.8 \\
\hline $\begin{array}{c}\text { Pad \& yoke shortened by } \\
170 \mathrm{~mm}\end{array}$ & -0.34 & -2.9 & -22.5 \\
\hline
\end{tabular}

The field enhancement can be further reduced by dividing the coil blocks in the ends and/or increasing the total length of the ends. ROXIE 3D electromagnetic computations show that dividing the ends in six blocks instead of four decreases the peak field in the coil ends by $0.4 \mathrm{~T}$. Increasing the length of the ends by $18 \mathrm{~mm}$ decreases the peak field in the coil end by $0.1 \mathrm{~T}$. 


\section{- Study of Integrated Field Harmonics}

The aim of the optimization is to assure that the average multipole content is lower than the expected random components $\left(\mathrm{b}_{6}<1.1\right.$ units, $\mathrm{b}_{10}<0.1$ units). The average multipole content is defined as:

$$
\bar{b}_{n}=\frac{\int B_{n}(I, z) d z}{B_{2}^{s s} l_{\text {mag }}(I)}
$$

where $B_{n}$ follows the convention

$$
B_{y}+i B_{x}=\sum\left(B_{n}+i A_{n}\right)(x+i y)^{n-1},
$$

$B_{2}^{S S}$ is the main field in the straight section and $l_{m a g}$ is the magnetic length defined as:

$$
l_{\text {mag }}(I)=\frac{1}{B_{2}^{s s}(I)} \int_{-\infty}^{+\infty} B_{2}(I, z) d z
$$

The magnetic optimization was performed in ROXIE and results were validated in OPERA model. Fig. 3.16 shows the comparison among models for 4-blocks variant.
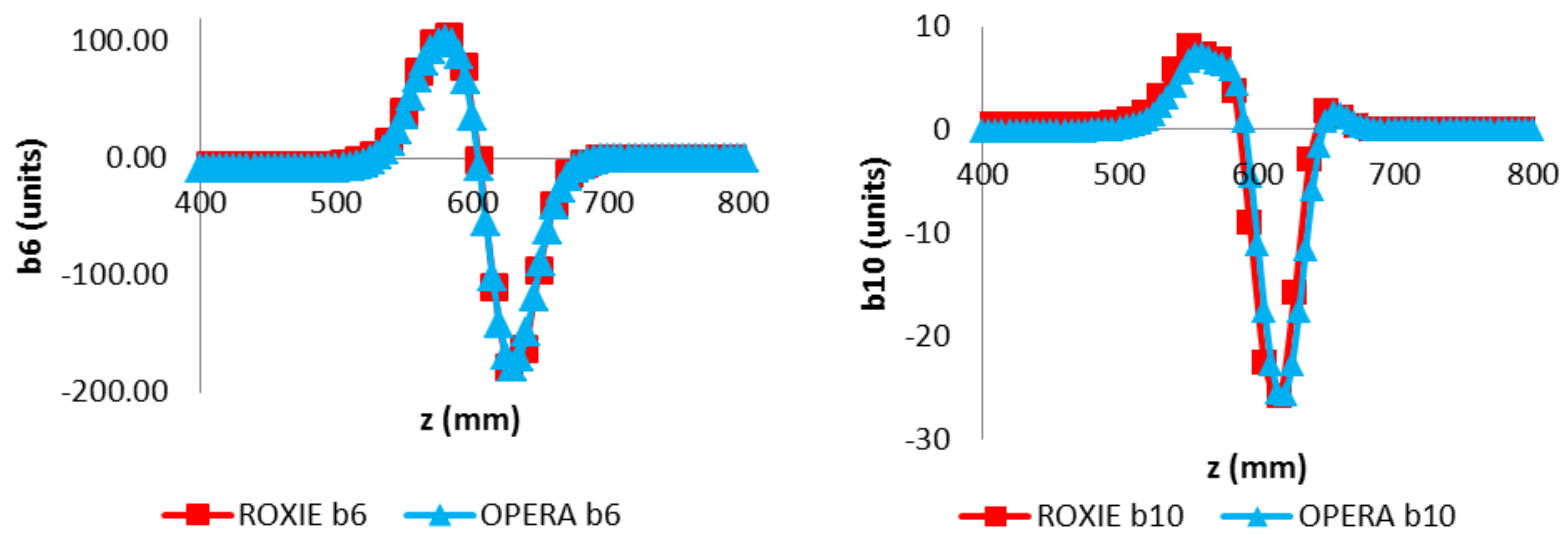

Fig. 3.16: Comparison of the multipole content, ROXIE vs OPERA model.

The average multipole content $\overline{b_{10}}$ cannot be reduced further than 0.5 units for the 4-blocks solution. If the ends are split into 6 blocks, the target $\overline{b_{10}}<0.1$ units can be achieved. The $\mathrm{b}_{6}, \mathrm{~b}_{10}$ and $\mathrm{b}_{14}$ variations along the magnet are shown in Fig. 3.17 for the 6-blocks variant. The amplitude of $b_{6}$ is quite large, reaching up to 150 units. Nevertheless, due to the end block position optimization, the integral remains within acceptable limits although further compensation of $b_{6}$ is needed to compensate the effect of the splice. This will be addressed in the second generation design. The impact of the current leads and layer jump is visible on the lead end side. 
Table 3.6: Integrated Field Harmonics.

\begin{tabular}{|l|c|c|c|c|}
\hline units at $R_{\text {ref }}=50 \mathrm{~mm}$ & $\bar{b}_{6}$ & $\bar{b}_{10}$ & $\bar{a}_{2}$ & $\bar{a}_{6}$ \\
\hline 2D & 0.3 & -0.4 & 0.0 & 0.0 \\
\hline 3D-SQXF (1.2 m) & 9.1 & -0.5 & -8.9 & 0.6 \\
\hline 3D-LARP-LQXF (4 m) & 2.9 & -0.4 & -2.7 & 0.2 \\
\hline 3D-CERN-LQXF (6.8 m) & 1.9 & -0.4 & -1.6 & 0.1 \\
\hline
\end{tabular}

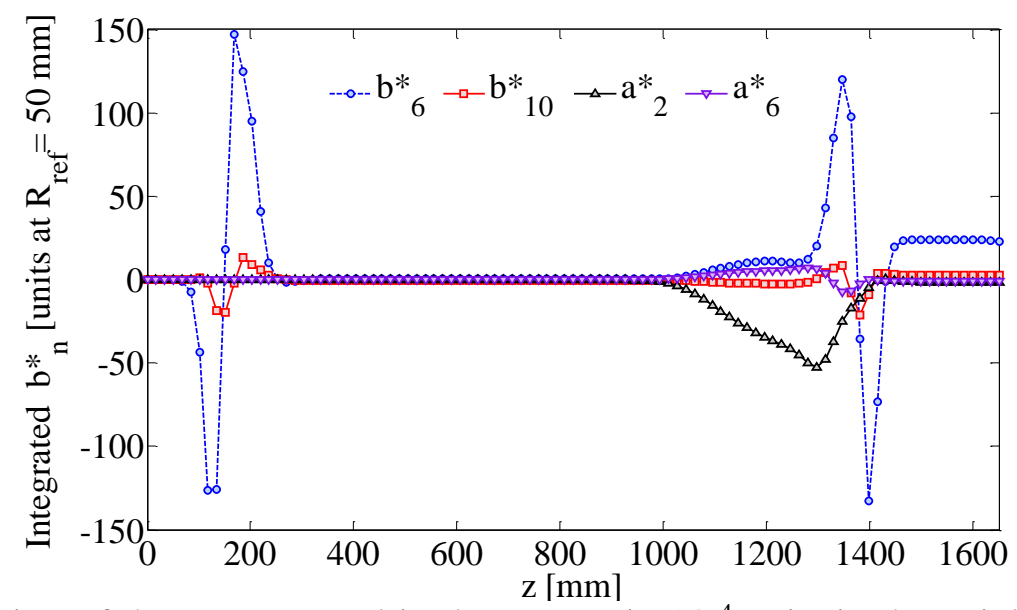

Fig. 3.17: Variation of the average multipole content in $10^{-4}$ units in the axial direction (from return end to lead end) computed by ROXIE. Multipoles computed at a reference radius of $50 \mathrm{~mm}$ for a magnetic length of $1.2 \mathrm{~m}$ (MQXFS).

\section{- MQXFS1 End Design}

The final choice considers the subdivision of the coil blocks in the ends due to the significant reduction of peak field and strain energy in the blocks. In addition, the 6-blocks solution allows further optimization in terms field quality. Fig. 3.18 shows the blocks sub-division for MQXFS1 end design.
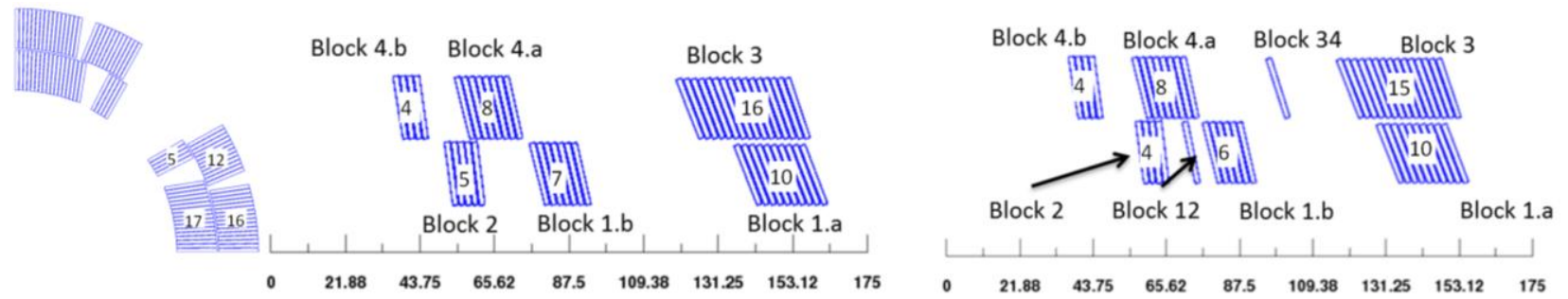

Fig. 3.18: Number of conductors per block in the straight section (left), return end (center) and lead end (right).

Fig. 3.19 shows a 3D detailed view of the ends. From left to right, the first image corresponds to the inner layer (IL) return end (RE), the second to the inner layer lead end (LE), the third to the outer layer (OL) return end and the last corresponds to the outer layer lead end. 


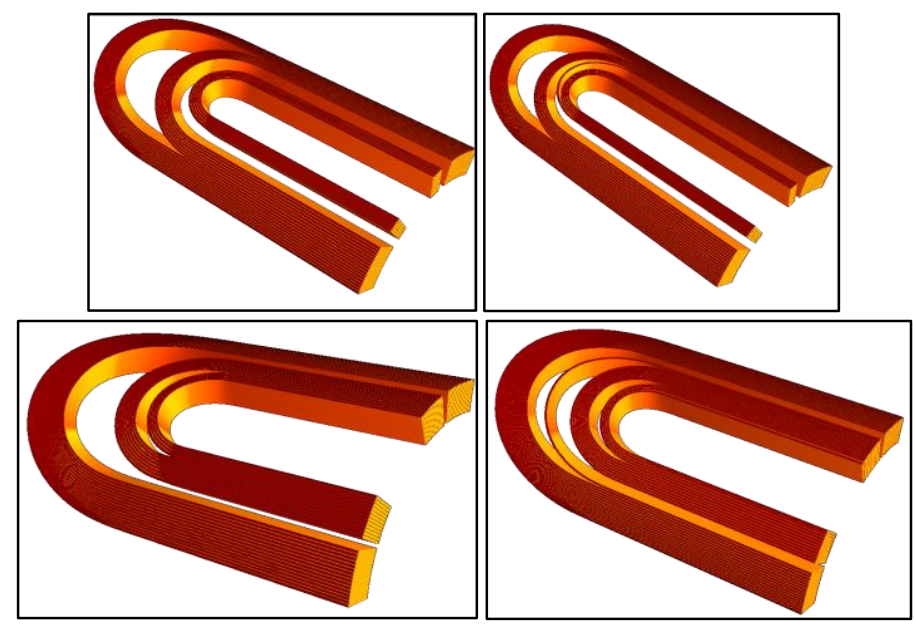

Fig. 3.19: Details of the coil geometry: IL/OL (top/bottom), RE/LE (left/right).

The dimensions of the layer jump were defined by scaling the hard way bending radius in HQ with the cable width. The overall layer jump length is $270 \mathrm{~mm}$ and the bending radius is $800 \mathrm{~mm}$. Fig. 3.20 shows the magnetic field in the conductor along the layer jump, which decreases from $12.1 \mathrm{~T}$ in the pole turn of the inner layer to $9 \mathrm{~T}$ at the end of the layer jump.

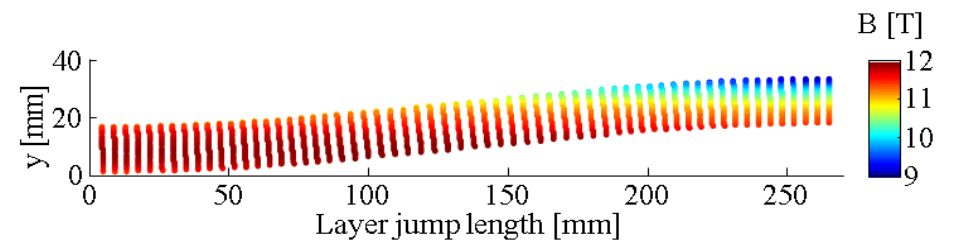

Fig. 3.20: Magnetic field in the layer jump at nominal current (17320 A).

Regarding the yoke cut-back, full yoke length and shorter pads were selected. Fig. 3.21 shows how the field decays very rapidly in the coil ends.

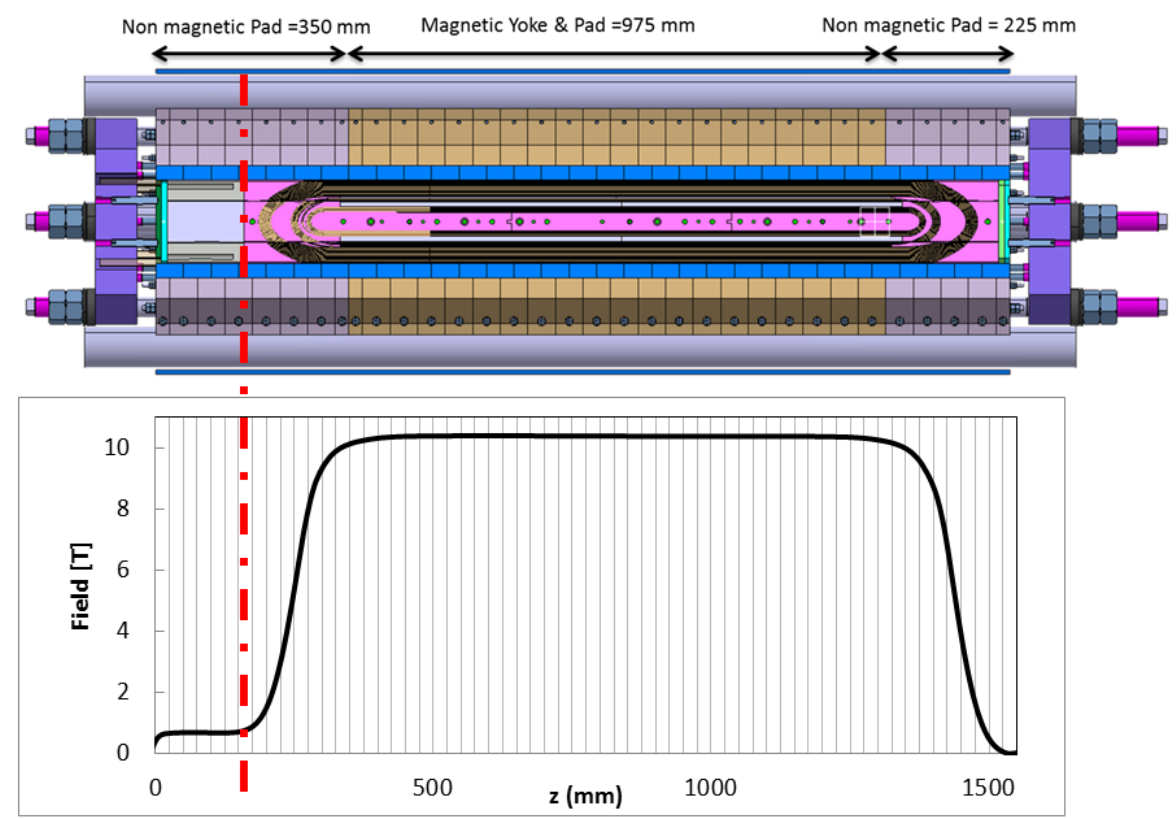

Fig. 3.21: Field at $\mathrm{x}=75 \mathrm{~mm}, \mathrm{y}=0 \mathrm{~mm}$ for nominal current $(17320 \mathrm{~A})$. 
Table 3.7 shows the relevant lengths for MQXFS and MQXFA.

Table 3.7: MQXFS and MQXFA relevant lengths.

\begin{tabular}{|l|l|l|l|}
\hline & Units & MQXFS & MQXFA \\
\hline Magnetic length & $\mathrm{mm}$ & 1192 & 4000 \\
\hline Overall coil length (including splice extension) & $\mathrm{mm}$ & 1510 & 4318 \\
\hline Magnetic yoke extension & $\mathrm{mm}$ & 1550 & 4358 \\
\hline Magnetic pad extension & $\mathrm{mm}$ & 975 & 3783 \\
\hline
\end{tabular}
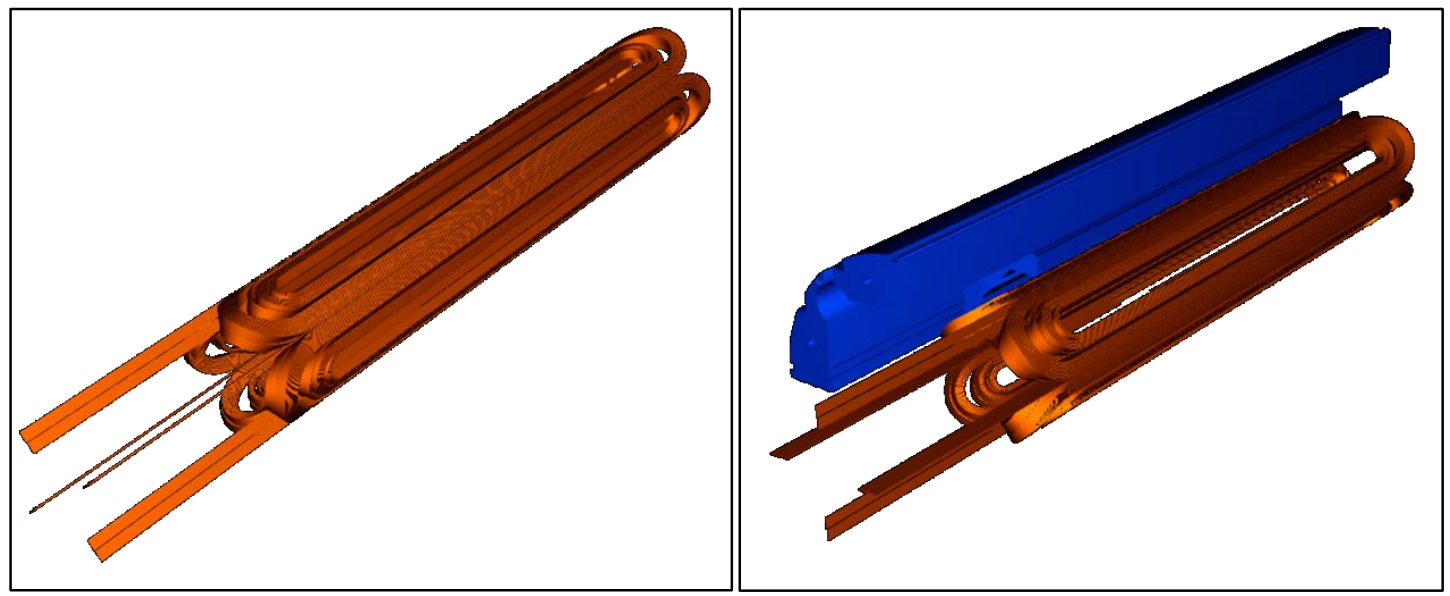

Fig. 3.22: 3D view of QXF coil.

\section{References}

[1] F. Borgnolutti et al., "Magnetic design optimization of a $150 \mathrm{~mm}$ aperture Nb3Sn low-beta quadrupole for the HiLumi LHC", to be published in proceedings of MT23, Boston, June 2013.

[2] S. Russenschuck, "Electromagnetic design and mathematical optimization method in magnet technology", eBook Fourth Edition, ISBN: 92-9083-242-8, http://russ.cern.ch/russ.

[3] A. Godeke et al., "A general scaling relation for the critical current density in Nb3Sn," Supercond. Sci. Technol., vol. 19, pp. R100-R116, 2006.

[4] B. Auchmann, S. Russenschuck. "Coil end design for superconducting magnets applying differential geometry methods", IEEE Transactions of Magnetics, vol 40, no. 2: 1208-1211, March 2013.

[5] C. Völlinger "Superconductor Magnetization Modelling for the Numerical Calculation of Field Errors in Accelerator Magnets", Ph.D dissertation, Berlin, Tech. Univerity, 2003.

[6] J. M. Cook. "Strain energy minimization in SSC magnet winding", IEEE Transactions on Magnetics, 27 (2/7): 1976-1980, March 1991.

[7] P. Ferracin, et al., "Magnet Design of the $150 \mathrm{~mm}$ Aperture Low- $\beta$ Quadrupoles for the High Luminosity LHC” IEEE Trans. Appl. Sup., vol. 24, no. 3, June 2014.

[8] H. Felice, et al., "Impact of coil compaction on Nb3Sn LARP HQ magnet," IEEE Trans. Appl. Sup., vol. 22, no. 3, June 2012. 


\section{COIL DESIGN, WINDING and CURING}

\section{a. Coil Design}

The MQXFS coil is a two-layer cos- $2 \theta$ coil with saddle-shaped ends. The two-layer coil is wound continuously, without a splice at transition between the inner and outer layers, using the double-pancake technique successfully used in all LARP coils and by several other $\mathrm{Nb}_{3} \mathrm{Sn}$ magnets. The cross-section for magnetic design is shown in Fig. 4.1. The coil inner radius is $75 \mathrm{~mm}$, and the outer radius is 113.13 $\mathrm{mm}$. In order to ensure reaching the target dimensions, the coil size is controlled at each fabrication step (details in Appendix A).

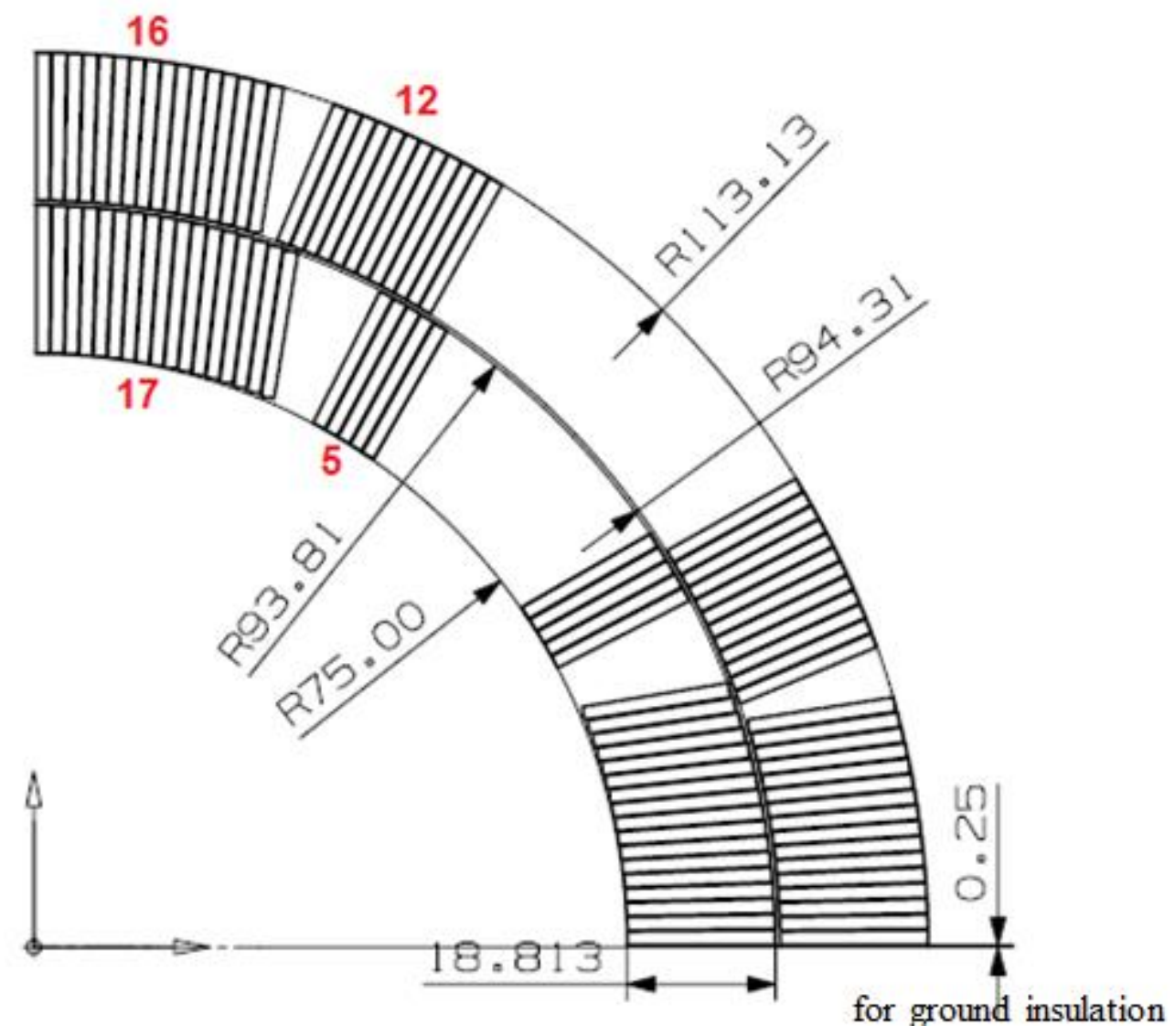

Fig. 4.1: Coil Cross-section.

The coil model is shown in Fig. 4.2. To meet the requirement of a magnetic length of $1.192 \mathrm{~m}$, the overall coil length will be $1.51 \mathrm{~m}$. Due to the remaining pole gap, the coil length may vary from 1.510 $\mathrm{m}$ to $1.515 \mathrm{~m}$. The coil consists of pole parts made of Ti-6Al4V, wedges made of phosphor bronze, and end parts made of SS 316. 

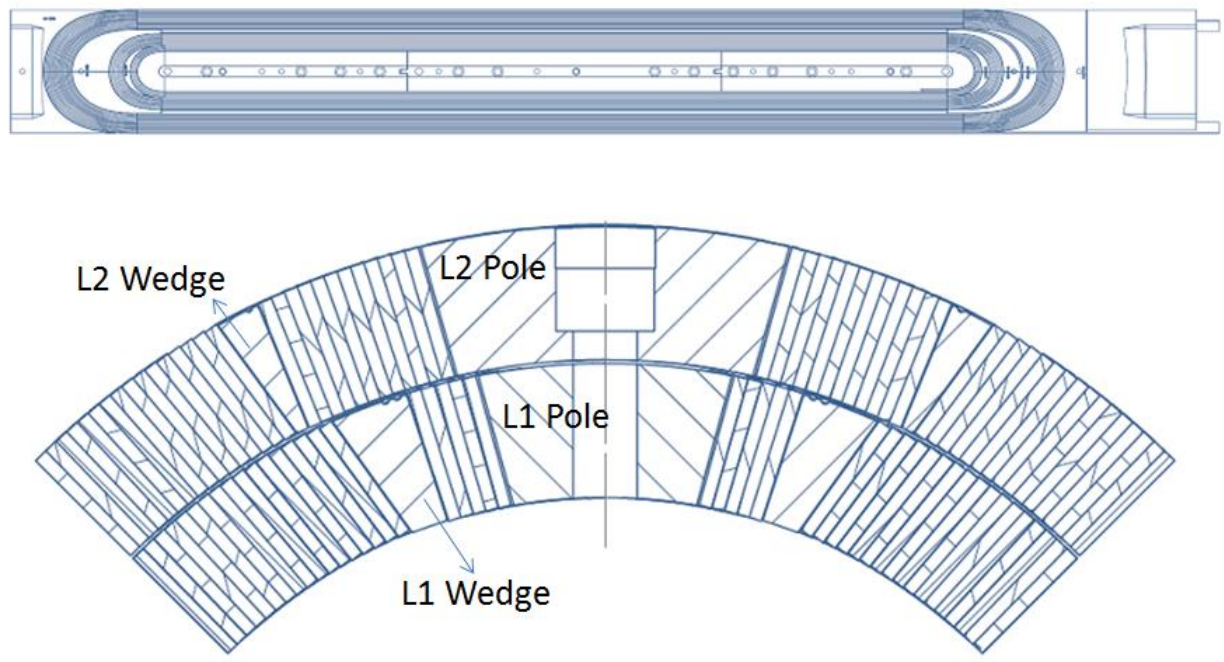

Fig. 4.2: MQXFS Coil Model.

\section{- Pole Parts and Wedges}

The MQXFS coil is wound around the pole. Fig. 4.3 shows the features of the inner and outer poles. Pole parts in each layer are aligned through the key stub, and pole parts between inner and outer layers are aligned through the pins. The poles are bolted to the winding anchor bars through clearances holes. The fabricated coil is lifted through lifting holes. Both clearance holes and lifting holes are designed with minimum $8 \mathrm{~mm}$ diameter and $50 \mathrm{~mm}$ spacing. These holes are also utilized as cooling channels to extract the heat from the coil aperture to the heat exchangers in the yoke. The wedge is fabricated through extrusion process to have the best uniform shape for each coil. Witness notches are added to each wedge for identification and orientation.

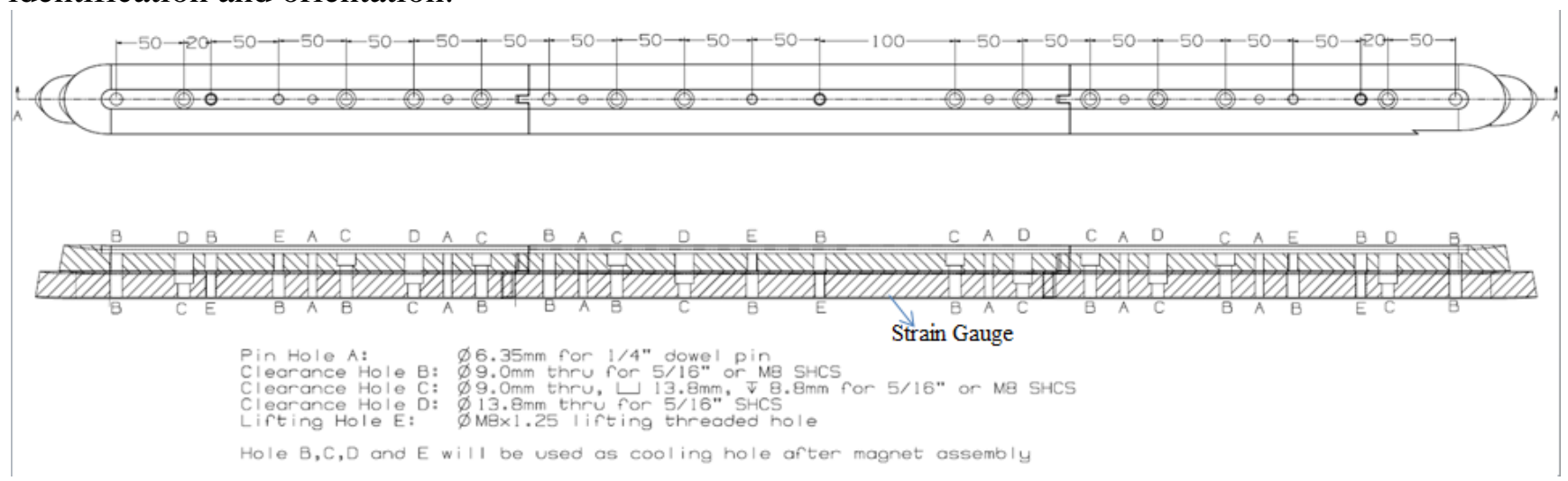

Fig. 4.3: Pole Parts Layout.

\section{- End Parts}

End parts, saddles and splice block are designed based on the nominal coil size after reaction. End parts have been designed and optimized using BEND [1] and ROXIE. After practice coils fabrication, the coil ends will be inspected and the final design will be decided. 
During winding, the coil is not fully constrained inside the envelope. This effect is most pronounced at the ends. Prior to curing, the cable tries to separate from the radial surface of the mandrel in some areas (springback), causing the shape of the turn not to match the shape of the end parts. The springback is larger with larger coil aperture and cable size. Therefore flexible features (slits) have been introduced in QXF coil design (Fig.4.4). This is an incremental change with respect to single slit design previously used in LARP coils. For rapid prototyping the end parts are fabricated through laser sintering process. To simplify the requirement to bridge the slits during rapid prototyping the slits are EDM cut.

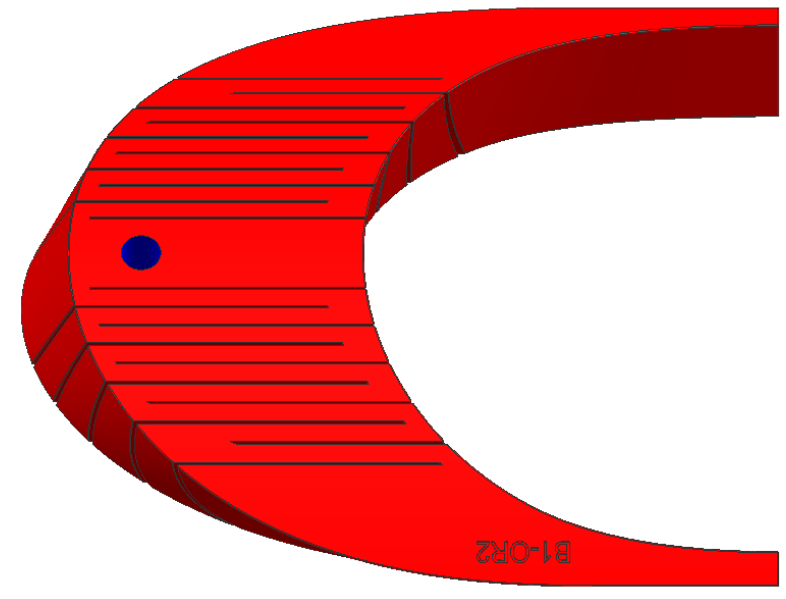

Fig. 4.4: Slits Design for End Parts.

End parts are then plasma coated at $250 \mu \mathrm{m}$ thickness to increase the dielectric strength. The part number is then re-stamped into the part for clear identification.

\section{b. Winding and Curing by LARP}

Fermilab will perform all MQXFS coil winding and curing by LARP with equipment, tooling and processes successfully used for several $\mathrm{Nb}_{3} \mathrm{Sn}$ quadrupoles (LARP) and dipoles (HFM). Some of the cured coils will be shipped to BNL and LBNL, and reaction and impregnation will be performed at BNL, FNAL and LBNL. The winding and curing tooling designed for MQXFS coils, including winding fixture, rollover station and curing mold, is shown in Fig. 4.5. 

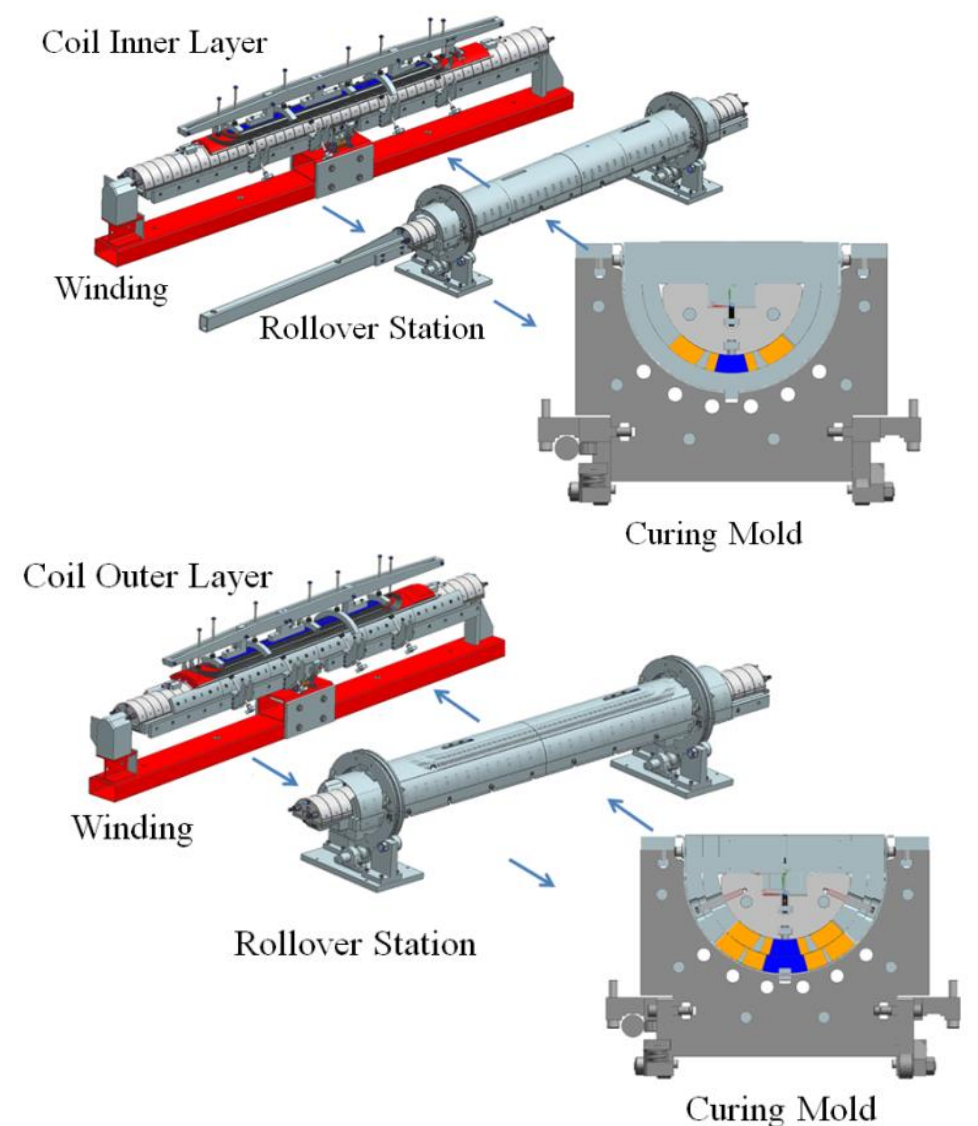

Fig.4.5: Winding and Curing Tooling.

The $2 \mathrm{~m}$ long curing press is shown in Fig. 4.6, and the press load to cure a MQXFS coil is shown in Table 4.1. The results of the stress analysis are shown in Fig. 4.7. The maximum stress under normal operation is lower than $100 \mathrm{MPa}$, less than $1 / 3$ of the yield strength of steel $1050(580 \mathrm{MPa})$.
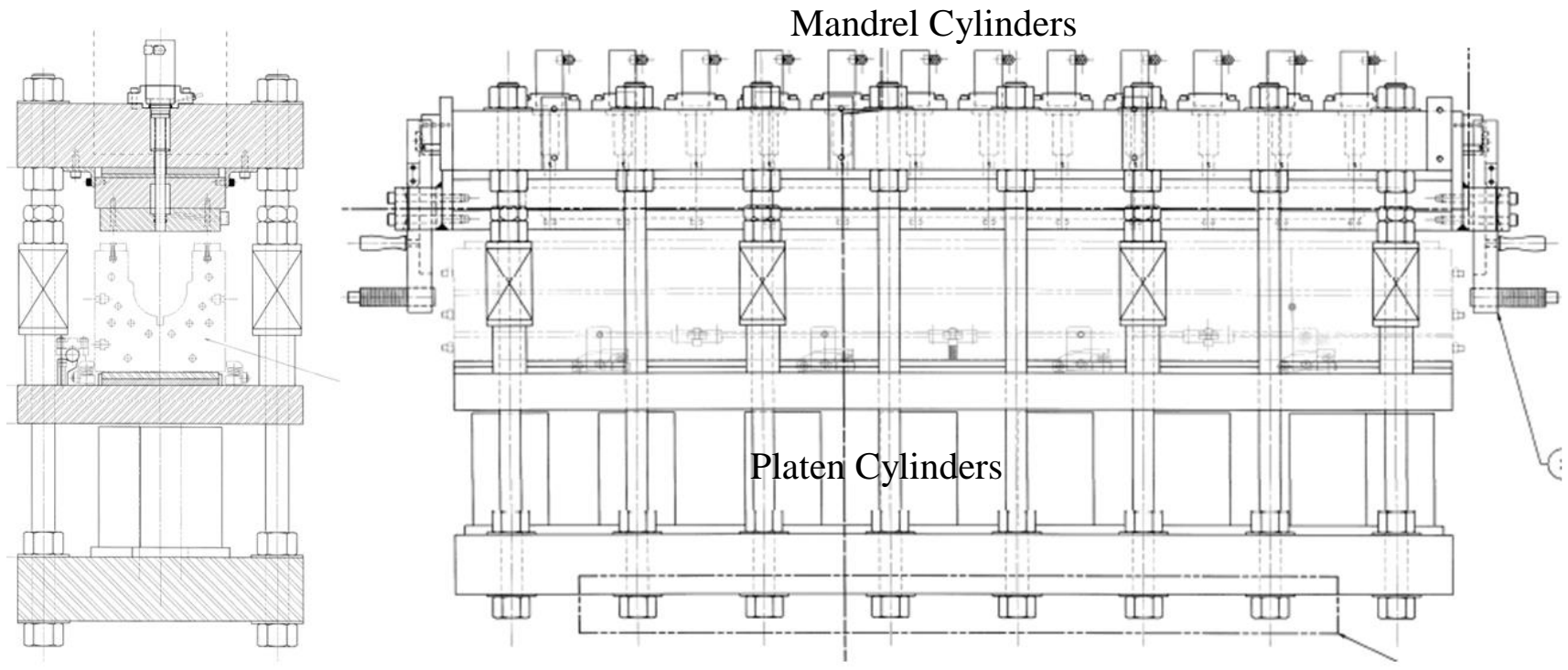

Fig. 4.6: Curing Press. 
Table 4.1: Curing Press Load for Curing MQXFS Coil.

\begin{tabular}{|c|c|c|c|c|c|c|}
\hline & $\begin{array}{c}\text { Capacity } \\
\text { (pump psi) }\end{array}$ & $\begin{array}{c}\text { Max. } \\
\text { force/cylinder } \\
\mathrm{kN} \text { (ton) }\end{array}$ & $\begin{array}{l}\text { Spacing } \\
\text { cm(inch) }\end{array}$ & $\begin{array}{c}\text { Max Unit Pres. } \\
\text { kN/m } \\
(\mathrm{lb} / \mathrm{in})\end{array}$ & $\begin{array}{c}\text { Cylinder } \\
\text { Load } \\
(\mathrm{kN} / \mathrm{m})\end{array}$ & $\begin{array}{l}\text { Short Press } \\
\text { (pump psi) }\end{array}$ \\
\hline Main Cylinders & 10000 & $534(60)$ & $15(6)$ & 3560 (20000) & 1672 & $\begin{array}{l}2345 \text { (L1) } \\
4690 \text { (L2) }\end{array}$ \\
\hline Mandrel Cylinders & 10000 & $90(10)$ & $15(6)$ & $600(3400)$ & 180 & 3000 \\
\hline
\end{tabular}

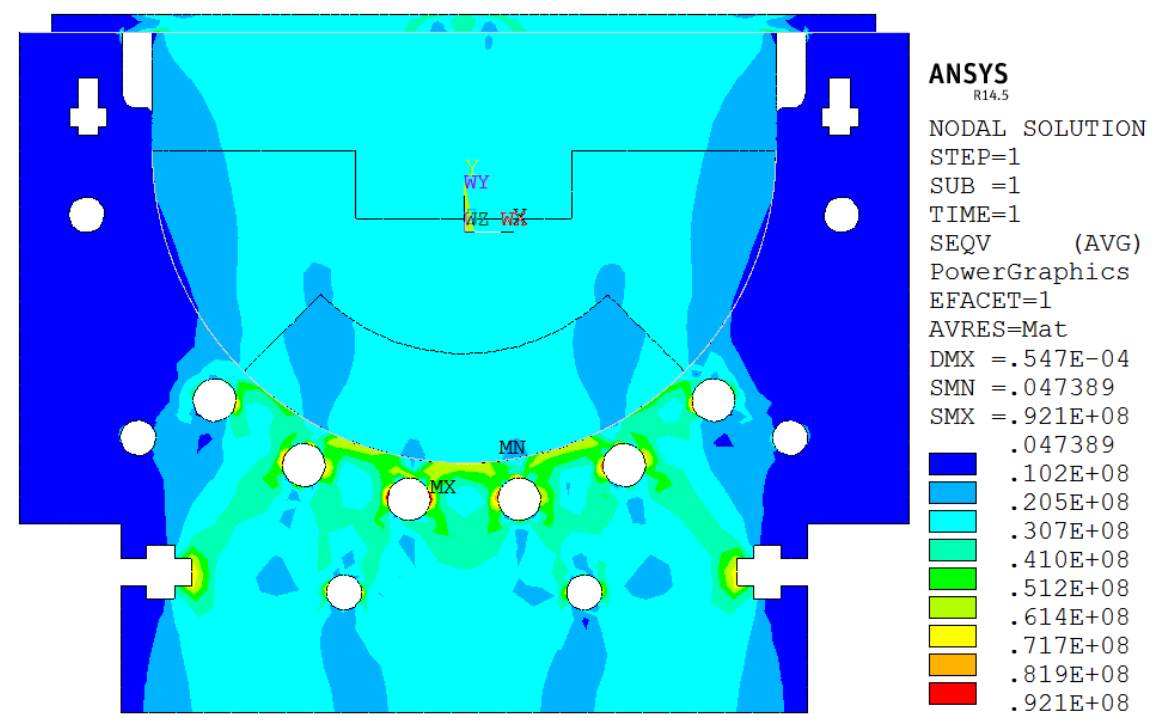

Fig. 4.7: MQXFS coil curing mold analysis showing stress lower than $100 \mathrm{MPa}$.

Typically, it takes 15 days for winding and curing one coil. A detailed version of the procedures can be found online at [2]. Inner and outer layers are wound without a splice between them, using a single piece of cable, as shown in Fig. 4.8. After winding the inner layer of the coil, the coil is painted with binder (CTD ${ }^{3}$-1202), packaged and transferred to the curing mold through the rollover station. After the inner layer is cured the coil is transferred back to the winding table. The layer-to-layer insulation is set in place and the outer layer is wound. When the outer layer winding is complete, the outer layer is painted with binder, packaged and cured in the curing mold.

\footnotetext{
${ }^{3}$ Composite Technology Development, 2600 Campus Dr \# D, Lafayette, CO 80026, USA.
} 


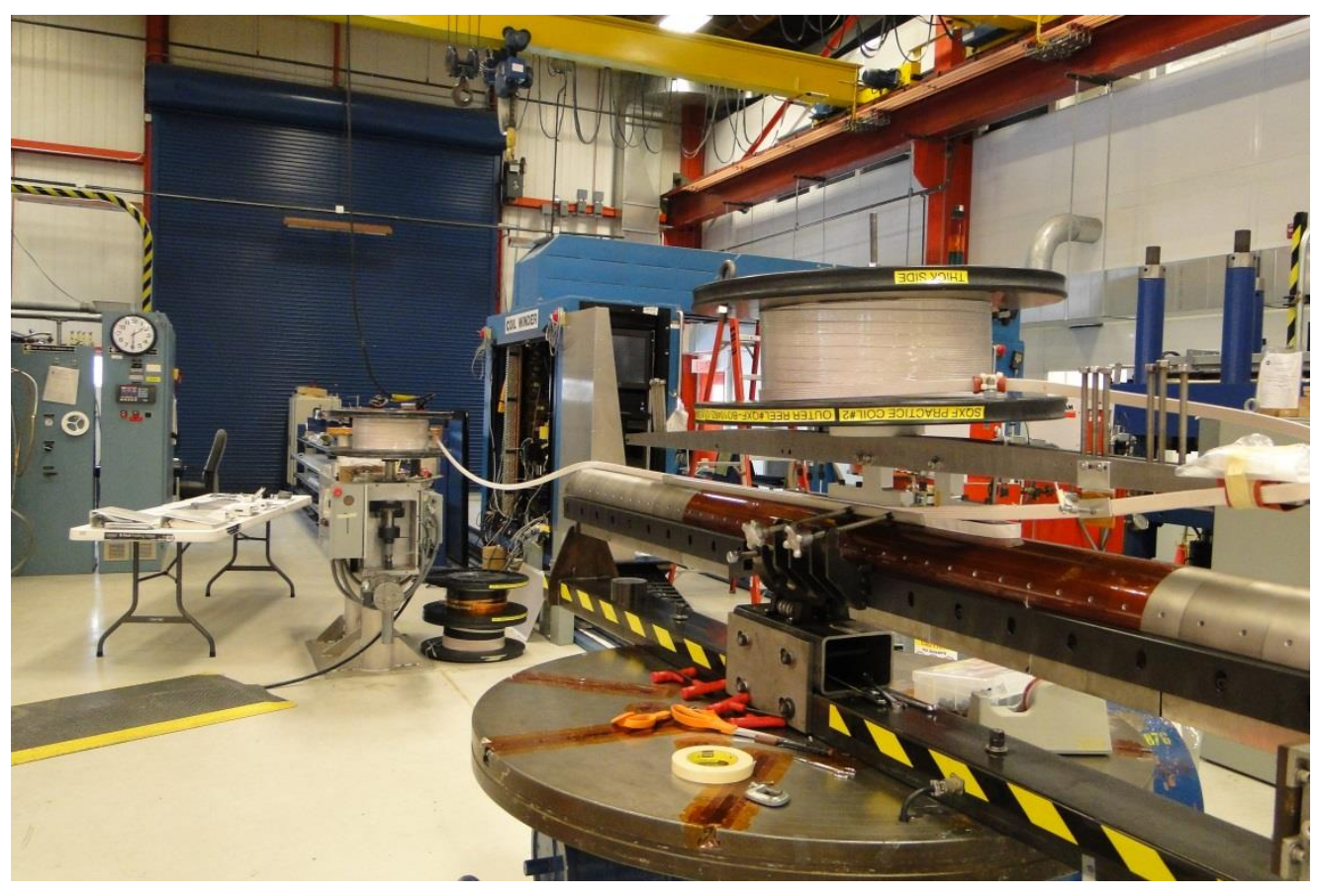

Fig. 4.8: Winding Setup.

The minimum unit length of cable to wind an MQXFS coil is $137 \mathrm{~m}$, including $10 \mathrm{~m}$ for the leads to the spools and to compensate for possible errors in re-spooling. The inner layer requires $61 \mathrm{~m}$ of cable, and the outer layer requires $76 \mathrm{~m}$. Winding tension for the first two turns of both L1 and L2 is 9 $\mathrm{Kg}(20 \mathrm{lbs})$, and $25 \mathrm{Kg}$ (55 lbs) from the third turn. In order to reduce the risk of turn-to-turn short due to popped strands, at each end of the turn the cable is painted with binder (CTD-1202) and cured using heat gun, and the winding tool is utilized as well.

To accommodate the coil length shrinkage due to the tension release after curing and thermal effects during reaction, $6.75 \mathrm{~mm} / \mathrm{m}$ pole gaps are introduced by design. These gaps have been designed for 25 $\mathrm{Kg}$ winding tension and are based on HQ/LHQ experience $(4.3 \mathrm{~mm} / \mathrm{m}$ with $16 \mathrm{Kg}$ winding tension). In MQXFS coil the tip-to-tip pole length is $1.1 \mathrm{~m}$. Therefore the total pole gap is set as $7.5 \mathrm{~mm}$ which ensures that during coil fabrication the pole gap remains open.

For the same reasons gaps between wedges and end parts are needed. In MQXFS1 these gaps are no less than $3 \mathrm{~mm} / \mathrm{m}$ longer than the pole gap if the pole gap is dimensioned to be closed or almost closed after heat treatment.

Each layer is cured under pressure in a closed cavity mold at $150{ }^{\circ} \mathrm{C}$ in air for 1 hour and 45 minutes. While the coil is inverted relative to winding orientation, the pole is radially compressed with mandrel cylinders. Subsequently the coil is azimuthally compressed with the platen cylinders until closure which typically occurs at $13 \mathrm{MPa}$ coil pressure (500 kN total coil force) for the inner layer and $27 \mathrm{MPa}(1000$ $\mathrm{kN}$ total coil force) for the outer layer. Curing is done to set the coil size for reaction, as well as to allow the coils to be easily handled, facilitating insertion into the reaction fixture without damage. Spacers simulating the outer layer are used during the curing of the inner layer. The outer layer is cured on the top of the inner layer. Therefore the same mandrel and mold are used to cure both the inner and the outer layer. 


\section{c. Winding and Curing by CERN}

The production of the coils from CERN side will be fully done at CERN.

The winding and curing machines designed for MQXFS coils are shown in Figs. 4.9 and 4.10.

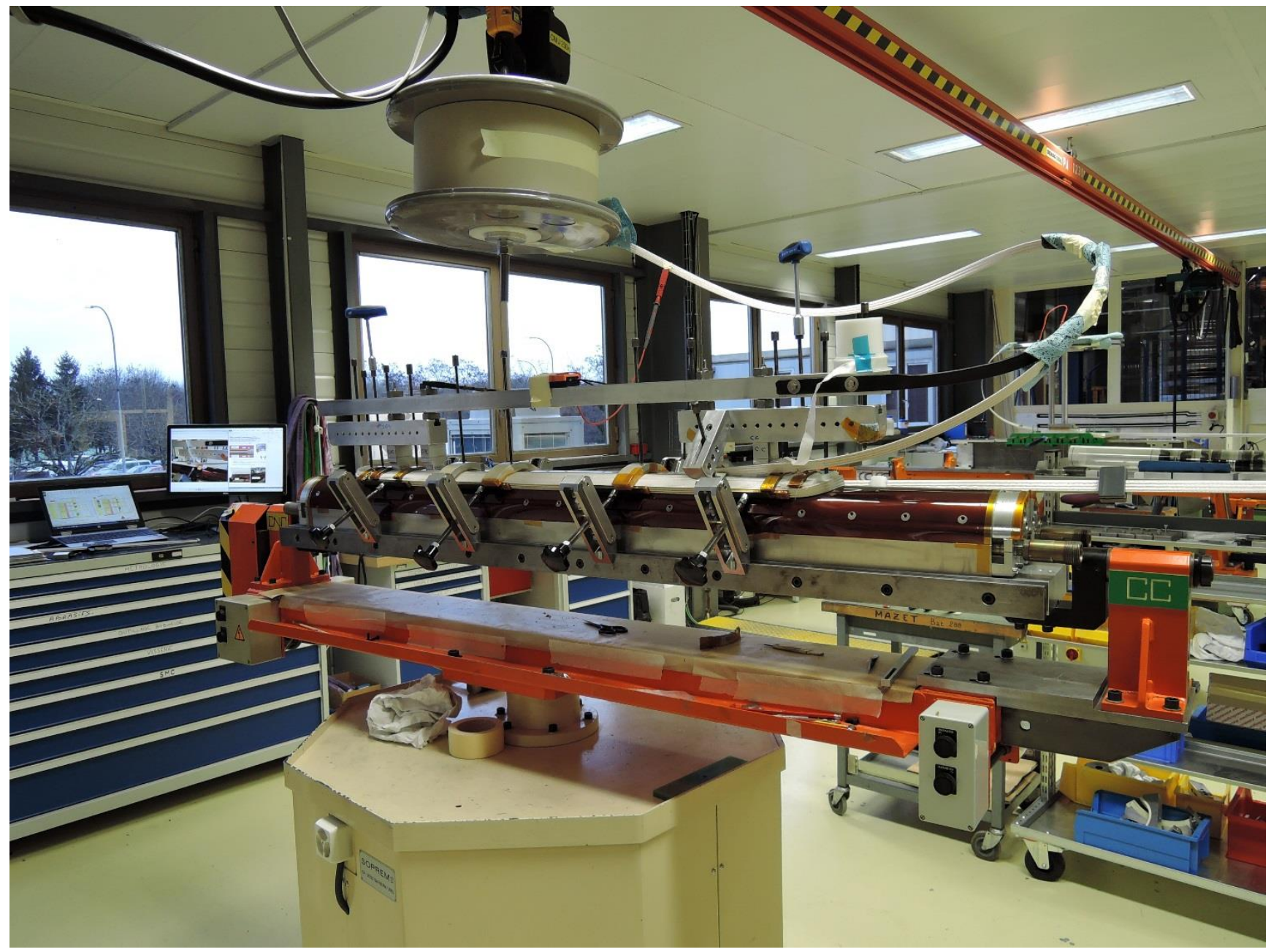

Fig. 4.9: Winding machine at CERN. 


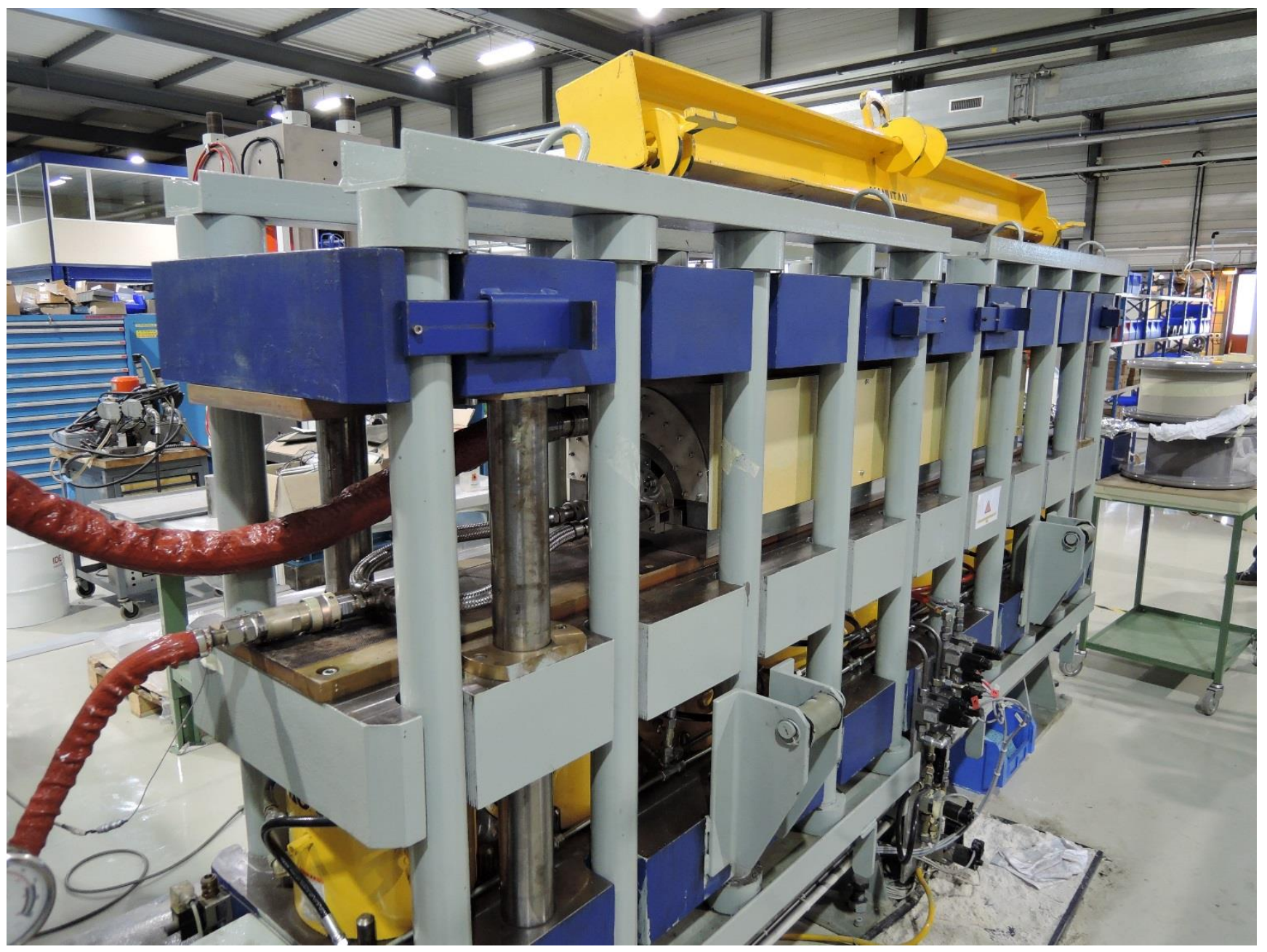

Fig. 4.10: Curing press.

Typically, it takes 10-11 working days for winding and curing one coil. Inner and outer layers are wound without a splice between them, using a single piece of cable. After winding the inner layer, the coil is painted with binder (CTD-1202 Ceramic matrix) and transferred to the curing mold. After the curing of the inner layer, the coil is transferred back to the winding table. The interlayer insulation is set in place and the outer layer is wound. When the outer layer winding is complete, the outer layer is painted with binder and cured again in the curing mold.

The tension applied on the cable during the winding of both inner and outer layer is always $25 \mathrm{~kg}$. In order to reduce the risk of popped strands, a tool is used during the turning around the pole ends. The aim of the tool is to clamp the cable, constraining it inside a cavity with proper width and keeping the strands compact.

The curing of both inner and outer layer is done inside the same press.

The two main parameters during the curing are the pressure applied to close the mold and the temperature to cure the binder. The pressing force is given by some hydraulic jacks, according to the following scheme. 
MQXFS1 Design Report

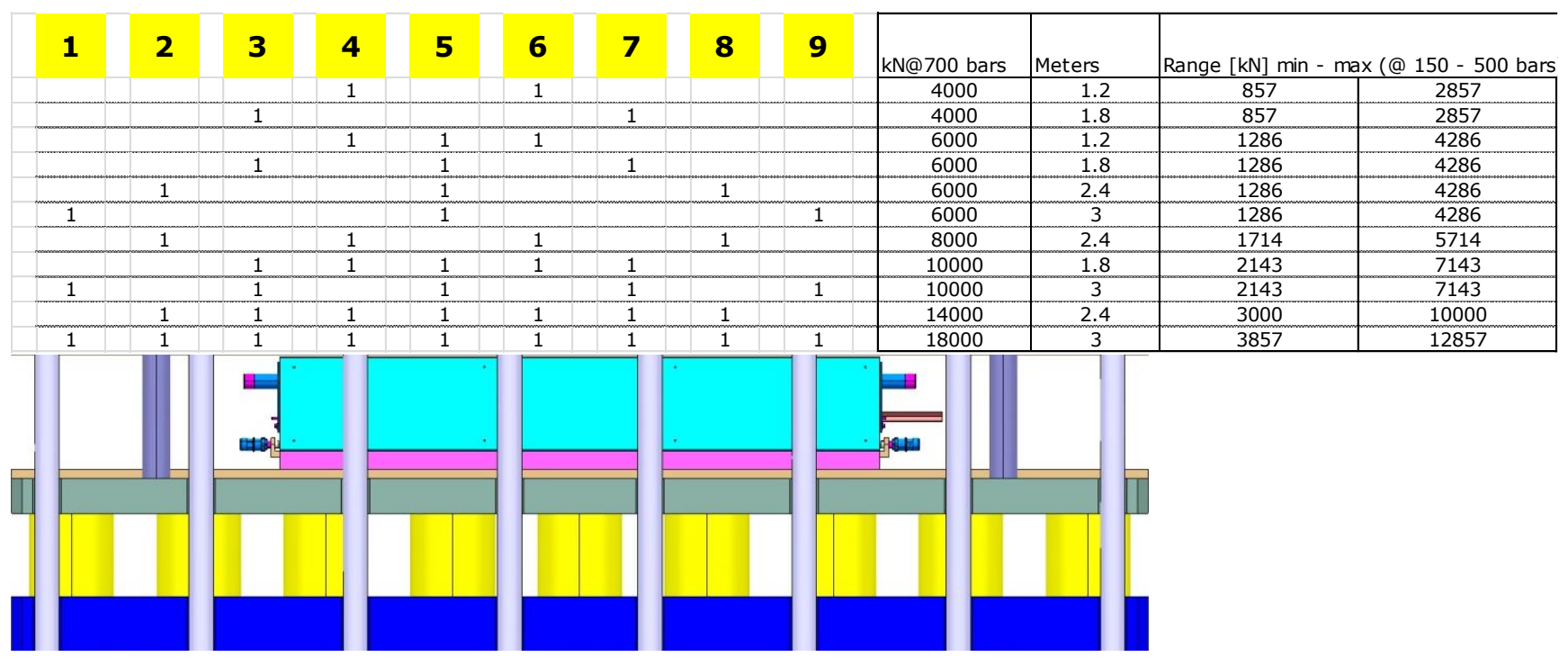

Fig. 4.11: Scheme of the curing press with table of the pressure/force capability of the jacks.

For the curing of MQXFS coils, only three jacks are used (3, 5 and 7 in Fig. 4.11), and the mold is closed with a pressure of $40 \mathrm{bar}$, which means a total force of $340 \mathrm{kN}$. The curing temperature is $150^{\circ} \mathrm{C}$ for two hours, with a pressure on the jacks that increases from 40 to 60 bars for inner layer and to 80 bars for outer layer.

The cavity in which the coil is set during the curing (Figs. 4.12 and 4.13) is sized according to the dimensions of the reacted coil, so it is bigger than the nominal for unreacted coils. For this reason, an azimuthal stress lower than $5 \mathrm{MPa}$ is expected on the coil during curing.

The curing is performed to give a first shape to the coil and to compact all the turns together, as well as to allow the coil to be easily handled, facilitating the insertion into the reaction fixture without damage. Spacers simulating the outer layer are used during the curing of the inner layer. The outer layer is cured on the top of the inner layer.

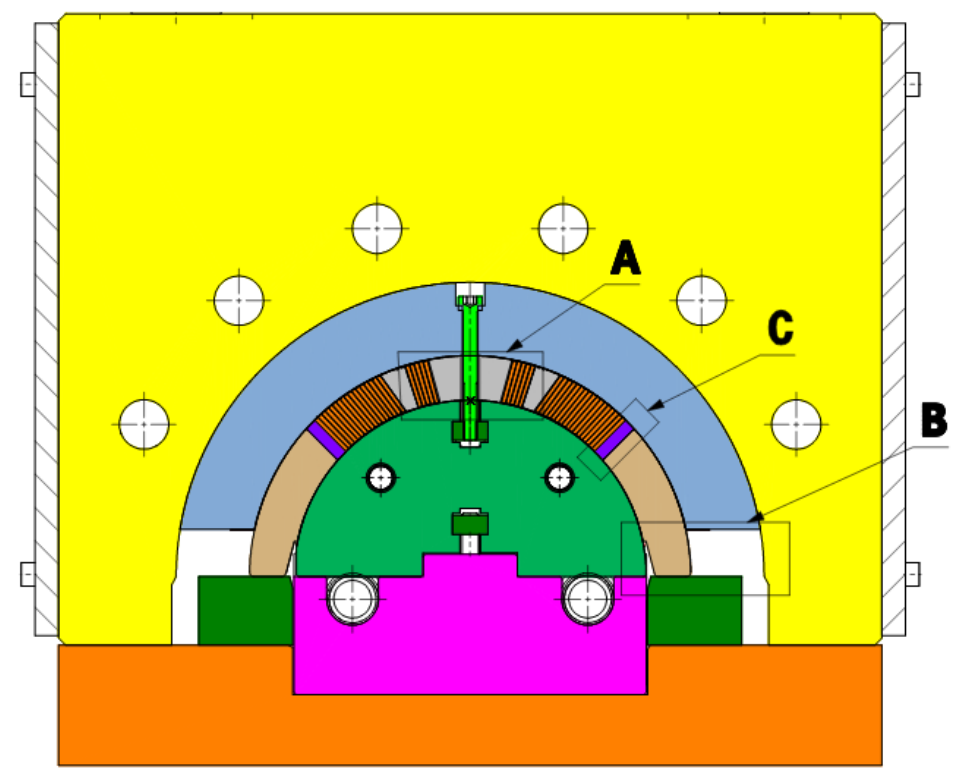

Fig. 4.12: Cross section of the coil inside the curing press, inner layer. 


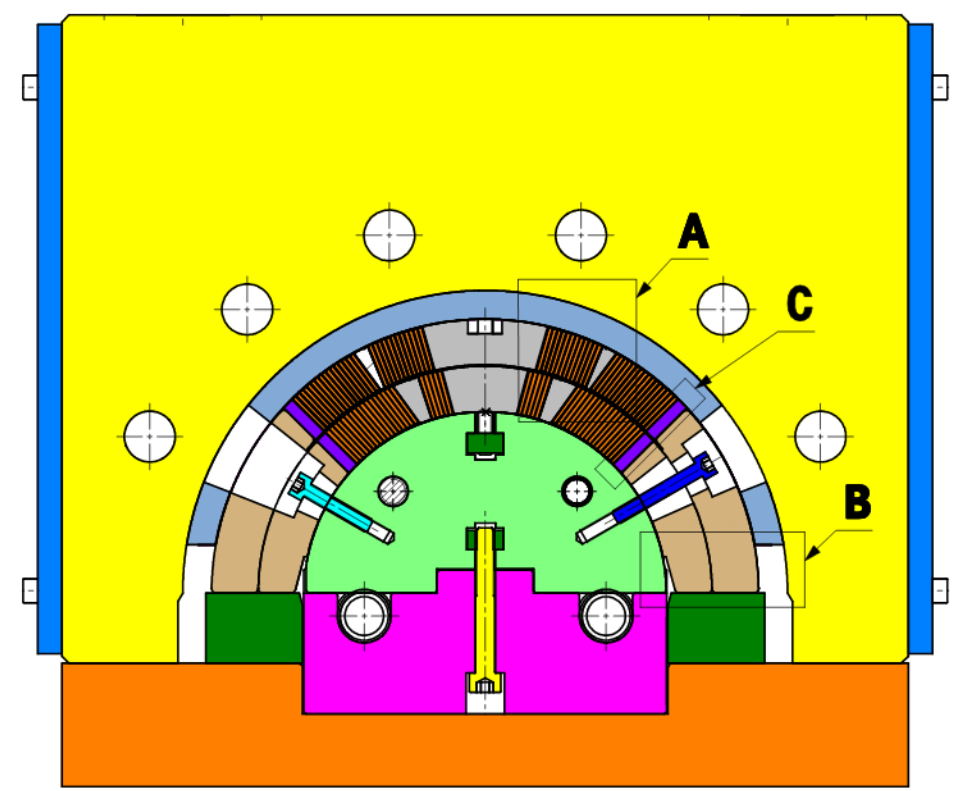

Fig. 4.13: Cross section of the coil inside the curing press, inner and outer layer.

After the winding and curing, the coil is dismounted (unbolted) from the winding mandrel: during this operation, the winding tension is released, so the coil contracts. To accommodate this contraction, and the one that is expected during heat treatment, a gap is left between the three pieces of the pole. Some iterations have been done with the different coils that have been fabricated, and a value of $2 \mathrm{~mm}$ of gap is sufficient to compensate these effects for RRP cable, with a few tenths of mm of residual gap.

The total gap between the copper wedges and the end spacers is $3 \mathrm{~mm}$ longer than the pole gap during winding: the reason is to have a residual gap of at least $3 \mathrm{~mm}$ between the wedges and the end spacers if the pole gap is closed after the heat treatment.

All the values of the gaps are intended to be referred to one meter of coil, so they will then be scaled to the final length of the long coils that will be produced in the future.

\section{References}

[1] J. M. Cook. "Strain energy minimization in SCC magnet winding", IEEE Trans. Appl. Sup., vol. 27, no. 2, March 1991.

[2] https://vector-

offsite.fnal.gov/SelectTravelerReadOnly.asp?sSeriesID=536\&sSerialNoID=all\&sReworkID=all\& $\mathrm{sSpecificationID=all \& sRevisionID=all \& sJobNo=all \& sStatusID=all}$ 


\section{COIL REACTION, IMPREGNATION and INSTRUMENTATION}

\section{a. Coil Reaction}

The MQXFS reaction/impregnation tooling design is based on the designs used for HQ and LHQ coils. A cross section is shown in Fig. 5.1. The closed cavity mold defines the coil size precisely and alignment pins are used to position the pole pieces during reaction and impregnation. The nominal fixture dimensions are shown in Fig. 5.2. Slender links connect the end saddles to the coil pole to keep the saddles in contact with the cable turns during reaction. A $0.6 \mathrm{~mm}$ radial filler is included to allow for a small adjustment of the coil outer diameter. The fixture temperature during reaction is monitored continuously by thermocouples placed on the outside of the reaction fixture.

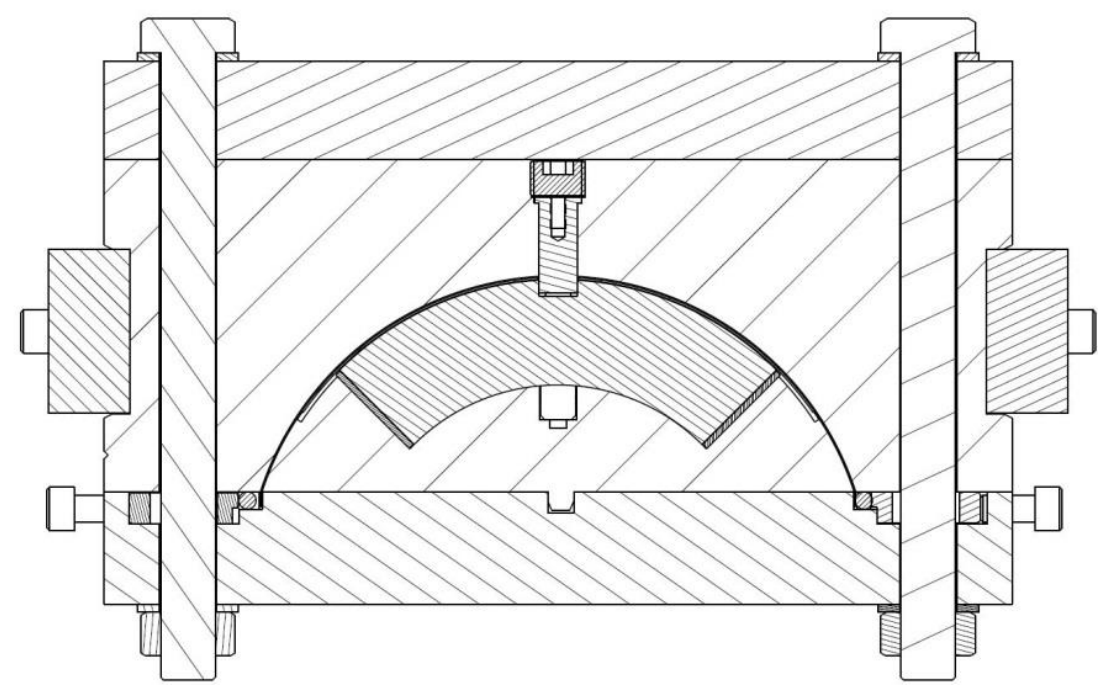

Fig. 5.1: Reaction / Impregnation fixture cross section.

Table 5.1: Reaction / Impregnation fixture dimensions.

\section{Reaction / Impregnation Fixture Dimensions:}

Includes stainless steel liner and radial filler on OD, stainless steel shims on midplanes:

Inner Radius $=74.75 \mathrm{~mm}$

Outer Radius $=113.63 \mathrm{~mm}$

Midplane offset $=0 \mathrm{~mm}$ 
Reaction takes place in a gas tight oven using an automatic program. The target cycle for the reaction fixture is shown in Table 5.1. The durations and ramp rates for the oven control may be varied in order to achieve the target temperature for the reaction fixture. The reaction fixture is sealed and a continuously flowing argon atmosphere is used to carry away any contaminants that are released during the reaction cycle. Argon flow is supplied independently to the oven at $50 \mathrm{SCFH}$ and to the reaction fixture within the oven at $25 \mathrm{SCFH}$. Flow rates are sufficient to maintain the oven at a small positive pressure relative to the external atmosphere and the reaction fixture at a positive pressure relative to the internal oven atmosphere. Argon flow is maintained throughout the entire cycle until the fixture has cooled to a temperature below $100 \mathrm{C}$. Temperature uniformity within the furnace volume can be maintained to within $\pm 3^{\circ} \mathrm{C}$ at all three temperature plateaus.

Table 5.2: MQXFS Coil Reaction Fixture Target Cycle.

\begin{tabular}{lllcc}
\hline \hline \multicolumn{2}{l}{ Step / Description: } & Average Rate & Time \\
\hline \hline Step 1 & Ramp & from 20C to 210C & 25 C/hour & \\
Step 2 & Soak & 210C & & 72 hours \\
Step 3 & Ramp & from 210C to 400C & 50 C/hour & \\
Step 4 & Soak & 400C & & 48 hours \\
Step 5 & Ramp & from 400C to 640C & 50 C/hour & \\
Step 6 & Soak & 640C & & 48 hours \\
Step 7 & Ramp & from 640C to 20C & $\sim 80$ hours \\
\hline \hline
\end{tabular}

Notes:

1. Average fixture ramp rate shall not exceed rates listed above.

2. Before step 3 the temperature of the reaction fixture shall NOT exceed $215 \mathrm{C}$.

Mica sheets are set around the coil in preparation for the reaction in order to reduce friction between materials with different thermal expansions. A sketch of the layers of material installed for reaction is shown in Fig. 5.2. A summary of the buildup of material used during reaction and impregnation is shown in Table 5.3.

Materials:

- Mica - Cogebi ${ }^{4}$ Cogemica Hi-Temp 710-1, 0.13 mm thick.

- $\quad$ Fiberglass - Hexcel ${ }^{5}$ \#4522 with F81 Silane Finish, 0.13 mm thick.

${ }^{4}$ Cogebi Inc. 14 Faraday Dr, Dover, NH 03820, USA.

${ }^{5}$ Hexcel Corporation, 281 Tresser Boulevard, Stamford, CT 06901, USA http://www.hexcel.com 


\section{MQXFS1 Design Report}

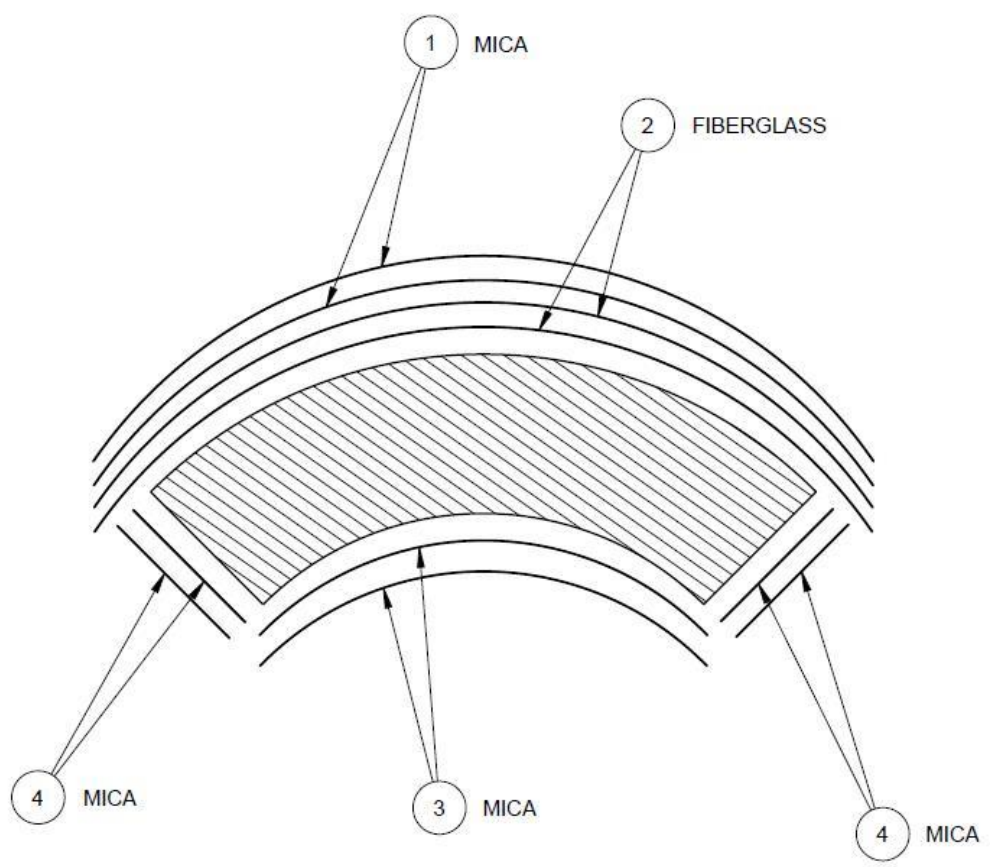

Fig. 5.2: Coil cross section during reaction.

Table 5.3: Material Buildup.

\begin{tabular}{lccc}
\hline \hline \multicolumn{4}{l}{ Reaction / Impregnation Material Build-Up } \\
\hline \\
\hline \hline Reaction & Inner Radius $(\mu \mathrm{m})$ & Outer Radius $(\mu \mathrm{m})$ & Midplanes $(\mu \mathrm{m})$ \\
\hline \hline Fiberglass & $\mathbf{2 5 0}$ & $\mathbf{5 0 0}$ & $\mathbf{2 5 0}$ \\
Fiberglass & & 125 & \\
Mica & & 125 & \\
Mica & 125 & 125 & 125 \\
\hline \hline Impregnation & 125 & 125 & 125 \\
\hline \hline Space for trace & $\mathbf{2 5 0}$ & $\mathbf{5 0 0}$ & $\mathbf{2 5 0}$ \\
Fiberglass & 125 & 125 & \\
G11 & 125 & 125 & 125 \\
Mylar & & & 125 \\
\hline \hline
\end{tabular}




\section{b. Coil Impregnation}

After reaction, coil lead splices are made and the instrumentation trace circuits are installed. The trace circuits consist of stainless steel foil, for the protection heaters and wiring for the voltage taps, glued to a layer of 2 mil polyimide film. A sketch of the layers of material installed for impregnation is shown in Fig. 5.3. The coil is vacuum impregnated with CTD-101k epoxy using a fixture similar to the one used for reaction. The impregnation process varies somewhat between the labs due to facility differences; below are descriptions of the process at each lab. The nominal impregnated coil dimensions are shown in Table 5.4.

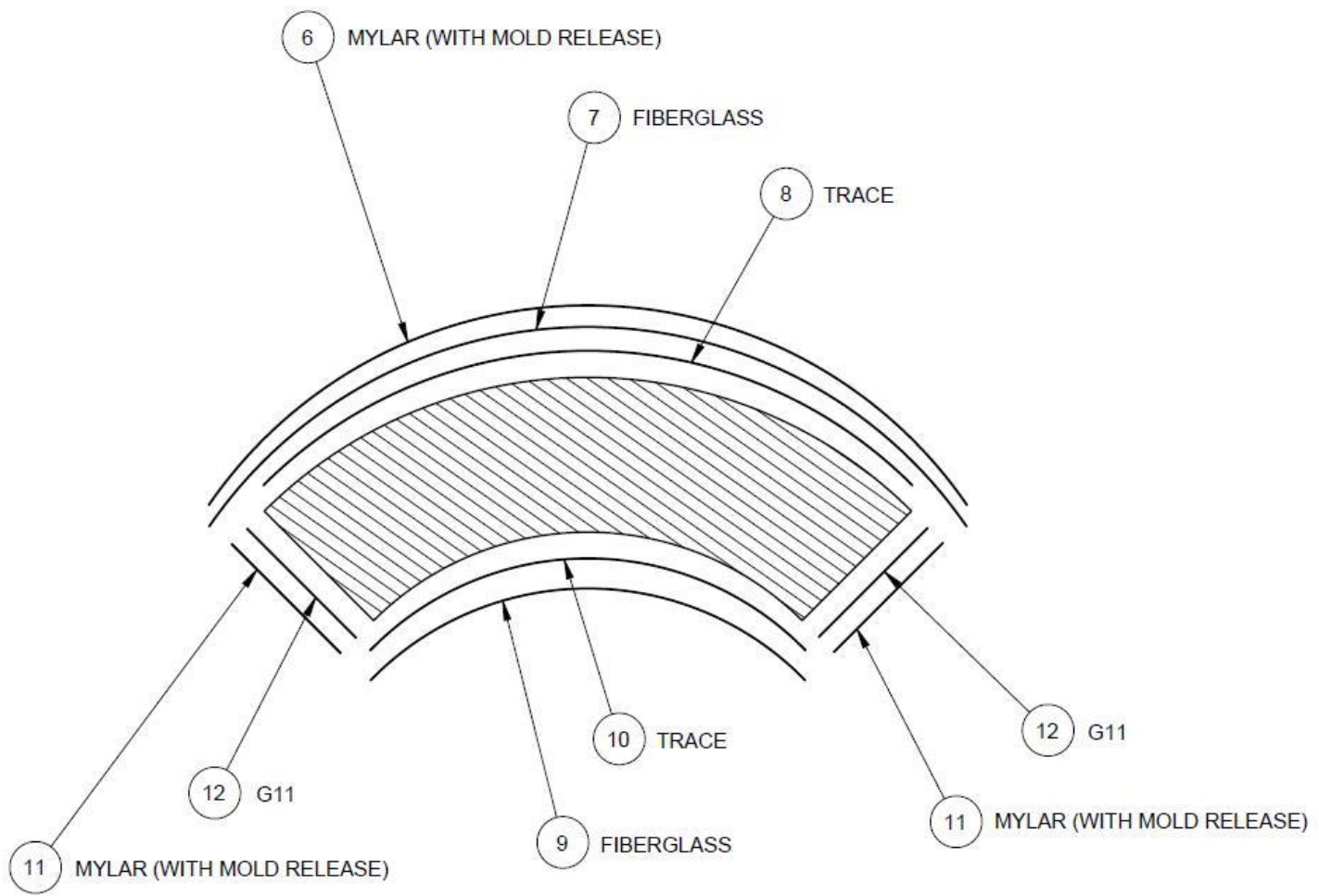

Materials:

- $\quad$ Trace Assembly - Kapton + stainless steel.

- $\quad$ Fiberglass - Hexcel \#4522 with F81 Silane finish, $0.13 \mathrm{~mm}$ thick.

- G11 - 0.13 mm thick.

- Mylar, midplanes - $0.13 \mathrm{~mm}$ thick (mold release applied).

- Mylar, coil OD - 0.25 mm thick (mold release applied).

Fig. 5.3: Coil cross-section during impregnation. 
Table 5.4: Impregnated Coil Dimensions.

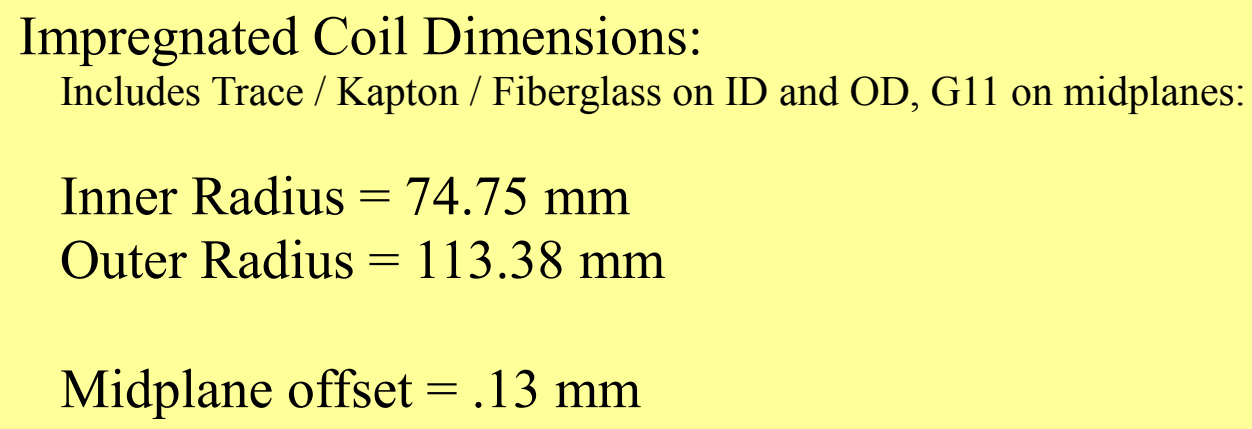

\section{BNL:}

The impregnation fixture is closed and sealed. The fixture is hung vertically in a vacuum tank. Strip heaters mounted to the outside of the fixture are used for heating. The fixture and the vacuum tank are evacuated to a vacuum level of $500 \mathrm{um} \mathrm{Hg}$ or better. While under vacuum, the coil is baked at $110^{\circ} \mathrm{C}$ for 8 hours then cooled back down to $55^{\circ} \mathrm{C}$ before the impregnation is started. The epoxy is mixed, warmed to $55^{\circ} \mathrm{C}$, and degassed to the same vacuum level as the coil. Once degassed, the epoxy pot is let up to atmospheric pressure and epoxy is introduced into the bottom of the impregnation fixture. The fill rate is controlled by a peristaltic pump with an expected fill time of about 2 hours. An exit line from the top of the impregnation fixture is connected to a resin trap outside the vacuum tank. When epoxy reaches the resin trap, the exit line is closed. The supply line remains open, with atmospheric pressure continuing to force resin into the coil. The coil is held overnight for approximately 16 hours at $55^{\circ} \mathrm{C}$ while allowing epoxy to continuously draw into the coil. After the overnight soak, the cure cycle is initiated. The epoxy is cured using an automatic cycle as shown in Table 5.5. Vacuum is maintained in the vacuum tank until the cure is complete.

Table 5.5: MQXFS Coil Impregnation Cycle.

\begin{tabular}{llll}
\hline Cure & & \\
\hline \hline & Ramp & from 55C to $110 \mathrm{C}$ & 4 hours \\
& Soak & $110 \mathrm{C}$ & 7 hours \\
& Ramp & from $110 \mathrm{C}$ to $125 \mathrm{C}$ & 1 hour \\
Soak & $125 \mathrm{C}$ & 16 hours \\
\hline \hline
\end{tabular}

FNAL:

The impregnation tooling is used to epoxy impregnate the coil in a vacuum oven. The coil is positioned at an incline within the vacuum furnace with the lead end of the coil elevated above the return end. The temperature and vacuum pressure is $55^{\circ} \mathrm{C}$ and $25 \mathrm{um} \mathrm{Hg}$ respectively and is maintained for 45 
hours before the epoxy is introduced. Epoxy mixing, heating and out gassing occur about 2 hours prior to the start of epoxy flow to the coil. Once the epoxy flows out into the overflow reservoir from the lead end of the coil, the epoxy input hose is clamped off at the return end and a 12 hour dwell period begins at atmospheric pressure. The tooling is then moved into a curing oven with a cure cycle of 5 hours at $110{ }^{\circ} \mathrm{C}$ followed by 16 hours at $125^{\circ} \mathrm{C}$.

Typical impregnation cycle at FNAL:

\begin{tabular}{|c|c|c|c|}
\hline DAY & TIME & HRS & DESCRIPTION \\
\hline MONDAY & 11:00 A.M. & 0 & start vacuum pump down and heating @ $55^{\circ} \mathrm{C}$ \\
\hline TUESDAY & 11:00 A.M. & 24 & continue vacuum pump down \\
\hline
\end{tabular}

\begin{tabular}{|l|l|c|l|}
\hline WEDNESDAY & 7:59 A.M. & 45 & total pre epoxy impregnation vacuum pump down time \\
\hline & 8:00 A.M. & 0 & start mixing, heating and out gassing CTD101K epoxy \\
\cline { 2 - 4 } & 10:00 A.M & 2 & start flowing epoxy @ $1 \mathrm{~cm} / \mathrm{sec}$ thru $0.39 \mathrm{~cm}$ I.D. glass tube \\
\cline { 2 - 4 } & 11:35 P.M. & 3.35 & see epoxy in overflow tube \\
\cline { 2 - 4 } & 12:30 P.M. & 4.5 & wait 30 minutes after seeing epoxy overflow \\
\cline { 2 - 4 } & 1:00 P.M. & 5 & clamp off epoxy input hose, stop vacuum and start soak time \\
\cline { 2 - 4 } & 1:30 P.M. & 5.5 & start $60^{\circ} \mathrm{C}$ overnight heating in vacuum chamber no vacuum \\
\hline
\end{tabular}

\begin{tabular}{|l|l|c|l|}
\hline THURSDAY & 7:00 A.M. & 23 & move to long oven start $110^{\circ} \mathrm{C}$ ramp \\
\hline & $8: 30$ A.M. & 0 & beginning of $110^{\circ} \mathrm{C}$ for 5 hours cycle \\
\cline { 2 - 4 } & 1:30 P.M. & 5 & start $125^{\circ} \mathrm{C}$ ramp \\
\cline { 2 - 4 } & 2:30 P.M. & 1 & beginning of $125^{\circ} \mathrm{C}$ for 16 hours cure cycle \\
\hline
\end{tabular}

\begin{tabular}{l|l|c|l|} 
FRIDAY & 6:30 A.M. & 16 & end of cure cycle oven door auto opens, need to shut off fans \\
\hline
\end{tabular}

\section{LBL:}

The impregnation fixture is placed into the vacuum chamber horizontally. Fill lines and upper reservoir lines are connected. Strip heaters and thermocouples are mounted to the fixture and plugged in. The vacuum chamber will be closed at this point in time, and then rotated upward at a $\sim 30^{\circ}$ angle.

Vacuum pumps are started, pumping down to $\sim 10-100$ mTorr. Coil fixture heaters are turned on to soak at $110^{\circ} \mathrm{C}$ for $\sim 6$ hours, and then brought back down to hold at $60{ }^{\circ} \mathrm{C}$. CTD epoxy is then mixed and degassed at 50-60 ${ }^{\circ} \mathrm{C}$ at approximately 300 mTorr. Vacuum chamber pressure is increased approximately to $1000 \mathrm{mTorr}$ and the epoxy supply line is unclamped to start the fill; approximately two hours are needed to fill until approximately two inches are visible in the upper reservoir, which is open to vacuum. The epoxy supply line is then clamped.

The vacuum chamber is let up to atmospheric pressure and then pumped down again two times. If it is noted between cycles that the upper reservoir level drops more than two inches, which would indicate that internal voids have been filled, the supply line is opened to top off the level again and then closed during a vacuum cycle.

The vacuum chamber is then let up to atmospheric pressure a final time and the fixture is allowed to soak overnight for approximately15 hours. 
Strip heaters are mounted to aluminum plates and then connected to the stainless impregnation fixture. Note that we offset the controller temperatures as indicated below so the mold will see the actual cure temperatures of $110 \& 125^{\circ} \mathrm{C}$ recommended by CTD.

While at atmospheric pressure:

- $\quad$ Ramp for 1.0 hours to $130^{\circ} \mathrm{C}$

- Hold for 7.0 hours at $130^{\circ} \mathrm{C}$ (temperature of mold is at $\sim 110^{\circ} \mathrm{C}$ for about 4 hours)

- Ramp for 1.0 hours to $145^{\circ} \mathrm{C}$

- Hold for 20.0 hours at $145^{\circ} \mathrm{C}$ (temperature of mold is at $\sim 125^{\circ} \mathrm{C}$ for about $17-20$ hours)

- Heat cycle off, drift down to ambient.

\section{c. Coil Shipping}

A coil shipping fixture is used to ship coils between labs. The fixture consists of an aluminum support tube mounted in an aluminum channel using rubber shock mounts. Full length rails support the coil midplane. A series of clamps are applied over the coil OD. Longitudinal restraint is provided by bolts contacting the ends of the coil saddles. A cross section of the fixture is shown in Fig. 5.4.

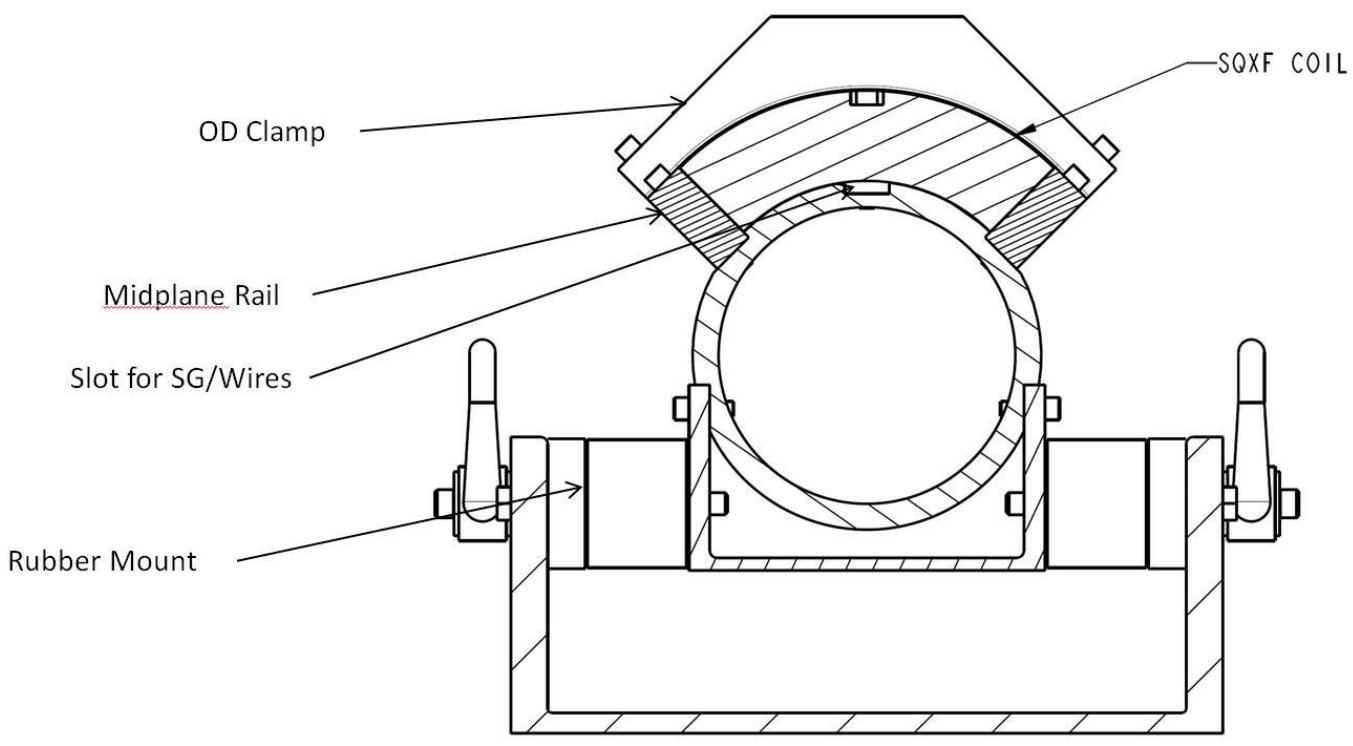

Fig. 5.4: Coil shipping fixture. 


\section{STRUCTURE DESIGN and INSTRUMENTATION}

\section{a. Design Concept}

The structure of MQXFS1 is based on an aluminum shell pre-tensioned at room temperature with pressurized bladders and interference keys (i.e. bladder and key technology). The cross-section of the MQXF1 is a direct scale-up of the previous successful HQ model. Fig. 6.1 shows the similarities between the two structures. The design comprises an iron yoke surrounded by a $29 \mathrm{~mm}$ thick aluminum shell, and includes four iron pads, four aluminum bolted collars and four coils wound around titanium poles. Between each pad and yoke two interference keys are used to balance the azimuthal tension in the outer shell with the azimuthal compression in the inner coils. The yoke, pads and collars are made of thick $(50 \mathrm{~mm})$ laminations assembled with tie rods.

Previous experience on long magnets (LR and LQ) has shown the importance of segmenting the shell longitudinally. During cool-down, the shell contracts more than the iron yoke but the friction between shell and yoke prevents the shell from sliding axially, putting the shell in strong axial tension. During excitation, the shell might slip, leading to a change in azimuthal preload of the coils. In order to minimize axial tension in the shell and to ensure a uniform azimuthal load on the coil, the decision was made to segment the shell for long magnets.

For the first short model (MQXFS1) an initial segmentation of the shell in 2 parts of $774 \mathrm{~mm}$ length was foreseen. Nevertheless, as discussed in Part 6.c.i, the shell was further segmented in 3 parts (1/4, $1 / 2,1 / 4)$. This solution improves the preload distribution, thereby reducing the stress variation along the magnet.

The axial preload is provided by four $36 \mathrm{~mm}$ diameter aluminum rods connected to $75 \mathrm{~mm}$ and 50 $\mathrm{mm}$ (LE and RE, respectively) thick Nitronic 50 endplates, connected to the coil end-saddles by mean of bullet screws. This system allows application of some axial preload at room temperature by pretensioning the rods with a piston. Final axial preload is achieved after cool-down through the shrinkage of the aluminum rods. Because of their large thermal contraction rate, aluminum rods are challenging on the $4.5 \mathrm{~m}$ long prototype MQXFA, and stainless steel rods are being considered as a better choice due to their thermal contraction rate that is closer to the coil contraction.

The maximum outer diameter of the cold mass including its LHe vessel is limited by the available space in the LHC tunnel and has been set by CERN to be $630 \mathrm{~mm}$. Therefore, the outer diameter of the MQXFS1 structure is $614 \mathrm{~mm}$ (to be compared with the $570 \mathrm{~mm}$ of the HQ structure) allowing for an $8 \mathrm{~mm}$ thick LHe vessel. 


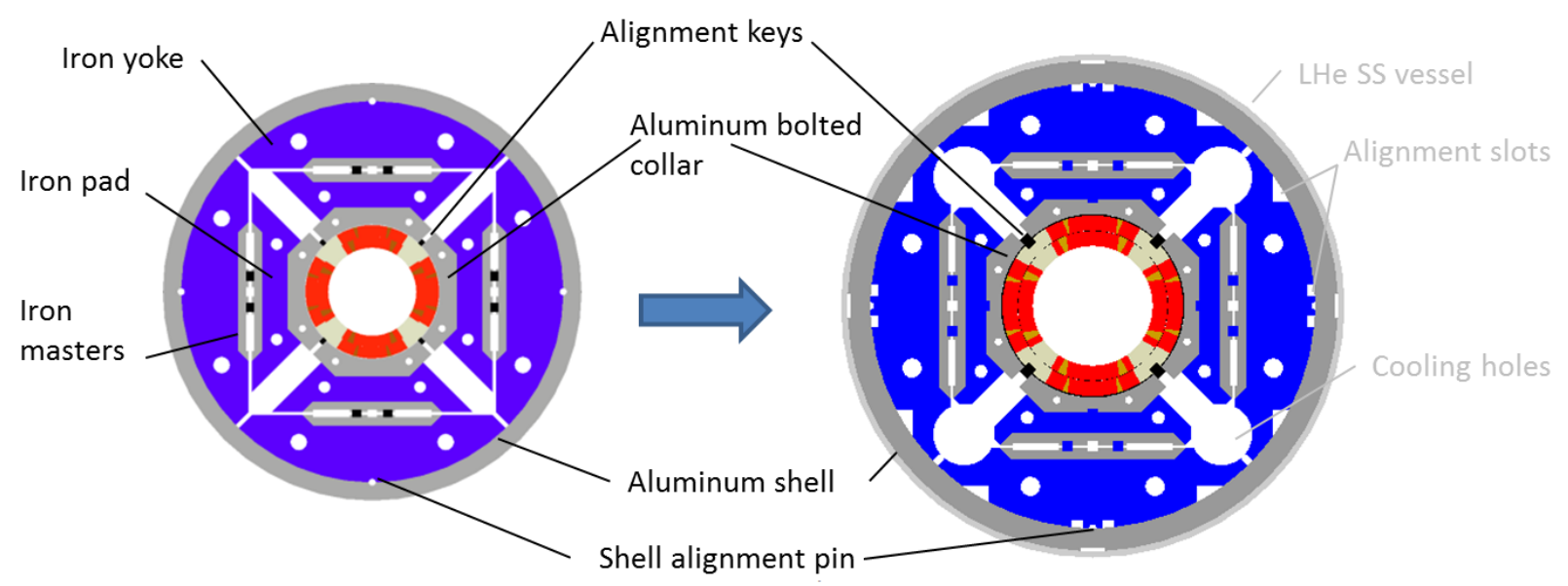

Fig. 6.1: Cross-section of HQ (left) and MQXF (right); new features are shown in light gray.

The MQXF magnet adopts a welded stainless steel shell as the LHe vessel, and the structure is designed with features allowing the welding of this shell. As shown in Fig. 6.2, these features include alignment slots in the yoke both at the mid-plane and at 45 degree. The mid-plane slots will accommodate welding blocks, which will be screwed to the yoke lamination. A backing strip will then be tack welded to the blocks. The aluminum shells have matching slots to accommodate the backing strip.

For the LHe vessel assembly, a half stainless steel (SS) shell is placed on top of the magnet and tack welded to the backing strip. The assembly (magnet + half SS shell) is then rotated and another half shell is placed on the magnet and welded to the first half shell, providing a longitudinal LHe vessel.

In addition, $77 \mathrm{~mm}$ diameter holes providing room for heat exchanger have been added to the structure as seen in Fig. 6.1.
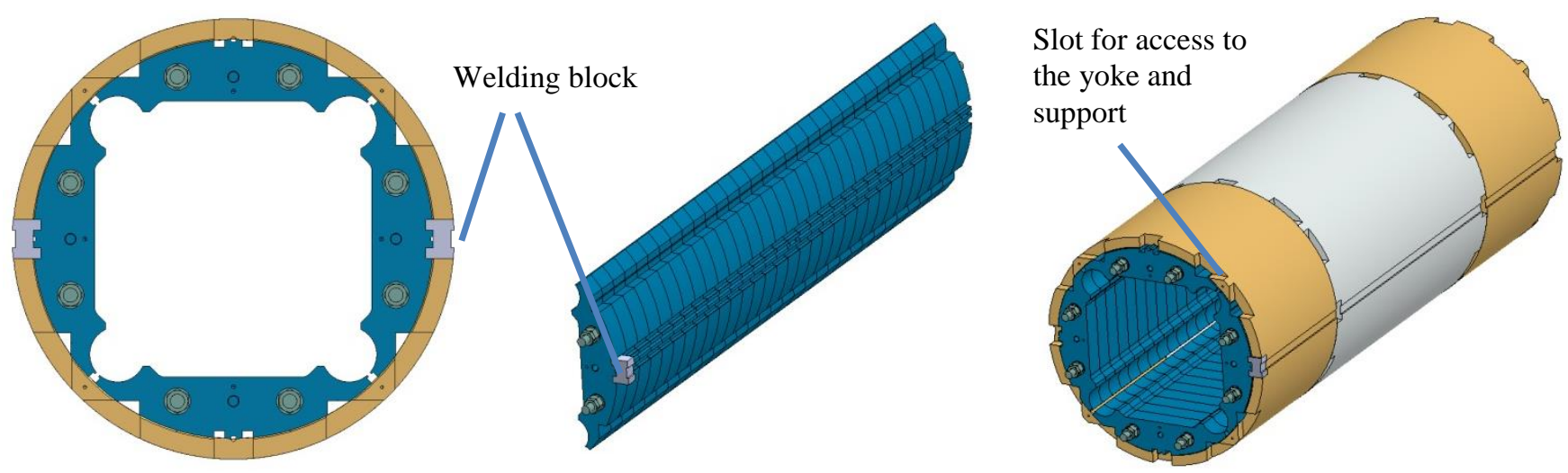

Fig. 6.2: Structure with features for welding the stainless steel shell. 


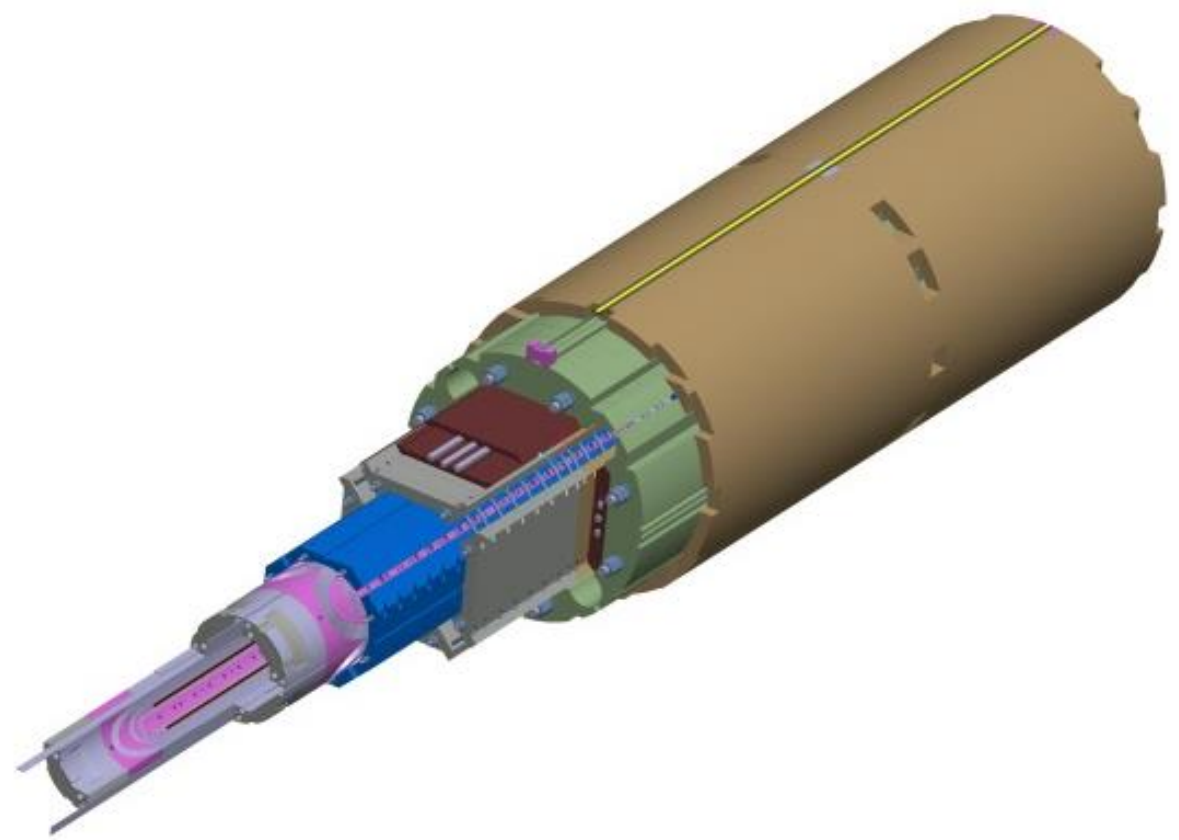

Fig. 6.3: Exploded view of the MQXFS1 structure (without axial load components and SS shell) showing in yellow the mid-plane backing strip (the magnet is shown here rotated by 90 degrees with respect to Fig. 6.1 and 6.2).

\section{b. 2D analysis}

A 2D numerical model of the MQXFS1 structure was developed using ANSYS to simulate its mechanical behavior. The FE model of MQXFS includes friction and simulates 5 steps:

- Bladder inflated

- Keys inserted (bladder deflated)

- LHe vessel welding

- Cool-down

- Excitation: nominal $140 \mathrm{~T} / \mathrm{m}$ \& maximum gradient $(152 \mathrm{~T} / \mathrm{m})$

The purpose of the preload is to minimize coil motion during excitation. Ideally, the coil pole turn should remain in compression at all steps. Nevertheless, as we are dealing with $\mathrm{Nb}_{3} \mathrm{Sn}$ strain sensitive material, a trade-off has to be made between level of preload and peak stress reached in the conductor. A common solution is to allow some tension at the pole / coil interface of the order of 10 to $20 \mathrm{MPa}$ at maximum gradient. This is achieved with an interference of $550 \mu \mathrm{m}$ on the loading keys at room temperature. During the assembly, a greater separation of the master keys (100 $\mu \mathrm{m}$ from nominal) is required in order to insert the shims. As a result, the bladders in the model will be pressurized to $40 \mathrm{MPa}$ to achieve an opening of about $650 \mu \mathrm{m}$. However, bladder operation within the simulation model leads to unrealistic lower strain levels by about $20 \%$ in the following steps. Studies on different cases show friction between the components may cause these unexpected results [1]. Friction makes some parts in the model behave not like "spring", as the real assembly, when simulating the bladder operation prior to the key shimming. However, both the dummy coil test and the MQXFS1 magnet test showed very nice 
agreement with the result without bladder operation. As a consequence, the elastic solution for the MQXF magnet is obtained from two separate simulations: a bladder solution dedicated model is used to simulate the bladder operation itself; and a different model is used for all remaining load steps starting from step 2 (keys) directly.

Material properties used for FEM analysis are shown in Table 6.1. The computations in both the 2D and 3D (discussed in Section 6.c) models were carried out in light of the following requirements [2]:

a. Keep the pole turns in contact with the winding poles with a pressure $\geq 2 \mathrm{MPa}$ at the midradius up to $90 \%$ of $I_{s s}$;

b. Limit the coil peak stress to $100 \mathrm{MPa}$ at $293 \mathrm{~K}$ and $150-200 \mathrm{MPa}$ at $1.9 \mathrm{~K}$;

c. Maintain the stress in the support structure components within the material limits (Discussed in Section 6.c);

Table 6.1: Material properties for the MQXF analysis

\begin{tabular}{lccc}
\hline \multirow{2}{*}{ Materials } & E at 293K & E at 4.2K & $\begin{array}{c}\text { Integrated thermal } \\
\text { contraction }(293 \mathrm{~K}-4.2 \mathrm{~K})\end{array}$ \\
\cline { 2 - 4 } & $\mathrm{GPa}$ & $\mathrm{GPa}$ & \\
\hline Coil * & 44 & 44 & $3.36 \mathrm{E}-03$ \\
Aluminum bronze & 110 & 120 & $3.24 \mathrm{E}-03$ \\
Aluminum & 70 & 79 & $4.20 \mathrm{E}-03$ \\
Iron & 213 & 224 & $2.00 \mathrm{E}-03$ \\
G10 (normal direction) & 10 & 10 & $7.30 \mathrm{E}-03$ \\
G10 (layer direction) & 30 & 30 & $2.44 \mathrm{E}-03$ \\
Notronic 50 & 210 & 225 & $2.60 \mathrm{E}-03$ \\
Stainless Steel ** & 193 & 210 & $2.90 \mathrm{E}-03$ \\
Titanium & 115 & 125 & $1.70 \mathrm{E}-03$ \\
\hline
\end{tabular}

*the coil properties such as modulus will be updated in the later simulations; the work in this report used the properties listed in this table.

**the integrated thermal contraction of stainless steel has a wide variation range over temperature; the value used in the simulations will be verified in the further work.

Stresses in the coils have been computed and displayed in a cylindrical coordinate system. Azimuthal stress distribution is checked in the coil as shown in Fig. 6.4. The coils are compressed from the bladder operation to cool-down; as mentioned above, the inner and outer layers at the coil/pole interface show an average tension of about $20 \mathrm{MPa}$ when energized to the normal gradient. The maximum $\sigma_{\theta}$ in coil is -94.6 MPa at RT, and -174 MPa after cool-down. Coil stress from the 2D computation is within the limit, it will be further discussed in Section 6.c. 

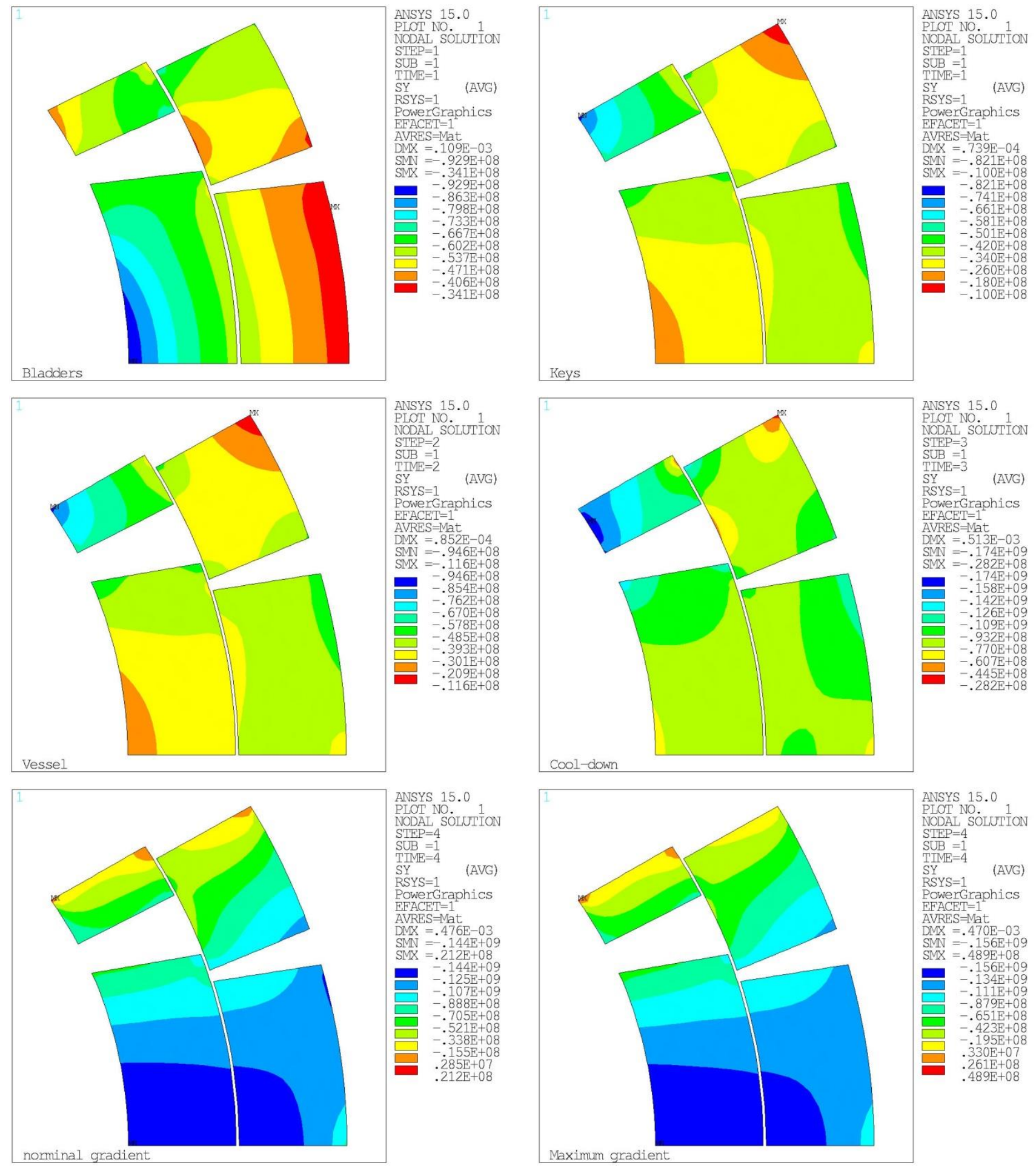

Fig. 6.4: Azimuthal stress distribution in the coil at various stages of assembly and operation.

Shear stress in the coils varies in the $\pm 35 \mathrm{MPa}$ range with the exception of a few corners (the outer corner of layer 1 pole turn and the inner corner of layer 2 pole turn, Fig. 6.5).

A peak shear stress after cool-down is observed at the corners on the coil/pole interface. 
MQXFS1 Design Report
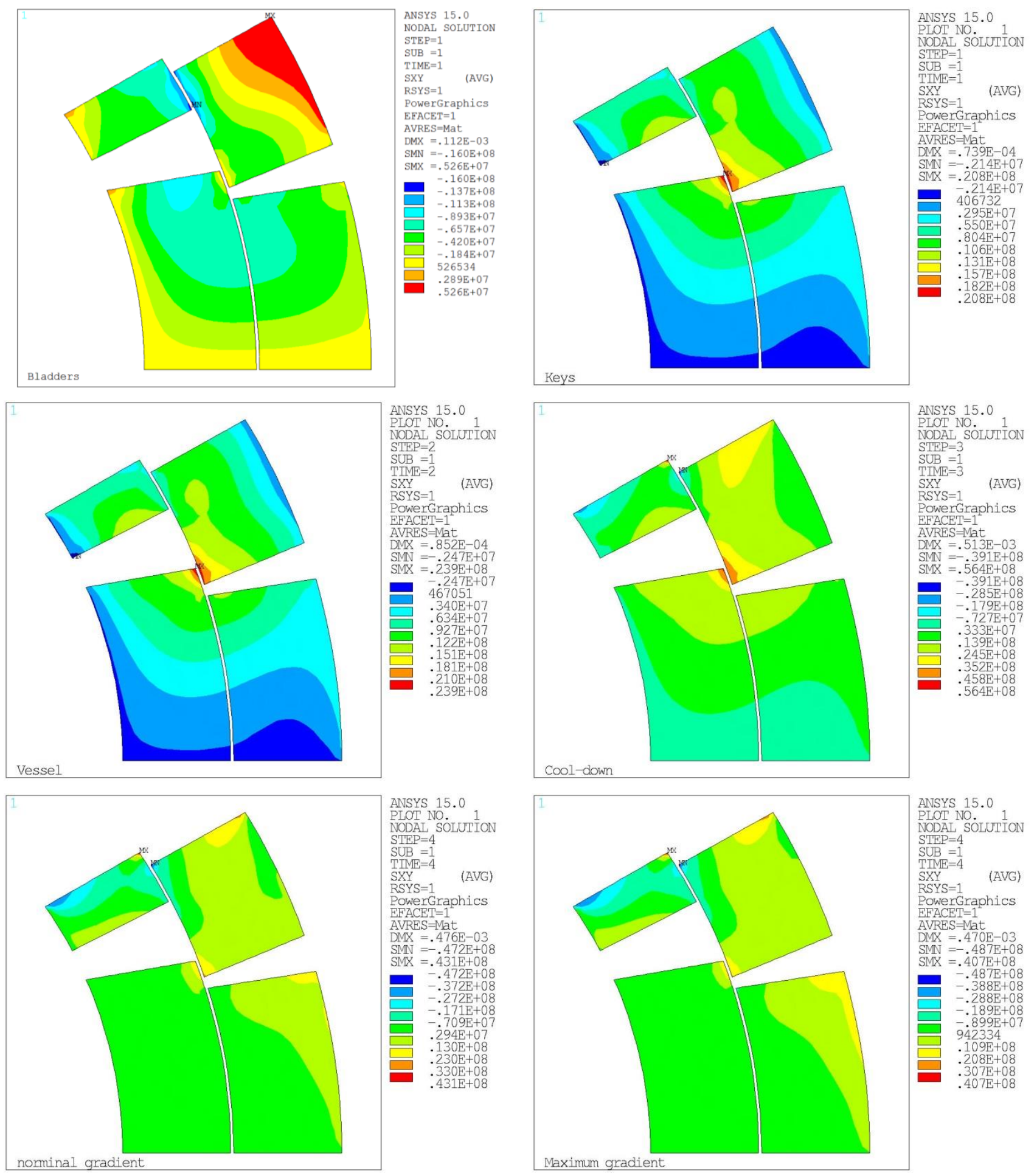

Fig. 6.5: Shear stress distribution in the coil.

Due to the longitudinal distribution, stresses in each part are studied in the 3D analysis section. 


\section{c. 3D analysis}

\section{- Shell segmentation}

As mentioned earlier, the shell requires segmentation to minimize the risk of uncontrolled slippage during excitation and in order to ensure homogeneous preload distribution. Three different configurations were considered for the 1.5 m models: single shell, two half shells, and a central halflength shell surrounded by two quarters. The $1^{\text {st }}$ version design reported in [3] had two half shells. Based on a subsequent stress variation study, the configuration for MQXFS1 and other short models was changed to the $3^{\text {rd }}$ option (Fig. 6.6).

The shell segment optimization was performed using a 3D ANSYS model with different shell configurations. Isotropic material properties are used in the in the 3D model (Table 6.1). For comparison, the interference in this analysis is same as the nominal value of $550 \mu \mathrm{m}$.
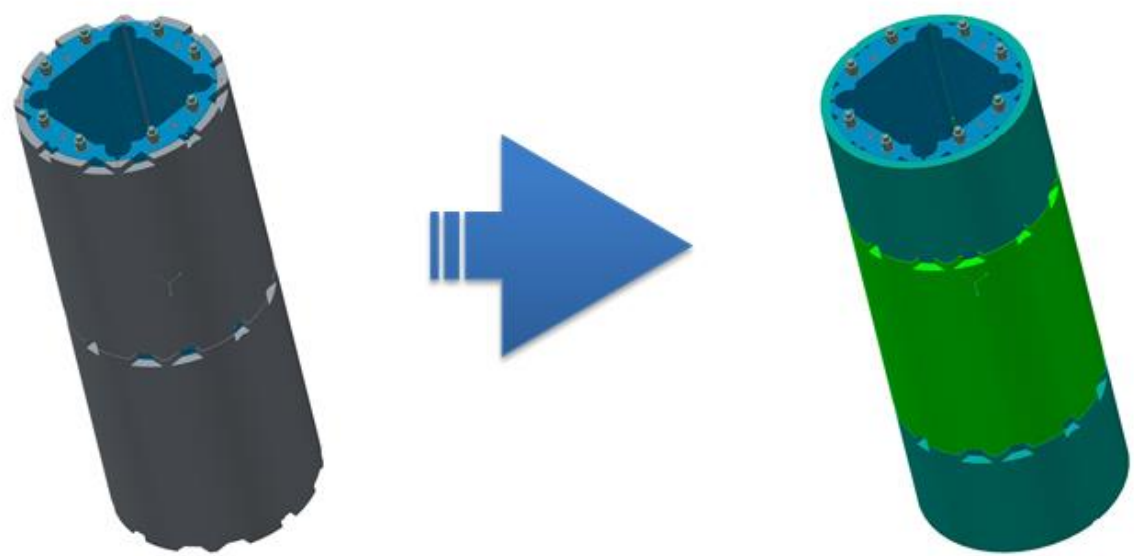

Fig. 6.6: shell segmentation optimization: from two half shells (left) to one half shell + two quarter shells (right).

The results show that the maximum longitudinal stress in the shell is proportional to the shell length. Fig. 6.7 shows the impact of shell segmentation on the shell and coil stress. Half-half division leads to an identical axial stress for both of the two half-length shells. The triple division was preferred since it not only reduces the axial stress on the two end shells, but also provides a greater azimuthal stress in the center of the magnet (Fig. 6.7 right). 

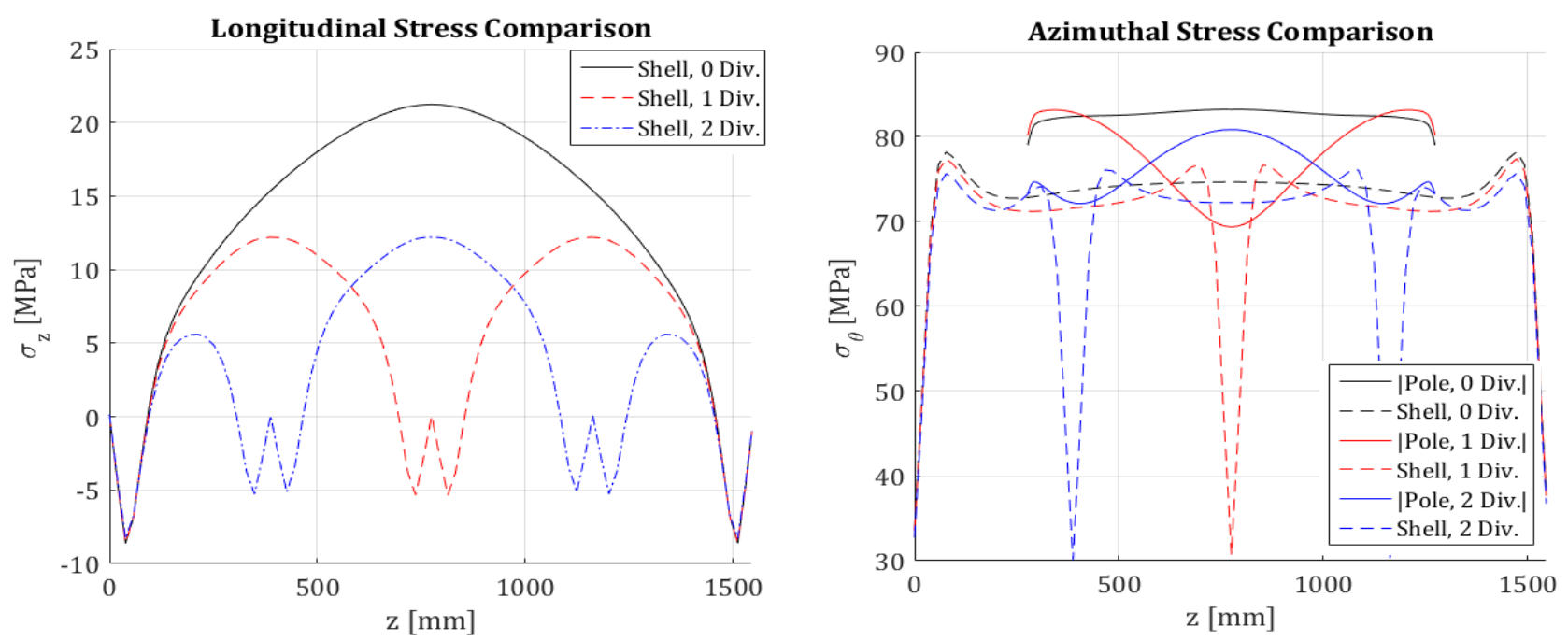

Fig. 6.7: Axial stress on shells (left) and azimuthal stress in shell and pole (right) for different shell segmentations of short models.

Another benefit from the triple division is to reduce the stress variation along the coil. As seen in Fig. 6.8, the azimuthal stress at the mid-point of the $1^{\text {st }}$ layer coil/pole interface varies maximum $+/-20$ MPa with 2 equal shell segments; the variation reduced to +/- $8 \mathrm{MPa}$ with the triple division. In particular, the end effect has been improved in the triple division. The end effect "drop" in the full length magnets (MQXFA/B) has been reduced significantly by adopting a similar shell segmentation (for instance, 5 half-length shells +2 quarter length shells at the extremities in MQXFA).
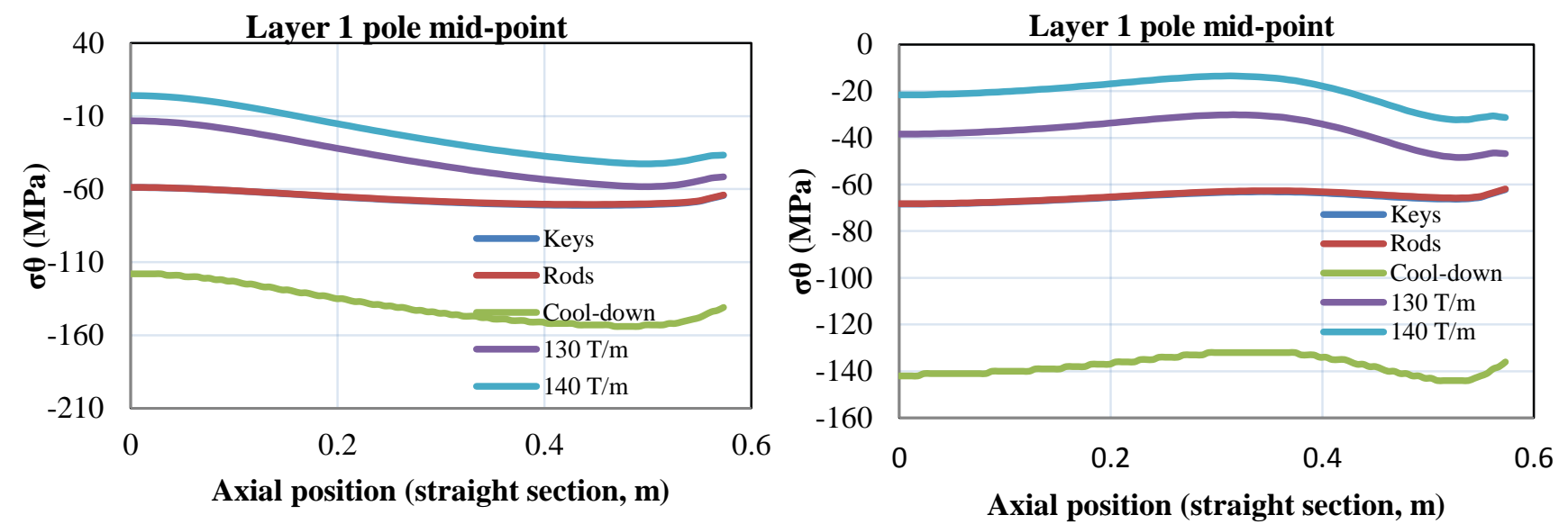

Fig. 6.8: Contact pressure variation along short model coils---left: two half shells; right: one half shell + two quarter shells.

\section{- Baseline case}

In order to check the stress distribution throughout the assembly, a 3D ANSYS mechanical analysis with the finalized shells and updated parameters and features was carried out. The following computational steps in the updated model were evaluated:

- Key insertion with $550 \mu \mathrm{m}$ interference;

- Axial loading with $-810 \mu \varepsilon$ strain pre-tension; 
- $\quad$ Nominal excitation $130 \mathrm{~T} / \mathrm{m}$ gradient;

- $\quad$ Maximum excitation $140 \mathrm{~T} / \mathrm{m}$ gradient.

Contact elements are used in the MQXF analysis. There are three locations where contacts are bonded: The interfaces inside the impregnated coil; the contact between the stainless steel pad and the iron pad; the contact between the radial shim and the collar. All the other surfaces are modeled as frictional contact with a friction factor of 0.2 .

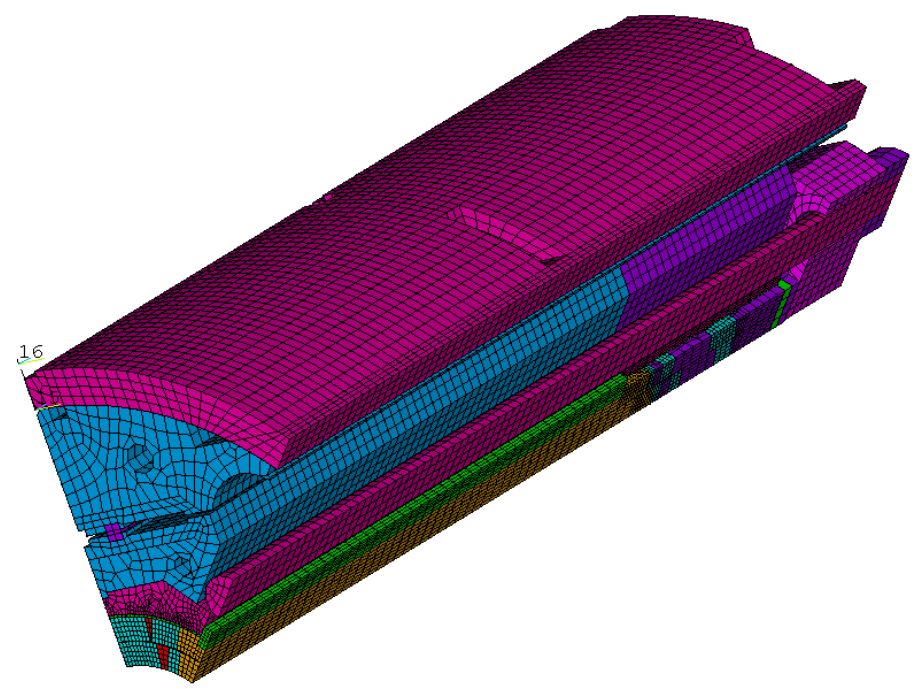

Fig. 6.9: 3D finite element model with updated features (materials are displayed by colors).

According to the requirements in Section 6.b, to ensure that pre-load is maintained to both coil layers during all magnet operations, the azimuthal stress at the mid-radius on the pole turns and mid-planes should remain negative (compression). The azimuthal stress at mid-radius of pole turn and mid-planes are given in Fig. 6.10. According to the result, the coils are compressed at all times during the operations under the given pre-load interference and the structure dimensions.
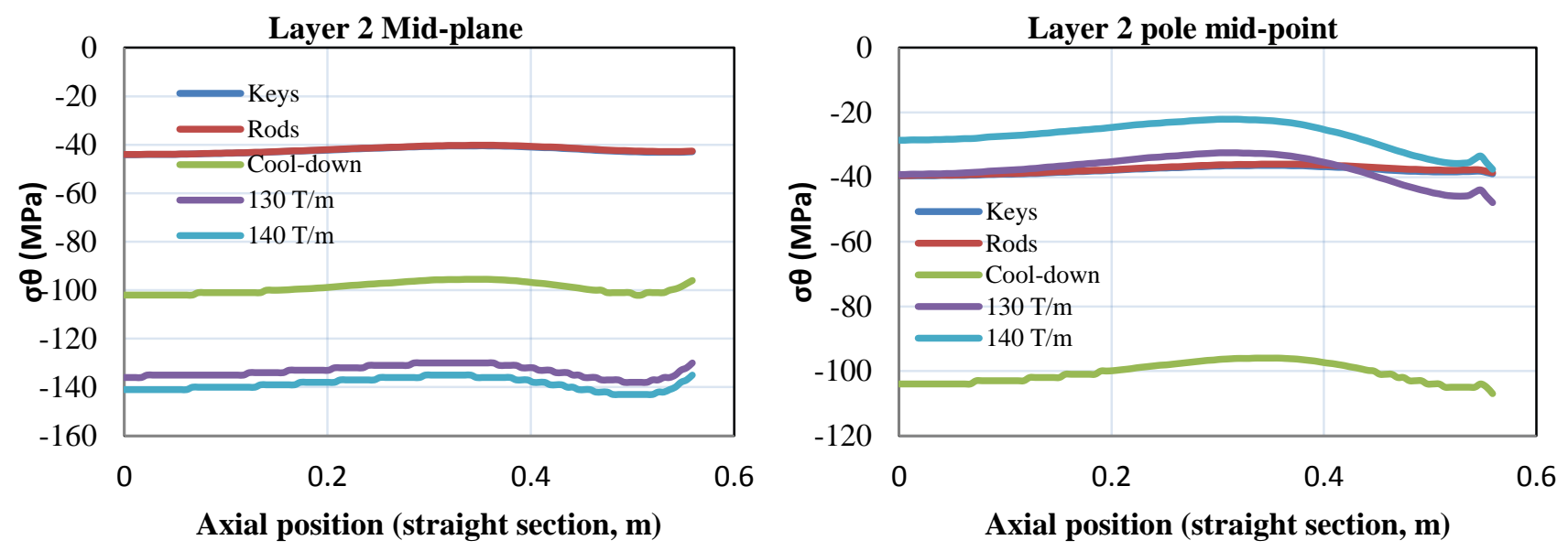

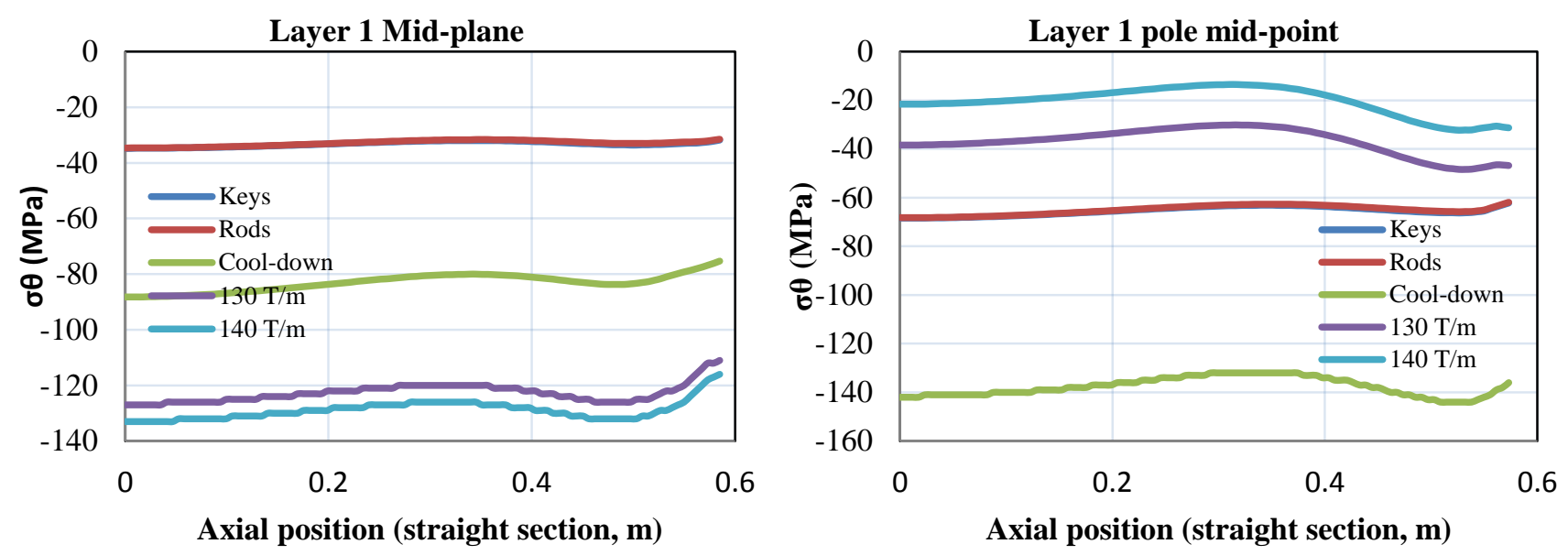

Fig. 6.10: Azimuthal stress along the MQXFS1 coil.

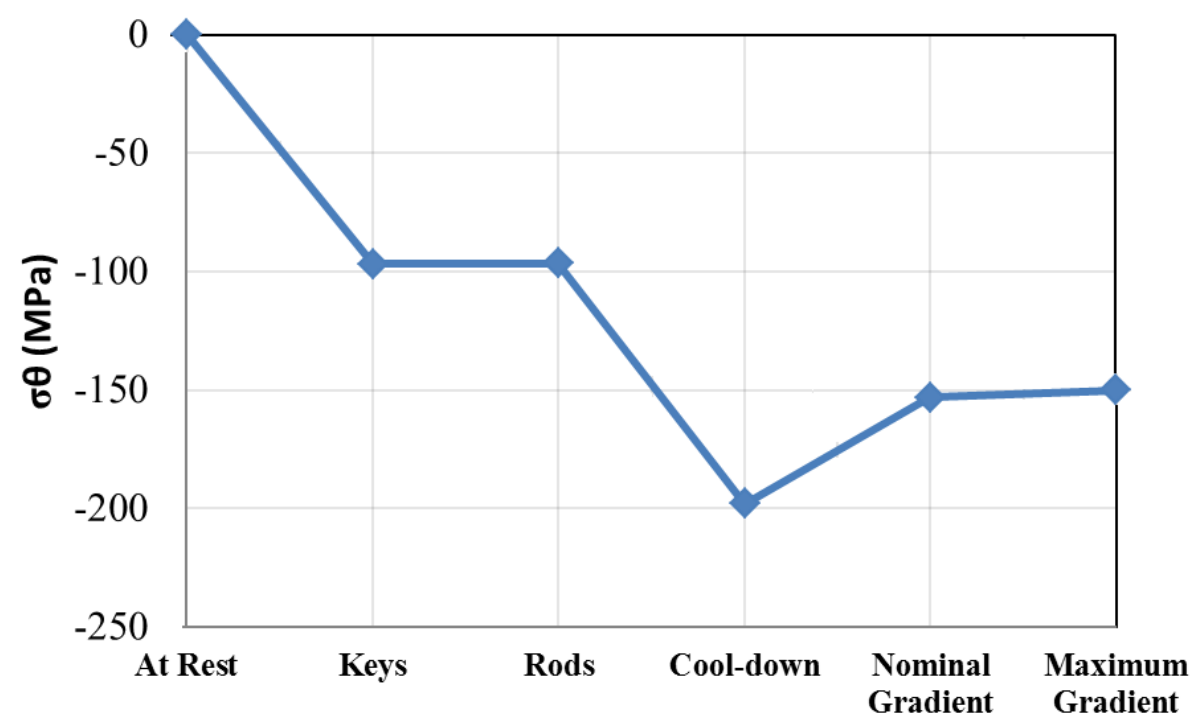

Fig. 6.11: Azimuthal stress evolution in the MQXFS coils.

The peak azimuthal stress evolution in the entire coil is given in Fig. 6.11. In the first step of key shimming, a maximum coil stress of $-97.6 \mathrm{MPa}$ is reached in the middle portion of the inner layer. Axial loading only impact the coil ends marginally. The coil reaches its peak stress of $-197 \mathrm{MPa}$ close to the end of the inner layer after cool-down, while it reduces to -150MPa when Lorentz forces are applied. The pole stress reduces, but a compression of about $15-20 \mathrm{MPa}$ is maintained even at the maximum gradient (

Fig. 6.10).

The axial load that counteracts the axial Lorentz force of $1.17 \mathrm{MN}$ on the coils is provided by four pre-tensioned $36 \mathrm{~mm}$ diameter aluminum rods and two Nitronic 50 end plates, which prevent the coils from detaching from the pole or end-spacers. Although the rods and plates were sized to accommodate the full axial load (Fz), in the simulation the magnet was axially preloaded to only $\sim 40 \%$ of this value due to friction forces between the coils and the support structures, which is based on previous experience on the HQ series. The four rods are pre-tensioned to $56.7 \mathrm{MPa}(\sim 810 \mu \varepsilon)$ corresponding to $231 \mathrm{kN}$ of total axial force at room temperature, and this will become $0.58 \mathrm{MN}$ after cool-down. 
The contact pressure at the coil ends is shown in Fig. 6.12. In general, the coil is kept in contact with pole and spacers.

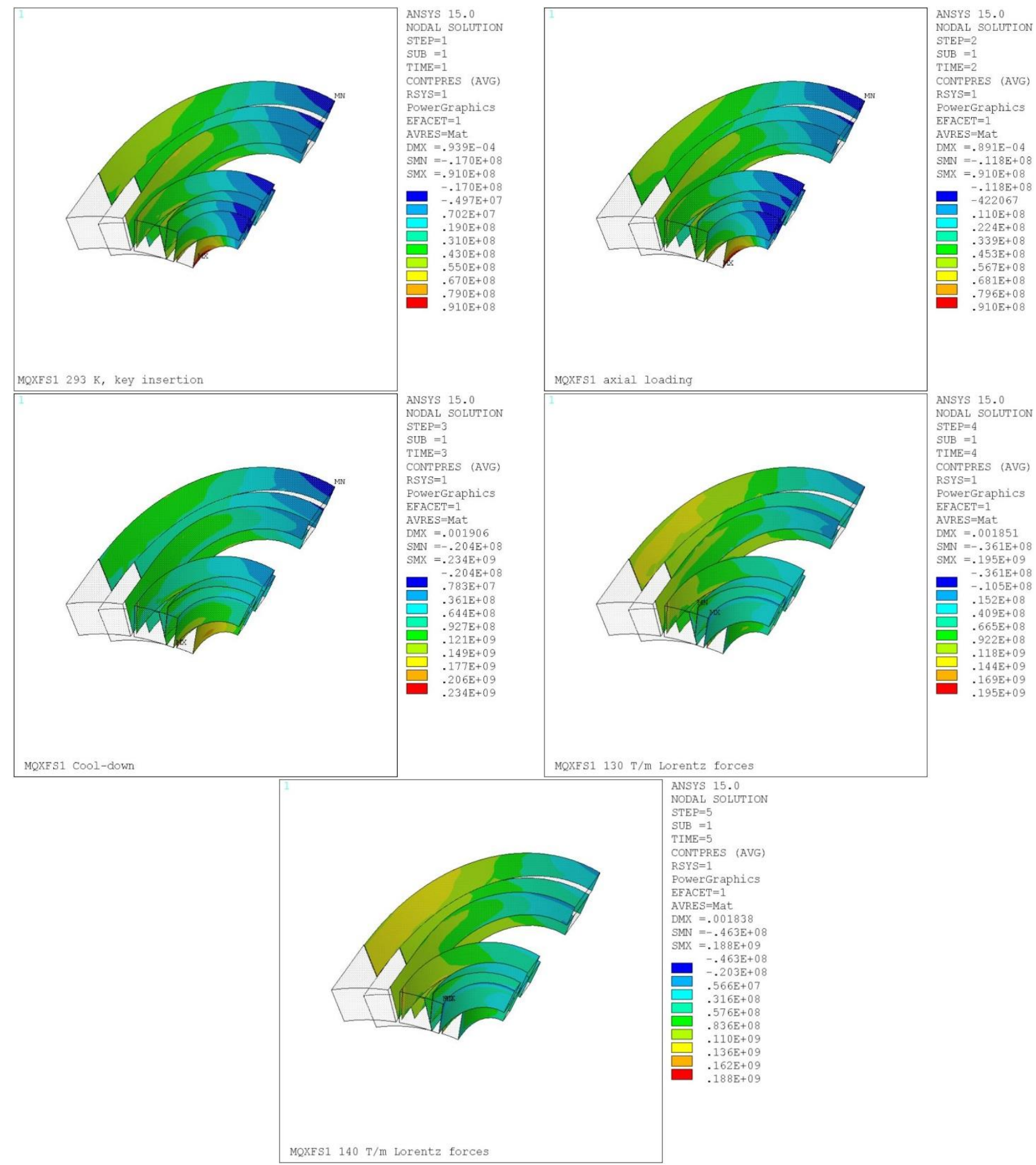

Fig. 6.12: Contact pressures at the coil/spacers interfaces $(\mathrm{Pa})$.

The stress in the structure parts should be maintained within the material limits listed in Table 6.2. For ductile material like aluminum, stainless steel, titanium and Nitronic 50, we use the Distortion 
Energy Theory as the criteria; for brittle materials like iron, we use the maximum normal stress criterion, which checks the principal stress instead of Von Mises stress.

Table 6.2: Materials strength limits

\begin{tabular}{ccc}
\hline \hline \multirow{2}{*}{ Material } & \multicolumn{2}{c}{ Yield strength $(\mathrm{MPa})$} \\
\cline { 2 - 3 } & $293 \mathrm{~K}$ & $4.2 \mathrm{~K}$ \\
\hline A1 7075 & 480 & 690 \\
SS316 LN & 350 & 1050 \\
NITRONIC 50 & 350 & 1240 \\
A36 Steel & 180 & 720 \\
Titanium & 830 & 1650 \\
\hline \hline
\end{tabular}
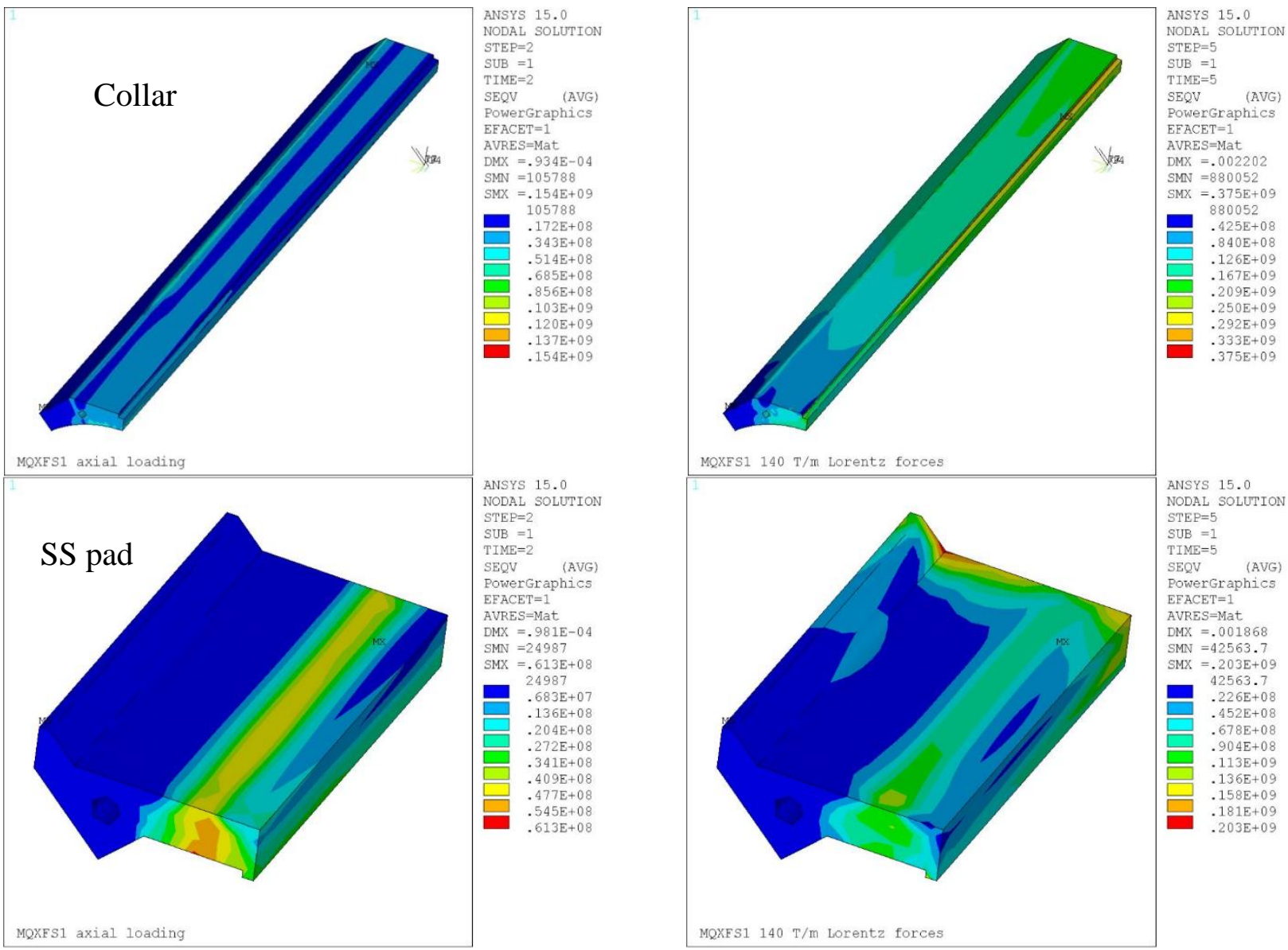

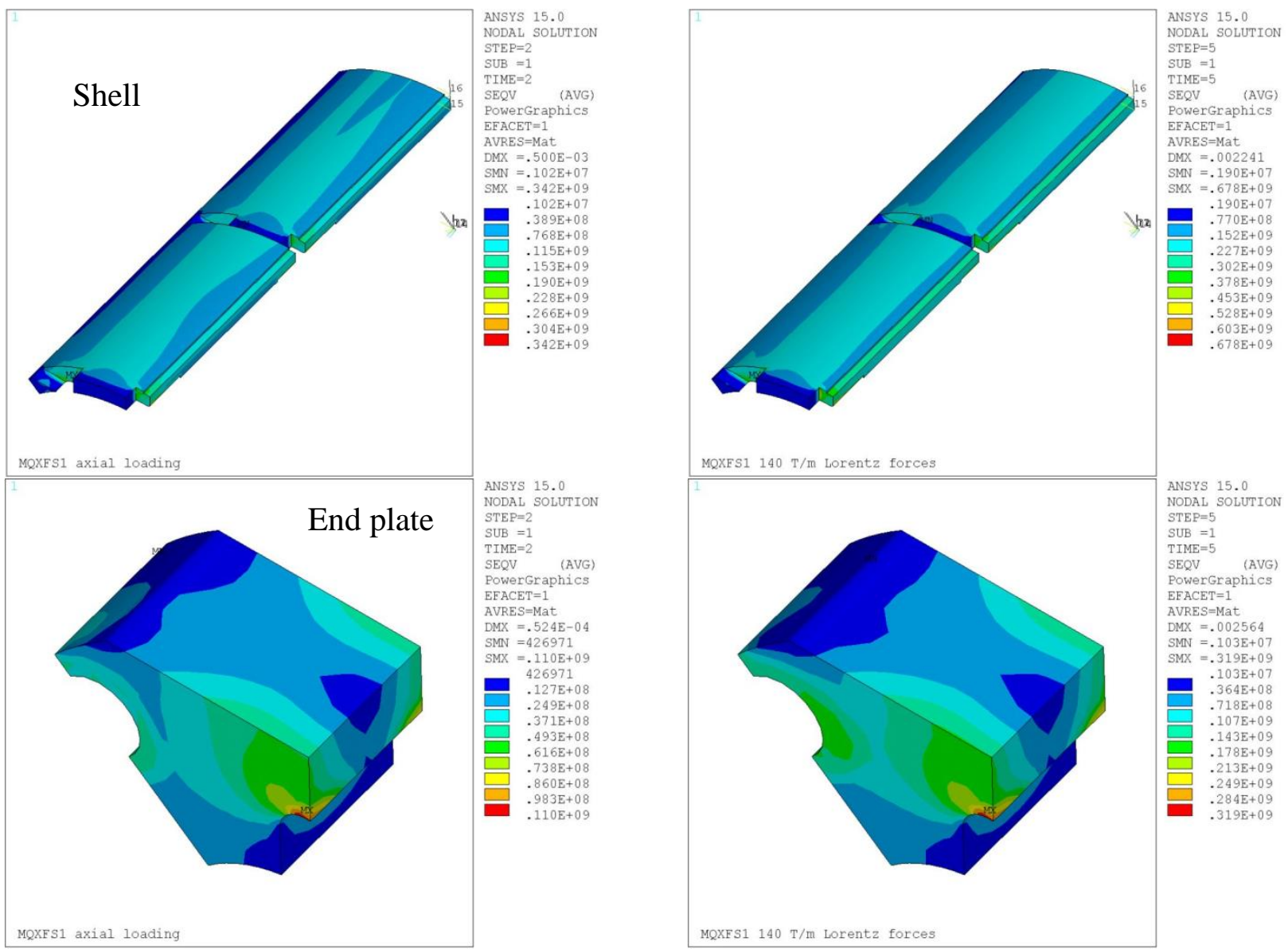

Fig. 6.13: Von Mises stress in collar, stainless steel pad and shells (Pa, left @ RT; right @140 T/m).

Fig. 6.13 shows the Von Mises stress of the ductile materials in the structure. The stresses of these parts with the Von Mises criteria are within the limits in Table 6.2. The shell has the minimum safety factor. However, the peak stress both at RT and at excitation is located at the corner of the alignment notch, where there is a sharp corner in the model that could be considered a singularity. In FEA models stresses in such situations is usually overestimated. Compared to the peak stress of $678 \mathrm{MPa}$ in the contour, the midpoint of the element of the peak stress shows $440 \mathrm{MPa}$ at excitation; to address the issue this corner will be rounded off in real structure. Future parts designs will address these corner areas as well.

For the iron parts, like yokes, masters, and the iron pads, stresses are checked with the maximum normal stress criteria. Fig. 6.14 shows the first principal stress of the iron parts. The yoke has a high stress at RT compared to the limit. Also in this case the peak stress is located in the alignment notch corner. The elements surrounding the peak stress area show an average of $160 \mathrm{MPa}$. Furthermore, the practical azimuthal preload target will be lower than $550 \mu \mathrm{m}$ for the larger safety margin at RT to be conservative. 

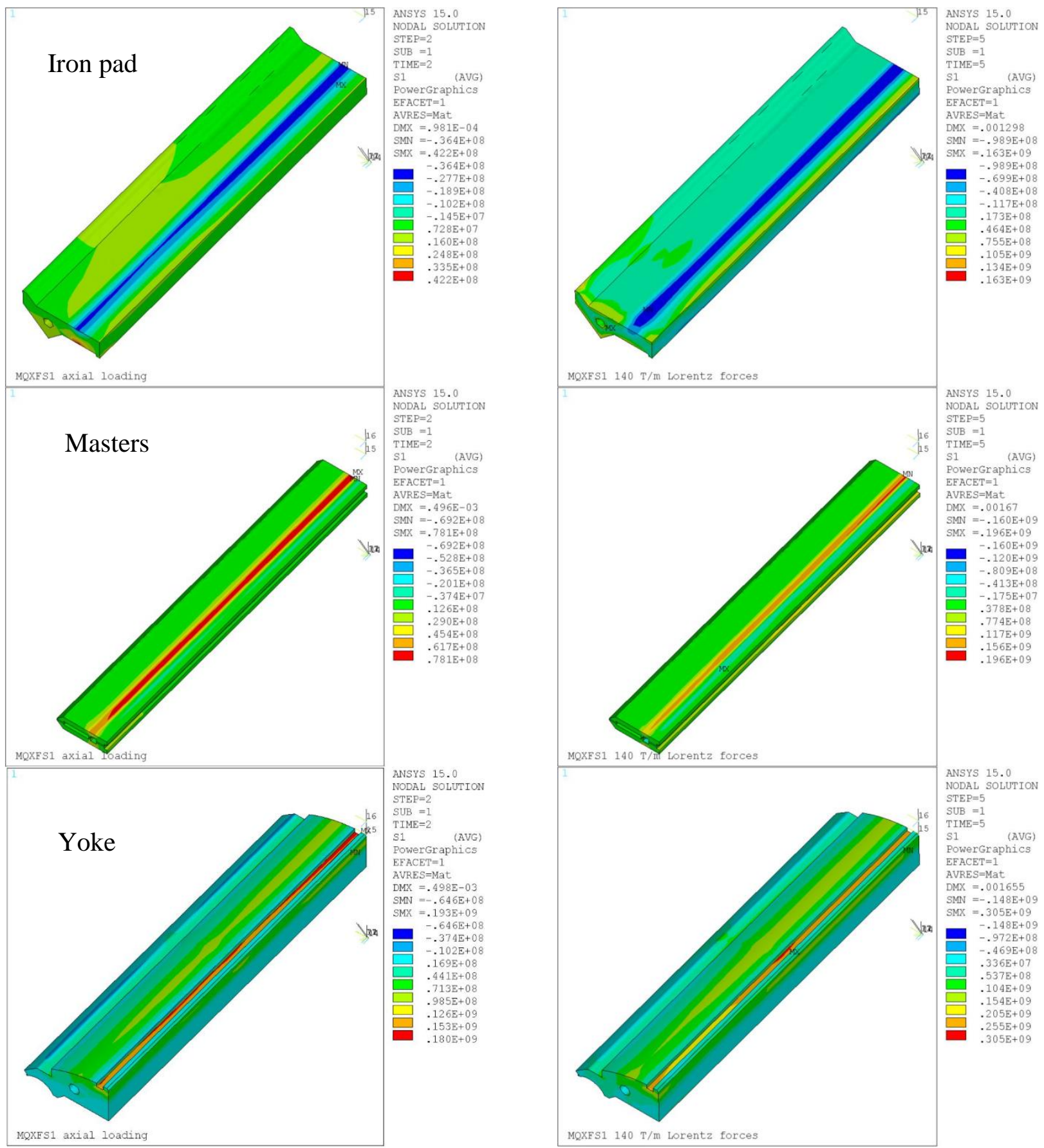

Fig. 6.14: $1^{\text {st }}$ principal stress in iron parts (Pa, left @RT; right @ 140 T/m).

\section{- Pole key detachment issue}

The alignment of the coil with respect to the structure is ensured by the pole key inserted in the coil poles and by thick-lamination bolted collars. The pole key will also intercept a fraction of the compressive force provided by the shell after cool-down. This plan requires that there is no separation 
between the pole key and the collars at all times. However, a gap was observed after cool-down in the baseline model of the MQXF simulations due to the thermal shrinkage of the G10 keys.

As a laminated material, G10 has different thermal contraction rate in directions normal and parallel to the cloth layers as listed in Table 6.1. Since G10 has the maximum compressive strength in normal direction, the baseline case has the pole key placed with the fibers oriented radially in order to better withstand the clamping force from the collars. However, G10 also has the maximum thermal contraction in this direction, resulting in about $98 \mu \mathrm{m}$ shrinkage from RT to $4.2 \mathrm{~K}$ over the width of $15 \mathrm{~mm}$, causing a gap between the key and collars (Fig. 6.15).

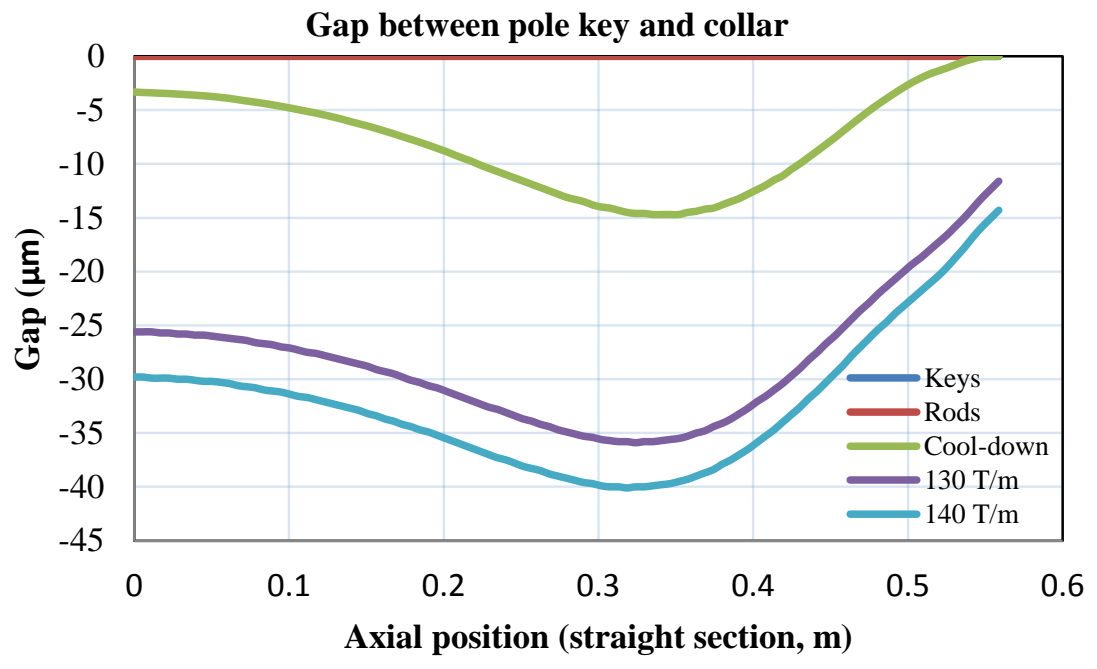

Fig. 6.15: Gap between the pole key and collar assembly.

Since in simulations the pole key was found to detach from collars due to high thermal contraction, a simple solution is to rotate the key 90 degree to make the fibers orient azimuthally (Fig. 6.16). In this orientation the key has an integral thermal contraction of $2.44 \cdot 10^{-3}$ (instead of $7.30 \cdot 10^{-3}$ with the original orientation).

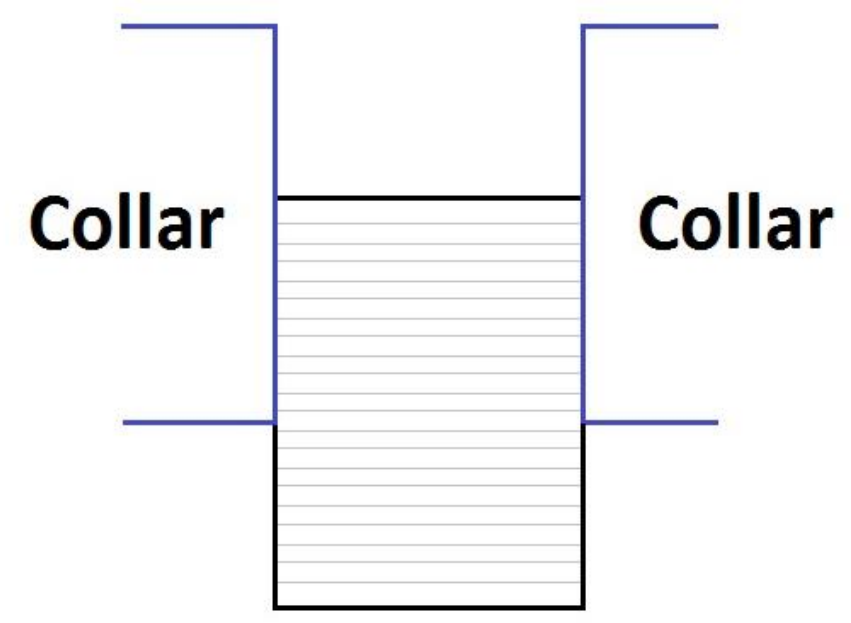

Fig. 6.16: Schematic for the rotated key solution.

The contact pressure along the pole key is shown in Fig. 6.17. The key is compressed with contact pressure of $30 \mathrm{MPa}$ at cool-down, and increases to about $\sim 50 \mathrm{MPa}$ in excitation. One concern about this 
solution is the shear stress in the key, which will be addressed in the design of the long MQXFA structure. The computed maximum shear stress is $21.5 \mathrm{MPa}$ after cool-down. The principal stress in the key is mainly compression; the maximum compression is $157 \mathrm{MPa}$ and occurs at RT.

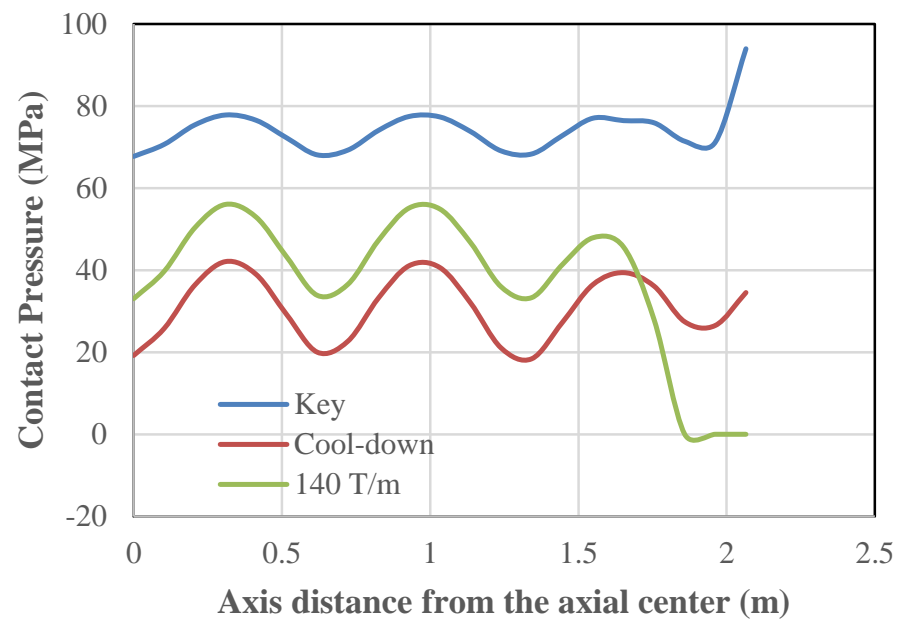

Fig. 6.17: Contact pressure in the key rotating solution.

\section{- Axial rods modifications}

The axial pre-load providing full contact between coil and end parts under the Lorentz forces is applied through four $36 \mathrm{~mm}$ diameter aluminum rods in the baseline design. Considering the $4.5 \mathrm{~m}$ long model (MQXFA), aluminum rods shrink too much compared with the coils. In order to better source the material, $33 \mathrm{~mm}$ (and/or 1-1/4") stainless steel rods are being considered to replace the current aluminum rods. When changing rods material, however, the final clamping force of the rods at $1.9 \mathrm{~K}$ should remain at the same level as that of the aluminum rods. Table 6.3: Axial rods parametersTable 6.3 lists the computed parameters of both aluminum rods and stainless steel rods to obtain similar force at $1.9 \mathrm{~K}$.

Table 6.3: Axial rods parameters

\begin{tabular}{l|l|l|l|l|l|}
\hline \hline Rod material & Rod force at RT & Rod force at $1.9 \mathrm{~K}$ & Rods $\sigma \mathrm{z}$ at RT & Rods $\varepsilon \mathrm{Z}$ at RT & $\begin{array}{l}\text { Loading } \\
\text { Target at RT }\end{array}$ \\
\hline $\begin{array}{l}36 \mathrm{~mm} \\
\text { Aluminum }\end{array}$ & $0.2 \mathrm{MN}$ & $0.58 \mathrm{MN}$ & $58 \mathrm{MPa}$ & $2110 \mu \varepsilon$ & $819 \mu \varepsilon$ \\
\hline $\begin{array}{l}33 \mathrm{~mm} \\
\text { Stainless Steel }\end{array}$ & $0.57 \mathrm{MN}$ & $0.56 \mathrm{MN}$ & $167 \mathrm{MPa}$ & $856 \mu \varepsilon$ & $799 \mu \varepsilon$ \\
\hline \hline
\end{tabular}

\section{d. Instrumentation: Strain Gauges}

All MQXF support structures are instrumented with strain gauges mounted on the shell, on the axial rods and on the coil pole piece. In the case of the shell and coil pole pieces, both axial and azimuthal strain data are temperature compensated and measured at various locations. Each location is called a station.

During assembly, this set of instrumentation allows measuring the transfer function between shell tension and coil pole compression and comparison to the 3D FE model. In the same way, the axial strain in the rods is measured as a function of the piston pressure and compared to the model strain values. 

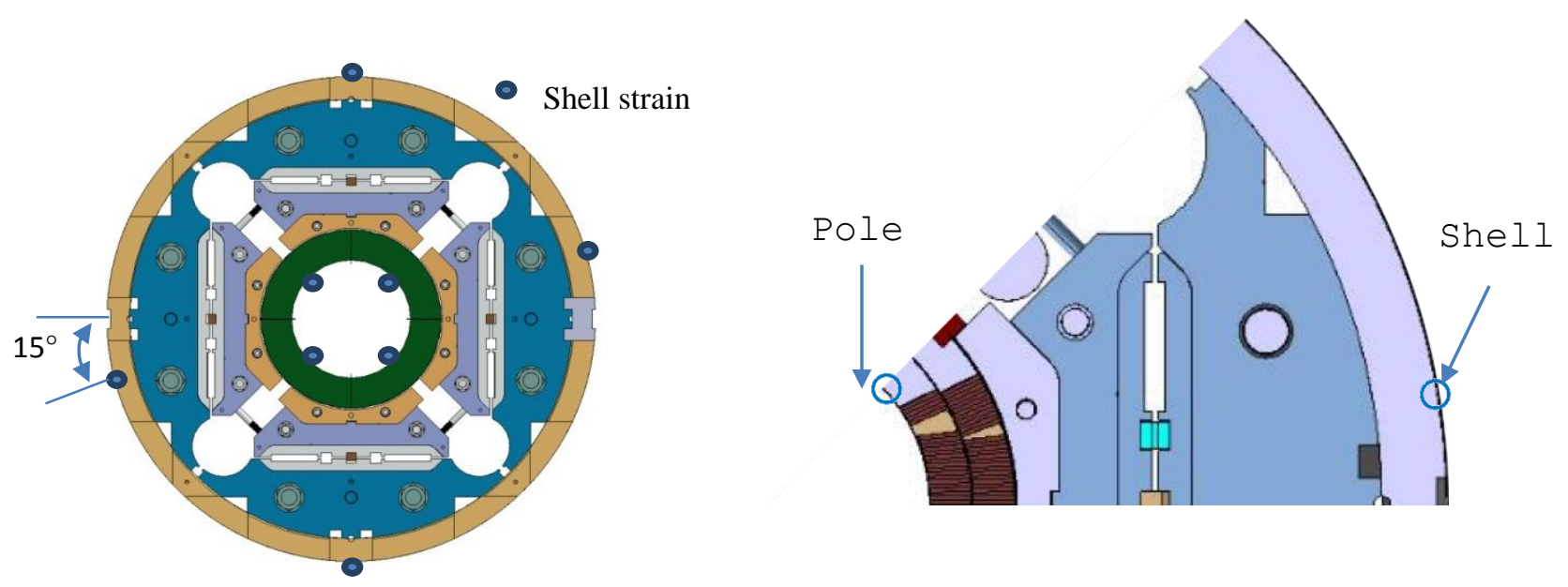

Fig. 6.18 Schematic of the strain station locations.

The instrumentation of MQXFS and future full-size models (MQXFA/B) will follow the same pattern. For the MQXFS1 the strains are monitored in a single station located at the magnet center, resulting in 4 strain gauges on the poles and 4 on the central shell segment (Fig. 6.18). The magnet is equipped by two types of strain measurement systems: (1) AC powered strain gauges, half bridged; (2) DC powered strain gauges, full bridged; the results of the two systems will be compared in the magnet tests in order to debug each system and select the best system for future magnets. In addition, the strain on the four axial rods are measured as a function of the piston pressure and compared to the model strain values.

\section{References}

[1] H. Pan. "Status of short model simulations and to do list" LARP structure WG, https://indico.fnal.gov/conferenceDisplay.py?confId=10796

[2] P. Ferracin, G. Ambrosio, M. Anerella, et. al, "Magnet Design of the $150 \mathrm{~mm}$ Aperture Low- $\beta$ Quadrupoles for the High Luminosity LHC”, IEEE Transactions ON Applied Superconductivity, Vol, 24, No. 3, 2014

[3] G. Ambrosio, et, al. "MQXFS1 design report, version 1" http://larpdocs.fnal.gov//LARPpublic/DocDB/ShowDocument?docid=1074 


\section{MAGNET ASSEMBLY, HANDLING \& SHIPMENT}

\section{a. Assembly Procedure}

The overall assembly process remains pretty consistent with the previous LARP magnets:

- Yoke-shell subassembly

- Collar-pack assembly: the four coils are assembled in the bolted collars

- Coil pack assembly: the collar-pack assembly is assembled in the bolted pads

- Coil pack insertion in the yoke-shell subassembly

- Rods and end-plate are positioned

- Azimuthal (using bladders and keys) and axial (using rods and piston) preloads are then applied.

Two MQXFS structures are being procured by CERN. One structure will be assembled at LBNL and one will be assembled at CERN. It is important to streamline the assembly process and to make it consistent between the two labs. Whereas the yoke-shell sub-assembly process does not have to be perfectly consistent, the coil assembly process in the collars and the remaining steps should follow the same procedure. Therefore work is presently done in both labs to converge on a common assembly procedure.

As part of this work, the design of the assembly tooling is also ongoing.

As part of the structure validation, the first assembly will be a mechanical model using instrumented aluminum dummy coils. This mechanical model will undergo a cold test in $\mathrm{LN}_{2}$ allowing checking the overall mechanical behavior of the support structure.

\section{b. Handling and shipment}

Magnet handling and shipment options are being considered. The magnet will be likely packaged in a crate (as HQ magnets) and shipped using a dedicated air-ride truck. 


\section{QUENCH PROTECTION}

The quench protection system for MQXFS1 aims at demonstrating the protection of the MQXF magnets in the LHC tunnel. Therefore it is based on quench heaters on both inner and outer layers, and will explore the use of the CLIQ (Coupling Loss Induced Quench) system [1] for MQXF magnets.

In order to assess the impact of dynamic effects on the quench protection, a small dump resistor (providing the same L/R of the MQXFs in the tunnel at quench onset) will be used during MQXFS1 test.

The quench heaters, made of $25 \mathrm{um}$ thick stainless steel, are photo-etched on a 50 um thik polyimide sheet, which provides the coil-heater insulation together with the cable insulation (150 um S-2 glass impregnated with CTD-101k epoxy). The polyimide thickness is the result of a trade-off between high electrical strength and short heat-diffusion time.

Heaters on both inner and outer layers will be copper plated in order to minimize the time to quench the whole coil, since copper plating allows for closer heating stations in long coils. Several designs are under development and are planned to be tested on different coils.

The use of quench heaters on the inner layer is facing two challenges: (i) the polyimide layer should cover $50 \%$ or less of the coil surface in order to allow efficient heat transfer from the coil to the helium ring in the aperture; (ii) the layout of heaters and polyimide layer should prevent the formation of the so called "bubbles" (i.e. detachment of the heater from the coil and/or detachment of the insulation from the heater) seen in several LARP magnets with heaters or traces in the inner layer [2]. Several techniques (punching, laser cuts) are being investigated for removing part of the polyimide sufficiently distant from the active trace elements. The most promising techniques will be used to make traces that will be tested with MQXFS1 coils.

\section{a. Heater Design}

The following set of heater design parameters has been agreed upon by LARP and CERN:

Table 8.1: Heater and HFU (Heater Firing Unit) Design Parameters.

\begin{tabular}{ll}
\hline \hline Peak power density & $50-150 \mathrm{~W} / \mathrm{cm}^{2}$ \\
HFU voltage & up to $450 \mathrm{~V}$ \\
HFU current & up to $220 \mathrm{~A}$ \\
HFU capacitance & $4.8-19.2 \mathrm{mF}$ \\
Distance between heating stations & up to $120 \mathrm{~mm}$ \\
\hline \hline Trace parameters & $50 \mu \mathrm{m}$ \\
\hline \hline Polyimide Insulation thickness & $25 \mu \mathrm{m}$ \\
Stainless Steel thickness & $10 \mu \mathrm{m}$ \\
Copper thickness & up to $25 \mu \mathrm{m}$ \\
Glue thickness & $<50 \% \mathrm{IL}$ \\
Coil surface coverage by trace & $7 \mathrm{~mm}$ or more \\
Min distance btw trace elements and & polyimide edge
\end{tabular}


To improve quench protection redundancy and allow more freedom to experiment with heater powering during quench training, 6 individual heaters are placed on each coil: four for the outer layer and two for the inner layer side (Fig. 8.1).

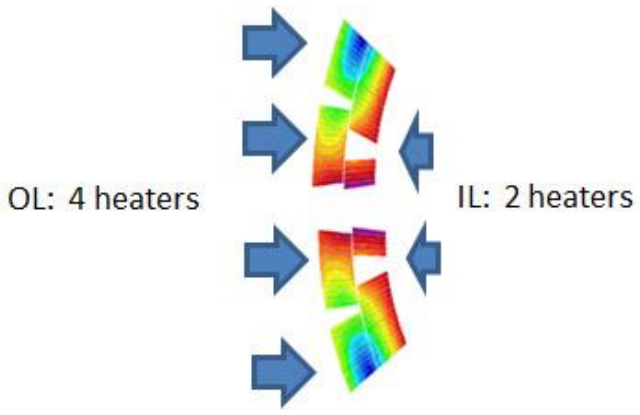

Fig. 8.1: OL and IL heaters.

The widths of the OL winding blocks are $31.74 \mathrm{~mm}$ and $23.74 \mathrm{~mm}$, respectively, for the mid-plane and pole sections. The widths of the IL winding blocks are 30.75 and $9.19 \mathrm{~mm}$ correspondingly for the mid-plane and pole sections.

\section{Various designs have been proposed and are being implemented:}

\section{- Stainless steel-only design}

This layout is a derivative of the earlier design used in long quadrupoles (LQ). The heater layout involves regularly spaced heating stations separated by wider bridges. The heater material is a uniform stainless steel (SS304) with thickness $d=25 \mathrm{~mm}$ and resistivity $\rho=5 \cdot 10^{-7} \Omega \mathrm{m}$.

We choose periodicity of the heating stations commensurate with the twist pitch of the cable as shown in Fig. 8.2:
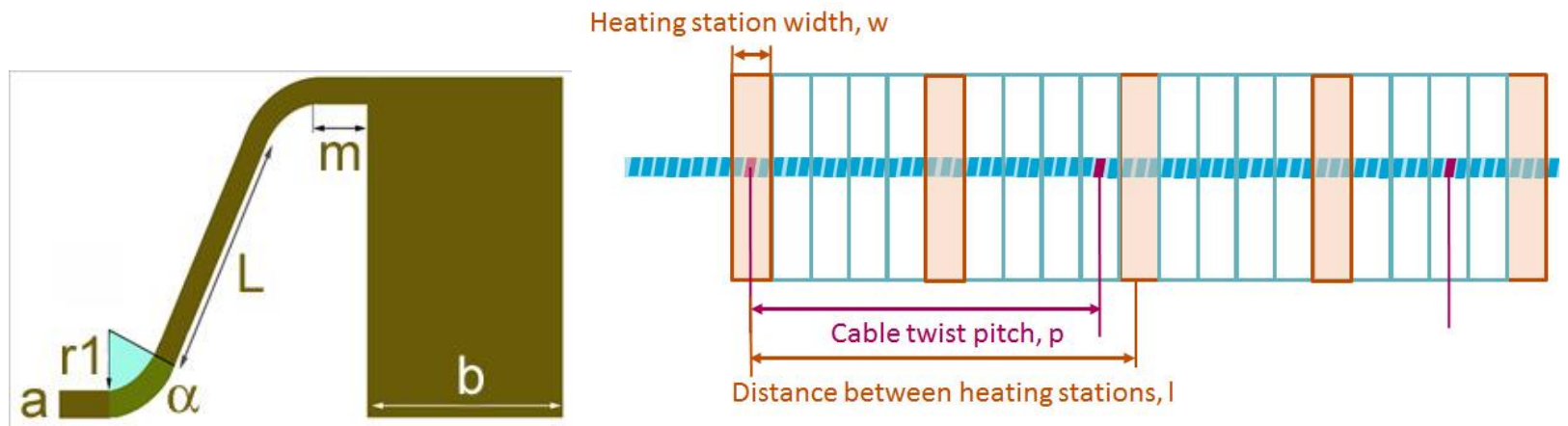

Fig. 8.2: Left: single element of heater layout. Right: a sketch showing the periodic heating station placement along the cable.

If $\mathrm{p}=2 \mathrm{nw}$ and $l=(2 \mathrm{n}+/-1) \mathrm{w}$, the supercurrent in all strands of the cable segment of length $\mathrm{L}=\mathrm{n} l$ can be interrupted simultaneously by the normal zones created with $\mathrm{n}$ heating stations. This approach can potentially improve heater efficiency, as all cable strands will become resistive and start dissipating heat at once. 
In the outer layer, the same heater width $(23.7 \mathrm{~mm})$ was chosen for the mid-plane block and the pole block in order to ensure proper spacing and voltage tap placing. Heater element dimensions are:

- $\quad \mathrm{a}=10.48 \mathrm{~mm}(\Rightarrow 12.11 \mathrm{~mm}$ along the cable $)$

- $\mathrm{r} 1=3 \mathrm{~mm} ; \mathrm{L}=15 \mathrm{~mm} ; \alpha=60^{\circ} ; \mathrm{m}=3 \mathrm{~mm}$

The length of the heater segment element is $60.7 \mathrm{~mm}$. The MQXFS design assumes 18 segments, which are placed along the straight portion of the winding. Heater peak power per straight portion of the heating station is calculated as $8.2 \cdot 10^{-3} \mathrm{~W} / \mathrm{V}^{2} \mathrm{~cm}^{2}$, or up to $1660 \mathrm{~W} / \mathrm{cm}^{2}$ of surface power at $450 \mathrm{~V}$ applied to the heater $\left(82 \mathrm{~W} / \mathrm{cm}^{2}\right.$ at $\left.100 \mathrm{~V}\right)$.

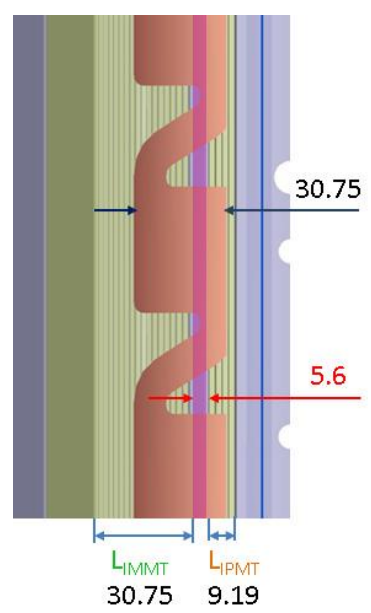

Fig. 8.3: A sketch of the inner layer heater layout. The heating stations run across the wedge separating two winding blocks.

For the inner layer, a requirement to have $<50 \%$ of the area covered by the heater is somewhat in conflict with the fact that the pole and mid-plane blocks are separated by a $\sim 4.5 \mathrm{~mm}$ wide wedge. The heater needs to be located closer to the pole turns to be more efficient, yet the wedge will then absorb a significant portion of the generated heat. As a compromise, a width of $30.75 \mathrm{~mm}$ was chosen, occupying $\sim 65 \%$ of the trace area and having about the same overall coverage area above the cable as the OL heater. The heater element dimensions are:

- $\quad \mathrm{a}=10.3 \mathrm{~mm}(\Rightarrow 11.87 \mathrm{~mm}$ along the cable $)$

- $\quad \mathrm{r} 1=3 \mathrm{~mm} ; \mathrm{L}=14.2 \mathrm{~mm} ; \alpha=60^{\circ} ; \mathrm{m}=3 \mathrm{~mm}$

The result is 16 heater segments, each $61.3 \mathrm{~mm}$ long, distributed along the straight part of the MQXFS coil. The expected heater resistance is $1.43 \Omega$ and the power is $9.13 \cdot 10^{-3} \mathrm{~W} / \mathrm{cm}^{2} \mathrm{~V}^{2}$, or up to $1860 \mathrm{~W} / \mathrm{cm}^{2}$ of surface power at $450 \mathrm{~V}$ applied to the heater.

\section{- Copper-plated heater design 1 (IL)}

Copper plating allows for scaling the heater length up to $6.7 \mathrm{~m}$ length and still permits the heater surface power to be above the design value of $150 \mathrm{~W} / \mathrm{cm}^{2}$. Furthermore, to better optimize heat 
deposition in the IL, the copper-plated bridges run across the wedge, while having heating stations only above the windings. The design is shown in Fig. 8.4.

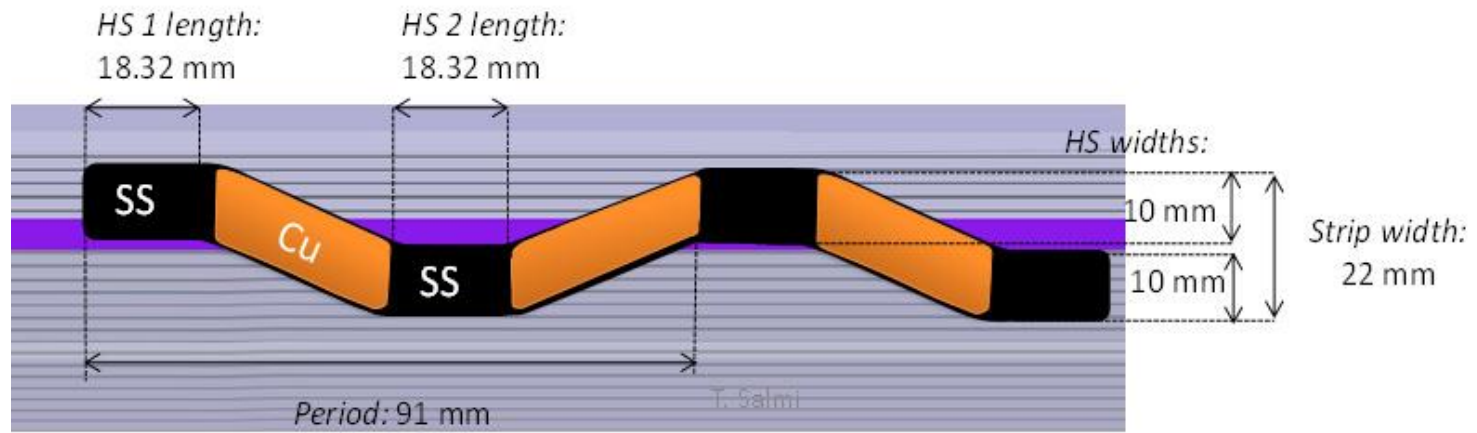

Fig. 8.4: "Snake" pattern for the inner layer heater layout. The copper-plated bridges run across the wedge separating two winding blocks, while heating stations are located within the winding blocks.

The main parameters of this layout are as follows:

Strip full span $=22 \mathrm{~mm}$ (leaving $>50 \%$ free at the coil midplane), covering

- 4 turns on pole block $(\sim 7.2 \mathrm{~mm})$

- 5 turns on midplane block $(\sim 9.2 \mathrm{~mm})$

- Heating station (HS) width $=10 \mathrm{~mm}$; length $=18.32 \mathrm{~mm}$

The optimization of the heating station length and period was conducted using "CoHDA" software [3] by T. Salmi. A summary of heater design and operational parameters for the different QXF lengths is given in Table 8.2.

Table 8.2: Summary of the IL heater parameters for the different QXF lengths.

\begin{tabular}{lcccc}
\hline \hline & & Short & Q1/Q3 & Q2 \\
\hline \hline Magnet length & $(\mathrm{m})$ & 1 & 4 & 7 \\
Heater width & $(\mathrm{mm})$ & 10 & 10 & 10 \\
Heater thickness & $(\mathrm{mm})$ & 0.025 & 0.025 & 0.025 \\
Station length & $(\mathrm{mm})$ & 18.3 & 18.3 & 18.3 \\
Station distance & $(\mathrm{mm})$ & 72.7 & 72.7 & 72.7 \\
Station resistance & $(\Omega)$ & 0.0366 & 0.0366 & 0.0366 \\
SS resistivity & $(\Omega \mathrm{m})$ & $5.00 \mathrm{E}-07$ & $5.00 \mathrm{E}-07$ & $5.00 \mathrm{E}-07$ \\
Cu resistivity & $(\Omega \mathrm{m})$ & $5.00 \mathrm{E}-10$ & $5.00 \mathrm{E}-10$ & $5.00 \mathrm{E}-10$ \\
Cu resistance & $(\Omega)$ & 0.0002 & 0.0002 & 0.0002 \\
Cu width & $(\mathrm{mm})$ & 9.4 & 9.4 & 9.4 \\
Cu thickness & $(\mathrm{mm})$ & 0.01 & 0.01 & 0.01 \\
Number of stations per turn & & 10 & 43 & 76 \\
Total resistance & $(\Omega)$ & 0.74 & 3.17 & 5.59 \\
Voltage & $(\mathrm{V})$ & 59 & 253 & 448 \\
Current & $(\mathrm{A})$ & 80 & 80 & 80 \\
Power density & $\left(\mathrm{W} / \mathrm{cm}^{2}\right)$ & 128 & 128 & 128 \\
\hline \hline
\end{tabular}




\section{- Copper-plated heater design 2 (IL/OL)}

As a next step towards heater optimization, another kind of the "snake" layout was proposed.

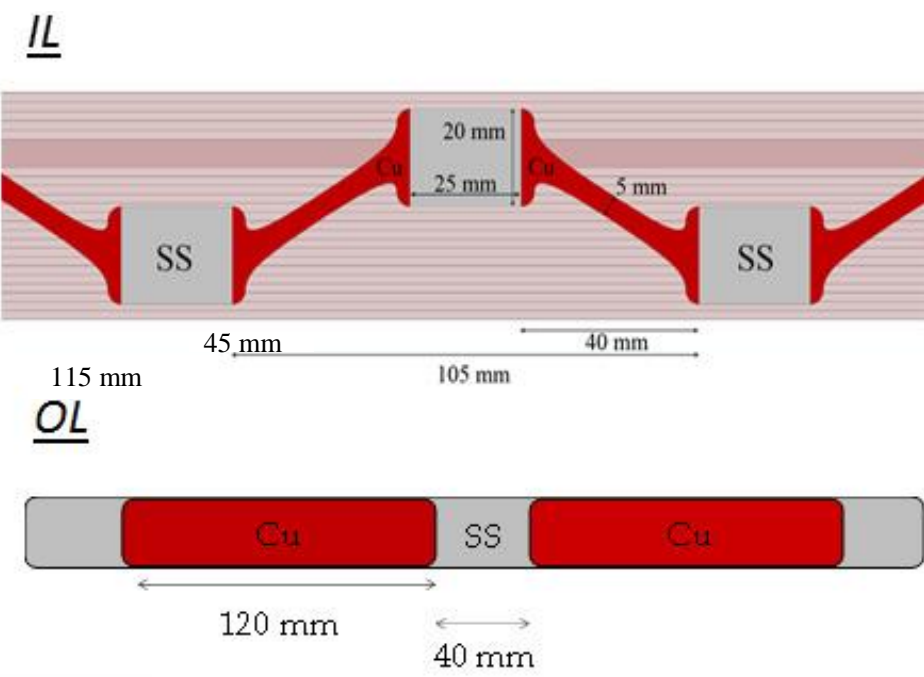

Fig. 8.5: The IL design features wide stainless heating stations connected by the narrower copperplated bridges. The OL design is simplified to a set of two parallel strips running across the winding blocks, with periodic heating stations formed by copper plating.

In this design, the copper-plated bridges are made narrower compared to the first copper-plated version. This should help improve heat transfer from the inner surface of the coils to the windings and allow for more spacing for perforations. Next, the heating station width is increased and they are brought farther apart azimuthally. Terminals of the heating stations are copper-plated to improve current flow uniformity.

At the same time, for the outer layer, a set of simple straight strips was proposed that spans along the coil and across each (pole and mid-plane) winding block. The heating stations are the entire winding block. The heating stations are $40 \mathrm{~mm}$ in width and are separated by $120 \mathrm{~mm}$ long copper-plated bridges. The design layouts for both layers are shown in Fig. 8.5 and the summary of design and operational parameters (at $1.9 \mathrm{~K}$ ) for the different magnet lengths are summarized in Table 8.3. 
Table. 8.3: Summary of the IL and OL heater parameters for the different QXF lengths.

\begin{tabular}{lcccc}
\hline \hline QXF IL Parameters & & short & US & CERN \\
\hline \hline Magnet length & $(\mathrm{m})$ & 1 & 4 & 7 \\
Heater SS width & $(\mathrm{mm})$ & 20 & 20 & 20 \\
Heater Cu width & $(\mathrm{mm})$ & 5 & 5 & 5 \\
Heater SS thickness & $(\mathrm{mm})$ & 0.025 & 0.025 & 0.025 \\
Heater Cu thickness & $(\mathrm{mm})$ & 0.01 & 0.01 & 0.01 \\
Station length & $(\mathrm{mm})$ & 25 & 25 & 25 \\
Station period & $(\mathrm{mm})$ & 140 & 140 & 140 \\
SS resistivity & $(\Omega \mathrm{m})$ & $5.00 \mathrm{E}-07$ & $5.00 \mathrm{E}-07$ & $5.00 \mathrm{E}-07$ \\
Cu resistivity & $(\Omega \mathrm{m})$ & $5.00 \mathrm{E}-09$ & $5.00 \mathrm{E}-09$ & $5.00 \mathrm{E}-09$ \\
Station resistance & $(\Omega)$ & $2.50 \mathrm{E}-02$ & $2.50 \mathrm{E}-02$ & $2.50 \mathrm{E}-02$ \\
Cu resistance & $(\Omega)$ & $1.00 \mathrm{E}-03$ & $1.00 \mathrm{E}-03$ & $1.00 \mathrm{E}-03$ \\
Number of stations & & 19 & 62 & 104 \\
Number of strips per coil & & 2 & 2 & 2 \\
Strip resistance & $(\Omega)$ & 0.49 & 1.61 & 2.70 \\
Voltage & $(\mathrm{V})$ & 99 & 322 & 433 \\
Current & $(\mathrm{A})$ & 200 & 200 & 160 \\
Power & $\left(\mathrm{W} / \mathrm{cm}^{2}\right)$ & 200 & 200 & 128 \\
\hline \hline
\end{tabular}

\begin{tabular}{lcccc}
\hline \hline QXF OL Parameters & & short & US & CERN \\
\hline \hline Magnet length & $(\mathrm{m})$ & 1 & 4 & 7 \\
Heater SS width & $(\mathrm{mm})$ & 20 & 20 & 20 \\
Heater Cu width & $(\mathrm{mm})$ & 20 & 20 & 20 \\
Heater SS thickness & $(\mathrm{mm})$ & 0.025 & 0.025 & 0.025 \\
Heater Cu thickness & $(\mathrm{mm})$ & 0.01 & 0.01 & 0.01 \\
Station length & $(\mathrm{mm})$ & 40 & 40 & 40 \\
Station period & $(\mathrm{mm})$ & 160 & 160 & 160 \\
SS resistivity & $(\Omega \mathrm{m})$ & $5.00 \mathrm{E}-07$ & $5.00 \mathrm{E}-07$ & $5.00 \mathrm{E}-07$ \\
Cu resistivity & $(\Omega \mathrm{m})$ & $5.00 \mathrm{E}-09$ & $5.00 \mathrm{E}-09$ & $5.00 \mathrm{E}-09$ \\
Station resistance & $(\Omega)$ & $4.00 \mathrm{E}-02$ & $4.00 \mathrm{E}-02$ & $4.00 \mathrm{E}-02$ \\
Cu resistance & $(\Omega)$ & $3.00 \mathrm{E}-03$ & $3.00 \mathrm{E}-03$ & $3.00 \mathrm{E}-03$ \\
Number of stations & & 8 & 25 & 44 \\
Number of strips per coil & & 4 & 4 & 4 \\
Strip resistance & $(\Omega)$ & 0.34 & 1.10 & 1.90 \\
Voltage & $(\mathrm{V})$ & 69 & 219 & 381 \\
Current & $(\mathrm{A})$ & 200 & 200 & 200 \\
Power & $\left(\mathrm{W} / \mathrm{cm}^{2}\right)$ & 200 & 200 & 200 \\
\hline \hline
\end{tabular}


MQXFS1 Design Report

\section{b. Trace Fabrication}

After the heaters have been designed they are drawn up in CAD, and the locations of the copper plating are also detailed. A negative mask of the trace elements is created, emulsion-side down, in order to mask off the areas for the photoresist.

In the meantime, the SS/polyimide material is copper plated, using a nickel (Wood's Nickel process is most common) strike layer that helps to bond the $10 \mu \mathrm{m}$ of copper to the stainless steel.

The trace fabrication process begins with lamination of the blank plated SS/polyimide material with a photoresist layer. The negative mask of the trace elements is then placed onto the photoresist layer and exposed to UV light, which polymerizes the resist in areas that were not masked off. A washing process follows the exposure step in order to remove the unexposed resist from the SS/polyimide laminate. This patterned laminate is then etched in a ferric chloride solution, which removes both the copper and the stainless elements not protected by the hardened photoresist. A final washing step in this process removes the polymerized photoresist layer, which leaves the copper-plated trace elements on the polyimide.

To selectively remove the copper layer from the stainless, a negative mask is generated and applied the same way as described above. Nonetheless, instead of etching in a ferric chloride solution, the etchant solution is ammonium persulfate, which attacks only the copper layer. After all the washings, the resultant trace has the patterned elements with select copper-plated areas.

The final step in the trace fabrication is to perforate the trace with a pattern of small holes. There are several methods that are being explored, but most commonly used are $\mathrm{CNC}$ drill setups, which machine a pattern of holes, approximately $3 \mathrm{~mm}$ in diameter spaced about $10 \mathrm{~mm}$ apart, but leaving path lengths of $>7 \mathrm{~mm}$ to any metallic trace element. This requirement is for voltage standoff requirements.

The inner layer traces should be perforated or cut in order to leave about $50 \%$ of the winding inner surface free from polyimide. This requirement is driven by the need for efficient heat extraction and by the need to avoid coil-trace delamination, commonly called "bubbles". The first sets of inner layer traces are going to explore different techniques for removing the polyimide even if they will not achieve $50 \%$ free surface, which may require no voltage taps and adjustments to the heater design.

Prior to use in a coil, all instrumentation traces are hi-potted to $3000 \mathrm{~V}$ to verify their electrical integrity.

\section{c. CLIQ}

MQXFS1 is going to explore and possibly demonstrate the use of CLIQ [1] for the protection of MQXF magnets. The CLIQ (Coupling-Loss Induced Quench) system was developed at CERN and successfully demonstrated for $\mathrm{Nb}_{3} \mathrm{Sn}$ magnets during the test of HQ02 [4].

MQXFS1 is going to have 3 special CLIQ leads coming out of the splice-connection box (sometimes referred to as "pizza box") in order to accommodate different CLIQ configurations: single CLIQ unit, and double CLIQ unit. The double CLIQ unit configuration is expected to be the most efficient for long magnets because it allows smaller voltages than the single CLIQ configuration. The test of MQXFS1 
should demonstrate this advantage by reproducing the protection of full-length MQXF magnets through scaling of CLIQ voltages during MQXFS1 test.

The CLIQ system is going to be tested on MQXFS1 in stand-alone mode and together with quench heaters on the outer layer.

\section{d. Analysis}

The quench analysis presented in this section was performed using the QLASA [5] code and the MATPRO [6] material property database.

The main assumptions used for this analysis are:

- Operating current (17.5 kA), $46 \mathrm{mOhm}$ dump resistor on Q1 and Q3 in series, $10 \mathrm{~ms}$ validation time, $100 \mathrm{mV}$ voltage threshold

- In all cases presented there are protection heaters installed on the Outer Layer. The design of these OL heaters and their delays (16 ms - time between heater firing and quench start) are presented in [3]

- In case of no heaters on the Inner Layer the quench propagation from the Outer to the Inner Layer is based on measurements and conservative hypotheses (propagation within the inner layer does not take pre-heating into account)

- The delay for the IL heater Version \#1 (13 ms) has been computed by CoHDA [3] for the high field zone, and no quench was assumed in the low field zone

- The delays for the IL heater Version \#2 (13/17 ms) have been computed by CoHDA [3] for the high/low field zones

- $\quad$ The quench propagation between heating stations is computed by QLASA.

- Dynamic effects are not taken into account (conservative hypothesis)

- CLIQ has been simulated by assuming that the whole magnet is quenched after $10 \mathrm{~ms}$ (conservative assumption at $80 \%$ of SSL based on HQ tests)

The results are shown in Table 8.4.

Table 8.4: Summary of the quench analysis.

\begin{tabular}{ccccc}
\hline \hline & No IL-PH & V1 IL-PH & V2 IL-PH & CLIQ \\
MIITs $\left(\right.$ MA $^{2}$ s) & 35.5 & 32.8 & 31.7 & 30.2 \\
$\begin{array}{c}\text { Hot spot } \\
\text { temperature (K) }\end{array}$ & 330 & 290 & 275 & 253 \\
\hline \hline
\end{tabular}




\section{References}

[1] E. Ravaioli, et al., "New, Coupling Loss Induced, Quench Protection System for Superconducting Accelerator Magnets", IEEE Trans. Appl. Supercond., Vol. 24, 500905, 2014.

[2] G. Ambrosio, et al., "Nb3Sn High Field Magnets for the High Luminosity LHC Upgrade Project", IEEE Trans. Appl. Supercond., Vol. 25, 4002107, June 2015.

[3] T. Salmi, et al., "Protection Heater Delay Time Optimization for High-Field $\mathrm{Nb}_{3} \mathrm{Sn}$ Accelerator Magnets" IEEE Trans on Applied Superc. Vol 24. No. 3, June 2014.

[4] E. Ravaioli, H. Bajas, V. I. Datskov, V. Desbiolles, J. Feuvrier, G. Kirby, M. Maciejewski, G.L. Sabbi, H. H. ten Kate, A. P. Verweij, "Protecting a Full-Scale Nb3Sn Magnet with CLIQ, the New Coupling-Loss Induced Quench System”, IEEE Trans. Appl. Supercond., Vol. 25, 4001305, June 2015.

[5] L. Rossi, M. Sorbi, "QLASA: a computer code for quench simulation in adiabatic multicoil superconducting windings", INFN/TC-04/13, 2004.

[6] G. Manfreda, L. Rossi, M. Sorbi, "MATPRO - Upgraded version 2012: a computer library of material property at cryogenic temperature", INFN 12-04/MI, 2012. 


\section{Appendix A - Coil Size Control}

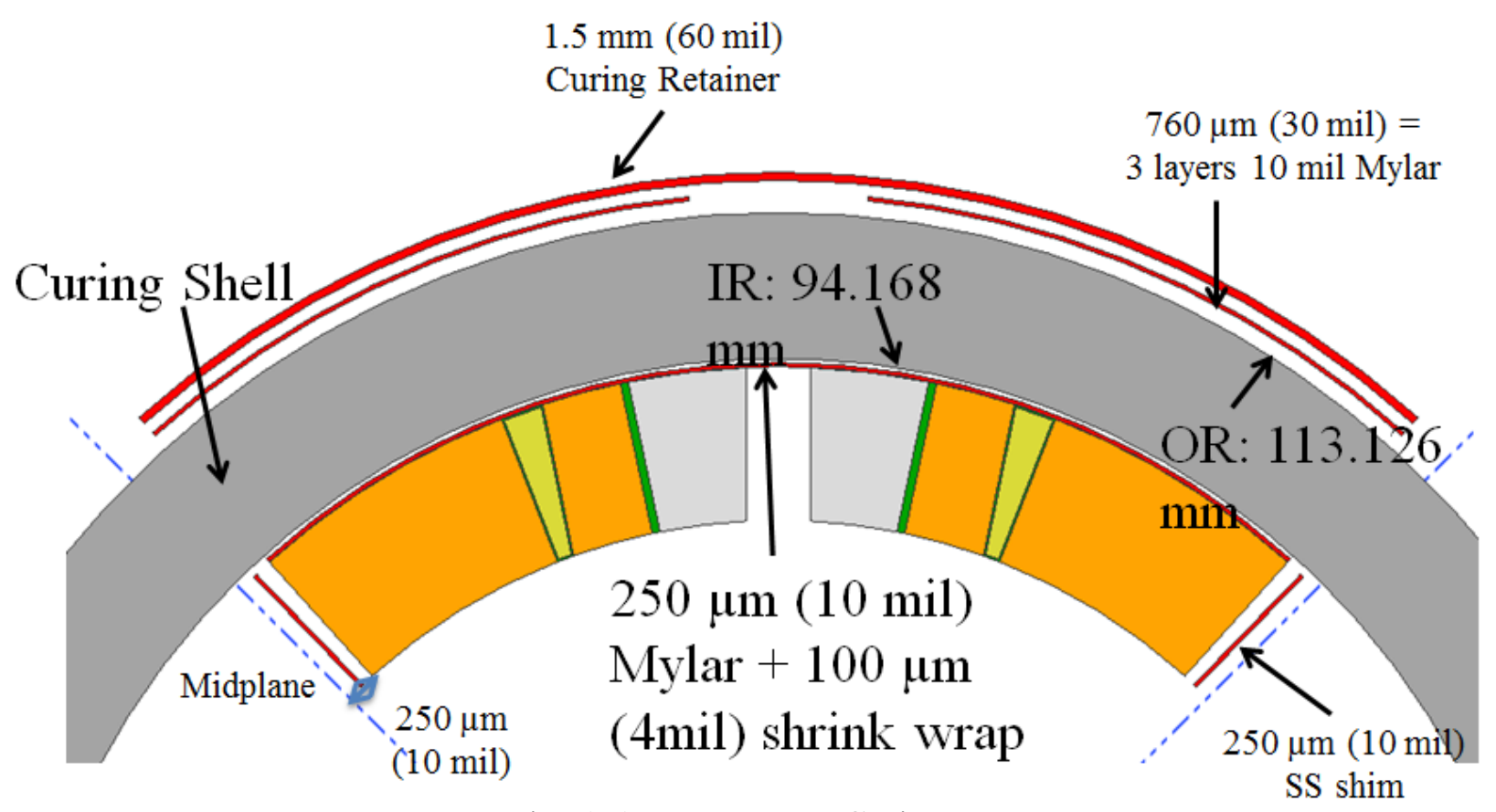

Fig. A.1: Inner Layer Curing.

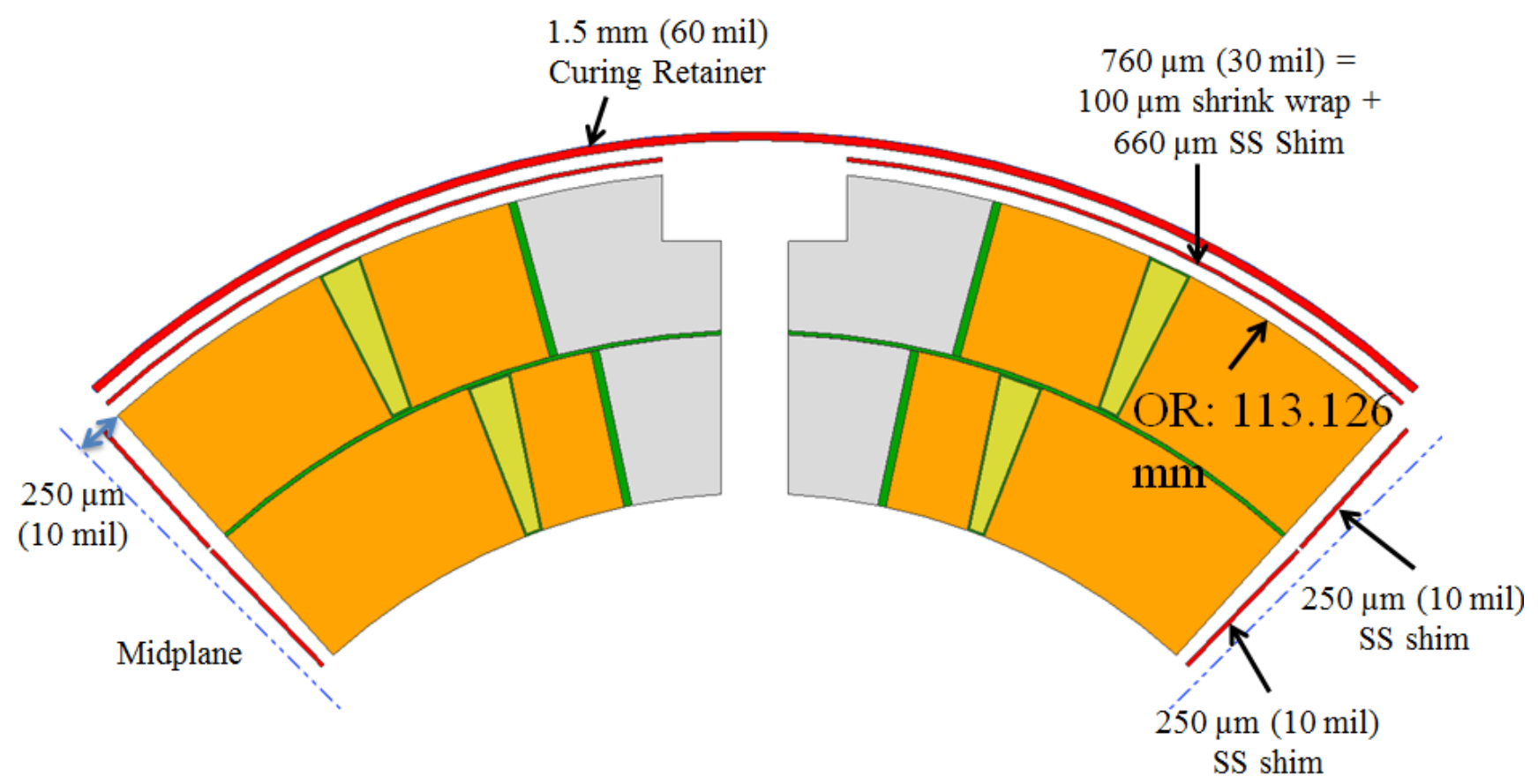

Fig. A.2: Outer Layer Curing. 

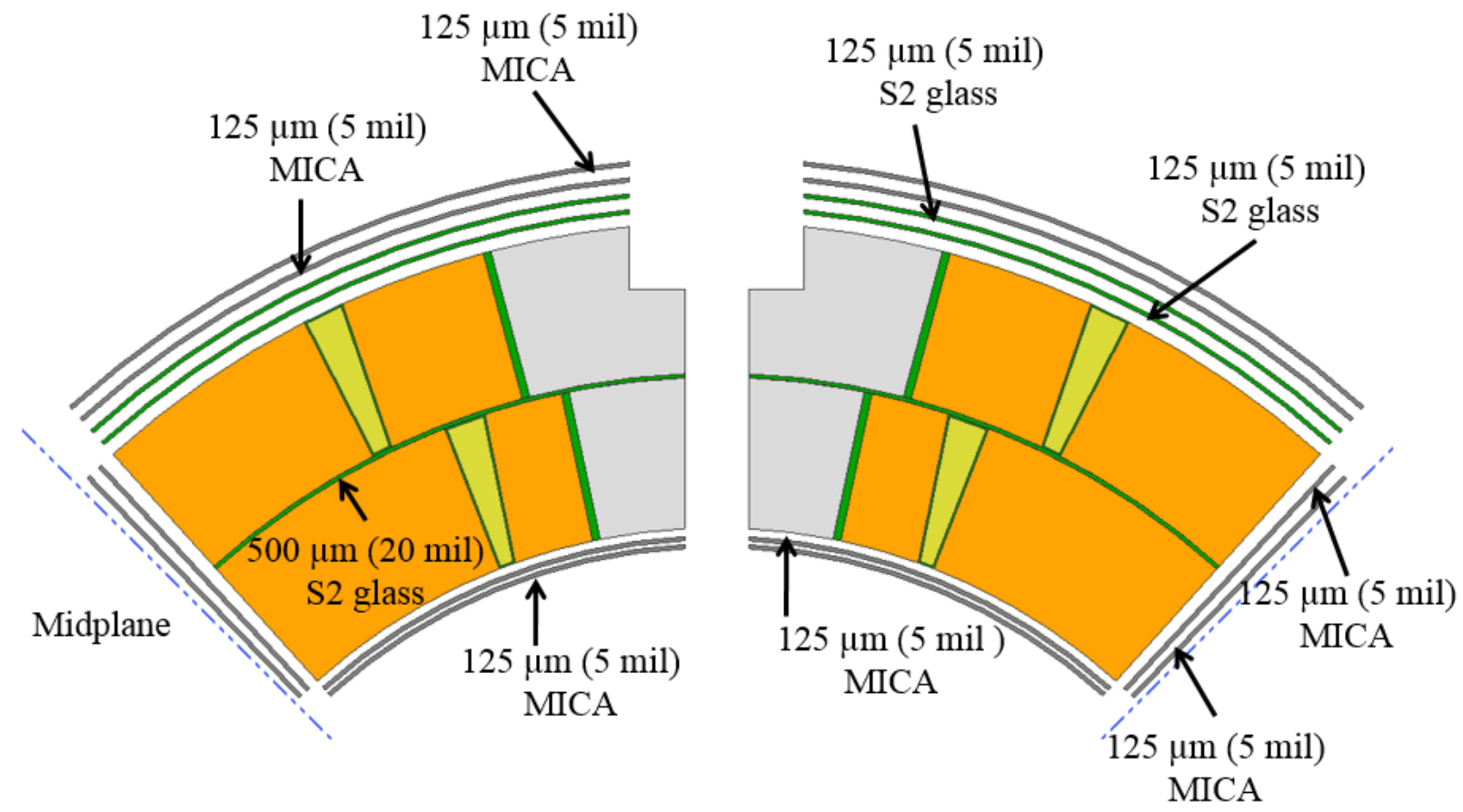

Fig. A.3: Reaction.

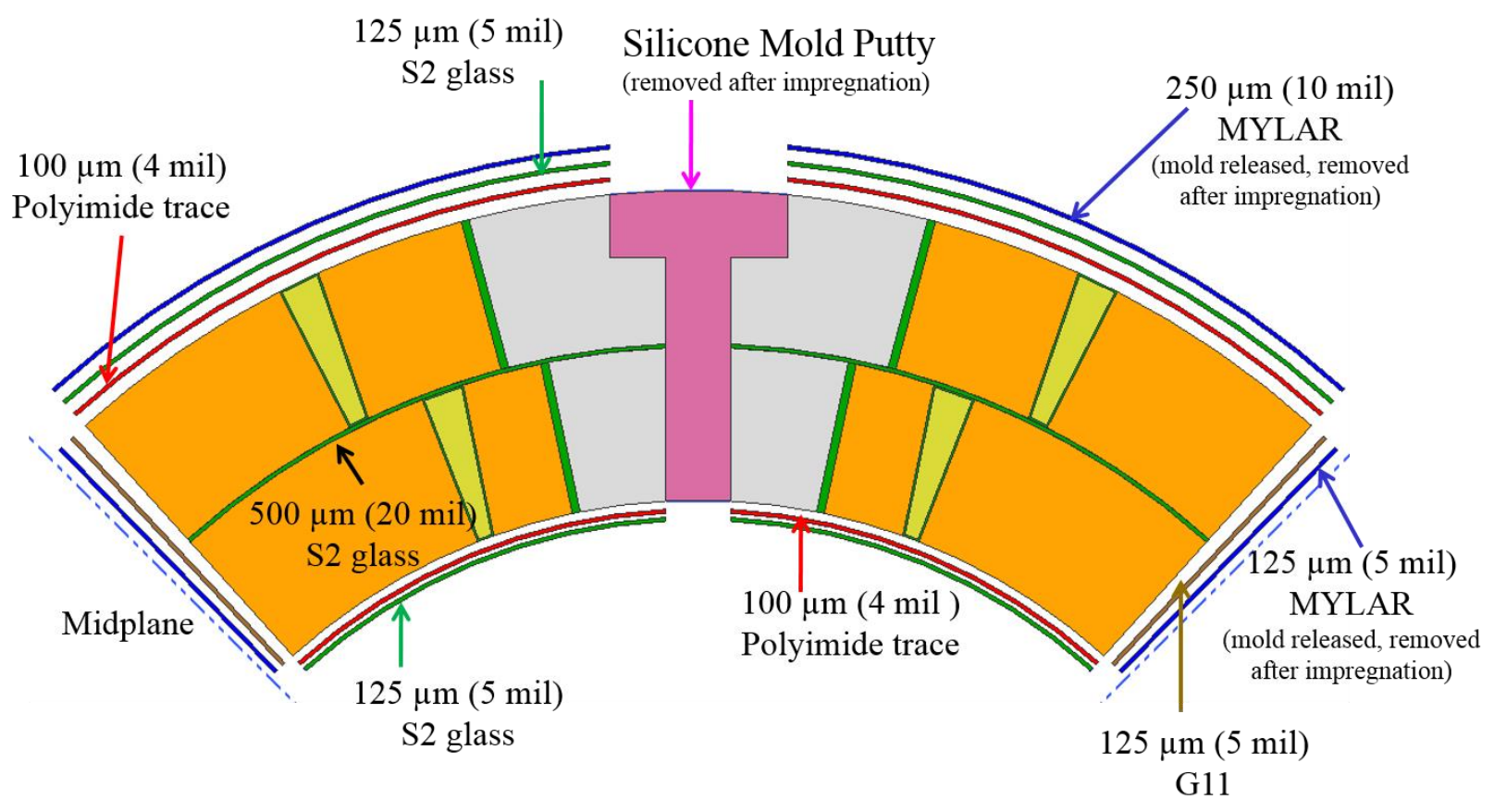

Fig. A.4: Impregnation. 